Interações gênicas usando redes booleanas

limiarizadas modeladas como um problema de satisfação de restrições

Tales Pinheiro de Andrade

DISSERTAÇÃO APRESENTADA

AO

Instituto de MatemáticA e EstatísticA

DA

Universidade De SÃo PAUlo

PARA

OBTENÇÃO DO TÍTULO

$\mathrm{DE}$

Mestre em CiênCIAS

Programa: Mestrado em Ciências da Computação

Orientador: Prof. Dr. Ronaldo Fumio Hashimoto 


\section{Interações gênicas usando redes booleanas limiarizadas modeladas como um problema de satisfação de restrições}

Esta versão da dissertação contém as correções e alterações sugeridas pela Comissão Julgadora durante a defesa da versão original do trabalho, realizada em 03/04/2012. Uma cópia da versão original está disponível no

Instituto de Matemática e Estatística da Universidade de São Paulo.

Comissão Julgadora:

- Prof. Dr. Ronaldo Fumio Hashimoto (orientador) - IME-USP

- Prof. Dr. Luiz Carlos da Silva Rozante - UFABC

- Prof. Dr. Evaldo Araújo de Oliveira Filho - UNIFESP 


\section{Agradecimentos}

Em primeiro lugar, aos meus pais, que sempre me incentivam e se orgulham a cada passo meu. E aos meus irmãos, Dácio e Ariana.

Também quero agradecer ao meu orientador, Prof. Ronaldo, sem o qual este trabalho não seria possível. E aos colegas e colaboradores Carlos Higa, Victor H. Louzada e Leandro de A. Lima.

Ao Wesley Seidel, que acompanhou todo o percurso, desde o começo, ajudando nos estudos, nas escolhas e nas dificuldades. E aos amigos Wonder Alexandre, Marcelo Reis, Welington Souza e Rodrigo Zaccara, pelas noites mal dormidas de estudos, assim como pela grande cervejada no final daquele semestre terrível de Analise de Algoritmos.

A Kerolin, que apesar dos pesares, foi uma das maiores incentivadoras no inicio da minha carreira acadêmica, sempre me dando forças e me levando para estudar madrugadas sem fim. Muito obrigado.

Quero agradecer ainda a minha prima Adriana, a primeira acadêmica da família (que eu conheço), que da longínqua São José do Rio Preto, tenho certeza, estava torcendo por mim e mandando as melhores das energias positivas. Ao meu primo Tácio, que começou o mestrado depois de mim, mas passou na minha frente e tendo tornando uma das minhas metas de superação. E a prima Katia, que se mostrou um exemplo de superação

Aos amigos do LIAMF que me acolheram como invasor, Fabio Franco, Henrique Bustamante, Vivi, Paulo de Tarso, Esdras, Erica Guetti, e aos demais amigos da IME-USP.

Aos amigos mais que especiais Newton Mota, Pedro Gabriel Borges e Cesar Ricardo Gimenes, meus sócios, e a todo pessoal da Newt Labs, por aguentarem minhas reclamações e ausências. E aos amigos virtuais e conhecidos da internet por suportarem meus devaneios noturnos. 


\title{
Resumo
}

\section{Interações gênicas usando redes booleanas limiarizadas modeladas como um problema de satisfação de restrições}

\author{
Autor: Tales Pinheiro de Andrade \\ Orientador: Ronaldo Fumio Hashimoto
}

As reações químicas que resultam da expressão de genes são complexas e ainda não são totalmente compreendidas. Sabe-se que os genes enviam, recebem, e processam informações formando uma complexa rede de comunicação, mas a arquitetura e dinâmica destas redes não são totalmente conhecidas. Dessa forma, um problema importante é determinar como os genes se relacionam dentro da célula. Esse processo de determinar o relacionamento entre os genes é conhecido como inferência de redes gênicas.

Uma das formas para representar o relacionamento entre os genes é usar modelos matemáticos e computacionais de Redes Gênicas. Em especial, um dos modelos de grande interesse é o de Redes Booleanas (BN - do inglês Boolean Networks), no qual os genes podem assumir dois estados, ativo ou inativo, se estão, respectivamente, expressos ou não. Estes estados podem variar ao longo do tempo, dependendo de como os genes se relacionam. Nosso interesse está em estudar um caso particular deste modelo, conhecido como Redes Booleanas Limiarizadas, onde apenas uma classe de funções booleanas é utilizada para construir as BNs.

Para inferir as Redes Booleanas Limiarizadas, usamos um algoritmo constituído de dois passos. Primeiro, usamos o arcabouço do Problema de Satisfação de Restrições (CSP - do inglês Constraint Satisfaction Problem) para inferir conjuntos de soluções consistentes com uma dada série temporal de um conjunto de genes. Em seguida analisamos o comportamento dinâmico das soluções encontradas, filtrando conjuntos de soluções de maior interesse para testes práticos em laboratório.

Usando o arcabouço do CSP, construímos um solver, usando a biblioteca Gecode, ${ }^{1}$ para inferência de redes consistentes, usando como entrada uma série temporal oriunda de dados de microarrays. Em seguida, através da simulação da dinâmica de uma amostra das redes encontradas no passo anterior, fomos capazes de determinar algumas restrições interessantes para filtrar o conjunto de redes. Aplicamos o nosso método para três conjuntos de dados: dois artificiais, e para validação, usamos uma série temporal de uma rede artificial conhecida na literatura. Com isso fomos capazes de inferir conjuntos de redes gênicas de possível interesse para testes em laboratório.

Palavras-chave: CSP, Redes booleanas, Inferência de Redes Gênicas

\footnotetext{
${ }^{1}$ http://www.gecode.org
} 


\title{
Abstract
}

\section{Gene interactions using thresholded boolean networks modeled as a constraint satsfaction problem}

\author{
Author: Tales Pinheiro de Andrade \\ Advisor: Ronaldo Fumio Hashimoto
}

The chemical reactions that result in gene expression are complex and not yet fully understood. It is known that genes send, receive and process information to form a complex network of communication, but the architecture and dynamics of these networks are not fully known. Thus, one major problem is to determine how genes are linked within the cell. This process of determining the relationship between genes is known as inference of genetic networks.

One way to represent the relationship between genes is to use mathematical and computer models of genetic networks. In particular, one of the models of great interest are Boolean Networks $(\mathrm{BN})$, in which genes can take two states, active or inactive, if they are, respectively, expressed or not. These states may vary over time, depending on how genes are related. Our interest is in studying a case of this particular model, known as thresholded Boolean networks, where only one class of Boolean functions is used to build the GNs.

To infer the thresholded Boolean networks, we use an algorithm that consists of two steps. First, we use the framework of Constraint Satisfaction Problem (CSP) to infer sets of solutions consistent with a time series of a given set of genes. Then analyze the dynamic behavior of the solutions, filtering sets of solutions with interest for practical tests in the laboratory.

Using the framework of the CSP, we constructed a solver, using the library Gecode, ${ }^{2}$ for inference of consistent networks, using as input a time series arising from microarrays data. Then, by simulating the dynamics of a sample of networks found in the previous step, we were able to determine some interesting constraints to filter the set of networks. We apply our method to three datasets: two artificial, and for validation, we use a time series of an artificial network known from literature. Thus we were able to infer genetic networks sets of possible interest for laboratory tests. Keywords: CSP, Boolean networks, Inference of genetic networks.

\footnotetext{
${ }^{2}$ http://www.gecode.org
} 


\section{Sumário}

$\begin{array}{ll}\text { Lista de Abreviaturas } & \text { ix }\end{array}$

Lista de Figuras $\quad$ xi

Lista de Tabelas $\quad$ xv

1 Introdução $\quad 1$

1.1 Redes de regulação gênica . . . . . . . . . . . . . . . . . . . . . . . . 1

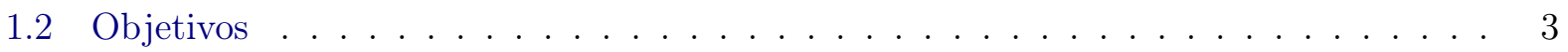

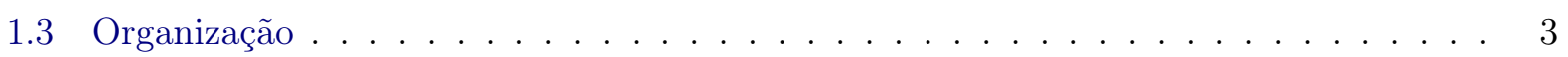

2 Revisão teórica $\quad 5$

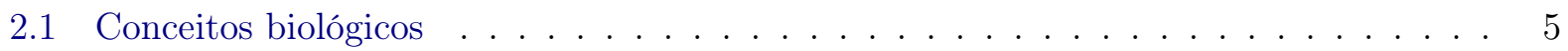

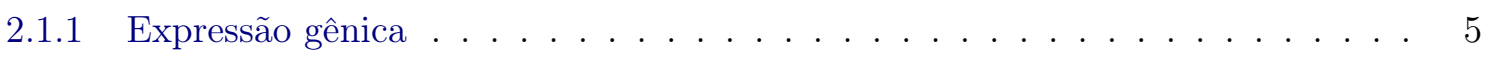

2.2 Inferência de Redes Gênicas . . . . . . . . . . . . . . . . . . . . . . 8

2.3 Redes Booleanas . . . . . . . . . . . . . . . . . . . . . . . . 9

2.3.1 Rede Booleana Limiarizada . . . . . . . . . . . . . . . . . . . . . . . . . 9

2.3 .2 Série consistente . . . . . . . . . . . . . . . . . . . . . 10

2.4 Problema de Satisfação de Restrições . . . . . . . . . . . . . . . . . . . . . . . . 11

2.4 .1 Resolução de CSP . . . . . . . . . . . . . . . . . . . . . . 12

3 Algoritmo de inferência $\quad 21$

3.1 Restrições . . . . . . . . . . . . . . . . . . . . . . . . . 21

3.1 .1 Primeiro conjunto de Restrições . . . . . . . . . . . . . . . . . . . . 21

3.1.2 Segundo conjunto de Restrições . . . . . . . . . . . . . . . . . . . . . . . . 22

3.1 .3 Terceiro conjunto de restrições . . . . . . . . . . . . . . . . . 23

3.2 Simulação da dinâmica . . . . . . . . . . . . . . . . . . . . . . . 25

3.2 .1 Critérios de geração das redes . . . . . . . . . . . . . . . . . . . . . . . . . . . 25

3.2 .2 Critérios de ordenação e escolha . . . . . . . . . . . . . . . . . 28

4 Resultados $\quad 31$

4.1 Implementação . . . . . . . . . . . . . . . . . . . . . . 31

4.2 Implementação em CUDA . . . . . . . . . . . . . . . . . . . . . . . . 32

4.3 Redes aleatórias . . . . . . . . . . . . . . . . . . . . . . . . 33

4.3 .1 Redes Erdős-Rényi . . . . . . . . . . . . . . . . . . . . . . 33

4.3.2 Redes Direcionadas Livres de Escala . . . . . . . . . . . . . . . . . . . 34 
4.3.3 Procedimento de simulação e validação . . . . . . . . . . . . . . . . . . . 35

4.4 Resultados Experimentais . . . . . . . . . . . . . . . . . . . . 39

4.4.1 Análise dos dados para redes DER e exemplos de redes inferidas . . . . . . . 39

4.4.2 Análise dos dados para redes livre de escala e exemplos de redes inferidas . 47

4.4 .3 Resultados para rede da levedura . . . . . . . . . . . . . . . . . . . 56

5 Considerações finais $\quad 65$

5.1 Trabalhos futuros . . . . . . . . . . . . . . . . . 66

6 Trabalhos publicados $\quad 69$

$\begin{array}{ll}\text { Referências Bibliográficas } & 71\end{array}$ 


\section{Lista de Abreviaturas}

BN Rede Booleana (Boolean Network).

cDNA DNA complementar (complementary DNA).

cPBN Rede Booleana Probabilística sensível ao contexto

(context-sensitive Probabilistic Boolean Network).

CSP Problema de Satisfação de Restrições (Constraint Satisfaction Problem).

DNA Ácido Desoxirribonucleico (Deoxyribonucleic Acid).

GAP Perfil de Atividade Gênica (Gene Activit Profile).

GRN Rede de Regulação Gênica (Gene Regulatory Network).

MCV Variável Mais Restrita (Most Constrained Variable).

mRNA RNA mensageiro (messenger RNA).

MRV Valores Restantes Mínimos (Minimun Remaining Values).

PBN Rede Booleana Probabilística (Probabilistic Boolean Network).

RBN Rede Booleana Restrita (Restricted Boolean Network).

TBN Rede Booleana Limiarizada (Thresholded Boolean Network).

RNA Ácido Ribonucleico (Ribonucleic Acid).

SAGE Análise Serial de Expressão Gênica (Serial Analysis of Gene Expression).

TP Verdadeiro Positivo (True Positive).

TN Verdadeiro Negativo (True Negative).

FP Falso Positivo (False Positive).

FN Falso Negativo (False Negative).

TPR Taxa de Verdadeiro Positivo (True Positive Rate).

FPR Taxa de Falso Positivo (True Negative Rate).

DER Redes Erdôs-Rényi Direcionadas (Directed Erdôs-Rényi).

PCR Reação em Cadeia de Polimerase (Polymerase Chain Reaction). 


\section{Lista de Figuras}

2.1 Esquema ilustrando os passos de um experimento de microarray (double-channel).

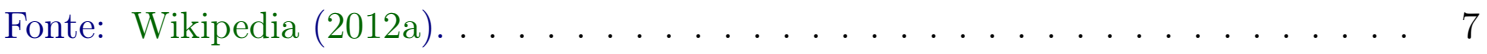

2.2 Diagrama representando a dinâmica de uma rede com quatro genes e 16 estados. . . 10

2.3 Um grafo de restrições, exibindo as variáveis (estados) e as restrições (fronteiras) para o problema de colorir o mapa do Brasil. . . . . . . . . . . . . . . . . . . 13

2.4 Parte da árvore de busca por simples backtracking para o problema da coloração dos estados do Brasil. . . . . . . . . . . . . . . . . . . . . . . . . . 15

2.5 Um jogo de Sudoku a esquerda, e sua solução a direita (figura adaptada de Tack

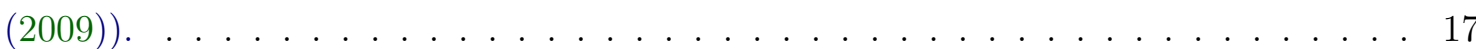

4.1 Exemplo de espaço ROC. . . . . . . . . . . . . . . . . . . . . . . 37

4.2 Rede Erdős-Rényi direcionada, gerada artificialmente, usada para validação. A rede foi simulada para gerar a série temporal, que foi então usada no algoritmo. . . . . . . 40

4.3 Dinâmica da rede Erdős-Rényi direcionada, gerada artificialmente, que foi usada para validação. A rede é exibida na Figura 4.2. . . . . . . . . . . . . . . . . . . . . . . 41

4.4 Espaço ROC para redes inferidas a partir da série temporal gerada da rede ErdôsRényi direcionada gerada artificialmente. Os pontos baixo da diagonal ascendente representam redes com taxa de falso positivo maior que a taxa de verdadeiro positivo, sendo então redes com topologia pior do que escolha aleatória (representada pela diagonal ascendente). Nesse caso, as redes densas têm maior taxa de acerto (compensada pelo acerto maior de verdadeiro positivo), mas prejudicado pela grande quantidade de falso positivo (por isso os pontos estão mais próximo do lado direito). Os valores são médias para dados de 50 redes com maior entropia do tamanho das bacias de atração. . . . . . . . . . . . . . . . . . . . . . . . . . . . . . . 42

4.5 Rede inferida, usando critério de redes esparsas, com dados de uma rede ErdôsRényi direcionada. Essa rede foi escolhida por apresentar a menor média $\left(S_{c}=\right.$ 0,05). Linhas cheias representam TP, enquanto linhas pontilhadas representam FP (regulações incorretamente inferidas, por não existirem na rede ideal). . . . . . . . . 44

4.6 Dinâmica da rede esparsa inferida, exibida na Figura 4.5, a partir da série gerada a partir de uma rede Erdős-Rényi direcionada artificial. O caminho representado pelo arco vermelho representa a série temporal usada como entrada. . . . . . . . . . . . . 45

4.7 Espaço ROC com TPR e FPR das 50 redes esparsas inferidas a partir da série temporal extraída de uma rede Erdős-Rényi direcionada artificial. . . . . . . . . . . . 46 
4.8 Distribuição das médias da entropia para redes inferidas a partir da rede da Figura 4.2. Os retângulos representam a distribuição $50 \%$ dos dados. A linha vermelha representa a mediana, cujo valor é apresentado sobre cada conjunto de dados. . . . . 47

4.9 Crescimento do valor da entropia para cada critério de construção de redes, a partir de uma rede ER direcionada. Aqui as redes foram ordenadas de forma crescente pelo valor da entropia. Cada linha representa 1000 redes simuladas para cada critério de construção de redes para simulação. . . . . . . . . . . . . . . . . . . .

4.10 Distribuição das médias do tamanho da maior bacia das redes inferidas da série da Tabela 4.4, extraída de uma rede Erdôs-Rényi direcionada, para cada critério de construção de redes. . . . . . . . . . . . . . . . . . . . . . . . .

4.11 Número de bacias das redes inferias a partir da série usada como entrada para inferência de redes DER (a série é exibida na Tabela 4.4). As regiões onde o tamanho da bacia não varia (representada por degraus) representam um conjunto de redes que têm o mesmo número de bacias de atração.

4.12 Rede artificial direcionada livre de escala, gerada pelo algoritmo da Subseção 4.3.2, usada para validação. . . . . . . . . . . . . . . . . . . . . . . 50

4.13 Dinâmica da rede direcionada livre de escala artificial da Figura 4.12, gerada para validação. . . . . . . . . . . . . . . . . . . . . . 51

4.14 Espaço ROC para redes inferidas a partir de dados gerados da rede artificial livre de escala da Figura 4.12. A linha diagonal ascendente representa escolha puramente aleatória, enquanto pontos mais próximos do canto superior esquerdo representam redes inferidas mais próximas da rede ideal. Cada ponto representa a média sobre 50 redes, escolhidas por terem a menor entropia do tamanho das bacias de atração. . .

4.15 Rede esparsa inferida a partir de uma série gerada da rede livre de escala exibida na Figura 4.12. Esta rede foi escolhida para exibição por possuir a menor média $S_{c}$. As linhas cheias representam TP, enquanto linhas pontilhadas representam FP (regulações que foram encontradas, mas não existem na rede ideal e que foram incorretamente inferidas). . . . . . . . . . . . . . . . . . .

4.16 Dinâmica da rede esparsa inferida, exibida na Figura 4.15, a partir de uma rede livre de escala direcionada. . . . . . . . . . . . . . . . . . . . 54

4.17 Espaço ROC com redes esparsas inferidas com dados da rede livre de escala. O ponto vermelho representa a rede com menor média $S_{c}$, exibida na Figura 4.15.

4.18 Histograma com distribuição da Similaridade $(\mathbf{A}, \mathbf{B})$ das 50 redes esparsas inferidas a partir da série temporal da rede artificial livre de escala. Apesar da Figura 4.17, aparentemente, exibir mais pontos acima da diagonal ascendente, vemos aqui que existe uma grande concentração de pontos mais próximas do meio da distribuição, o que explica o ponto mais próximo da diagonal ascendente. 
4.19 Boxplot a partir da entropia das 1000 redes inferidas, para cada critério de construção de redes, a partir de dados de uma rede com topologia livre de escala. O retângulo representa a concentração de $50 \%$ dos dados, e a linha vermelha a mediana (cujo valor está expresso no topo do gráfico). Apesar de possuir muitas redes com entropia mais alta, poucas redes esparsas tem entropia mais baixa, favorecendo encontrar redes mais interessantes. Neste caso, redes densas ou redes com hub de saída e preditores limitados entre dois e quatro têm uma grande quantidade de redes com entropia baixa, dificultando encontrar 50 mais interessantes, já que vimos que a entropia do tamanho das bacias não é a única chave para encontrar redes interessantes. . . . . . 56

4.20 Variações do tamanho da maior bacia para 1000 redes inferidas para cada critério de construção de redes. A linha vermelha representa o tamanho mediano. Podemos ver que, em relação a Figura 4.19, os gráficos são praticamente inversos: redes com bacias maiores geram entropias menores. . . . . . . . . . . . . . . . . 57

4.21 Rede para levedura. Representamos com setas $(\rightarrow)$ as ativações, e traços $(\dashv)$ as inibições. Figura adaptada de Li et al. (2004). O nó "tam. da célula" como um ponto de entrada para o processo do ciclo celular. . . . . . . . . . . . . . 58

4.22 Espaço ROC para médias encontradas para cada critério de seleção de 50 redes inferidas com dados da Série temporal da levedura (Tabela 4.10) . . . . . . . . . . . 60

4.23 Rede inferida a partir da Série temporal da levedura com menor média $S_{c}$ (a série usada para inferência é exibida na Tabela 4.10). Linhas cheias representam TP, linhas pontilhadas representam FP. Setas $(\rightarrow)$ representam ativação, enquanto traços $(-1)$ representam inibições. . . . . . . . . . . . . . . . . . . 61

4.24 Dinâmica da rede esparsa com menor média $S_{c}$, exibida na Figura 4.23, inferida a partir da Série temporal da levedura (a série usada como entrada do algoritmo é exibida na Tabela 4.10). A série é representada na figura por linhas vermelhas. . . . 62

4.25 Espaço ROC das 50 redes inferidas usando critério de redes esparsas, para dados da rede artificial da levedura. O ponto vermelho representa a rede com menor média $S_{c}$, exibida na Figura 4.23 . . . . . . . . . . . . . . . . . . . . . . . 63 


\section{Lista de Tabelas}

3.1 Exemplo de série temporal . . . . . . . . . . . . . . . . . . . . . . . 22

3.2 Restrições de transição de estados . . . . . . . . . . . . . . . . . . . . . . . 23

3.3 Terceiro Conjunto de Restrições . . . . . . . . . . . . . . . . . . . . . . . . . . . 24

4.1 Exemplo de Matriz de Confusão . . . . . . . . . . . . . . . . . . . . 36

4.2 Médias dos dados de topologia das redes inferidas a partir da série gerada da rede DER da Figura $4.2 \ldots \ldots \ldots \ldots$. . . . . . . . . . . . . . . . . . . . . . 41

4.3 Médias dos dados da dinâmica das redes inferidas a partir de série identificada para a rede DER da Tabela $4.4 \ldots \ldots$. . . . . . . . . . . . . . . . . . . 43

4.4 Série usada como entrada para inferência de redes DER . . . . . . . . . . . . 43

4.5 Tamanho das bacias para rede esparsa inferida . . . . . . . . . . . . . . . . . 43

4.6 Médias dos dados de topologia para redes inferidas a partir de dados originados de uma rede artificial livre de escala geradas segundo o algoritmo descrito na Subseção 4.3.2 49

4.7 Medias dos dados da dinâmica das redes inferidas com dados da rede da Figura 4.12, a partir de uma rede com topologia livre de escala . . . . . . . . . . . . . 50

4.8 Atratores e tamanho das bacias de atração da rede esparsa inferida exibida na Figura 4.15 , a partir da rede livre de escala da Figura $4.12 \ldots$. . . . . . . . . . . 54

4.9 Série temporal identificada da rede livre de escala, usada para inferência da rede da

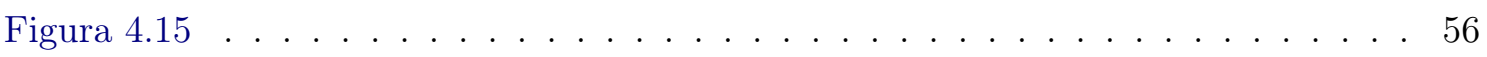

4.10 Série temporal da levedura . . . . . . . . . . . . . . . . . . 57

4.11 Bacias para a rede artificial da levedura . . . . . . . . . . . . . . . . 59

4.12 Dados da topologia para rede inferida com dados da levedura . . . . . . . . . . . 59

4.13 Dados da dinâmica das redes inferidas da levedura . . . . . . . . . . . . . . . 60

4.14 Bacias para rede da levedura Inferida: Esparsa . . . . . . . . . . . . . . . 62 


\section{Capítulo 1}

\section{Introdução}

Uma das metas da Bioinformática é estudar e compreender os mecanismos internos de funcionamento de uma célula, como o ciclo celular, diferenciação celular e o metabolismo. O termo Bioinformática foi cunhado por Hogeweg (2011), definido como sendo "the study of informatic process in biotic systems". Mas mesmo antes disso, foram feitos alguns trabalhos de Biologia Teórica, como o trabalho de Waddington et al. (1972), além do trabalho de Kauffman (1969) com Redes Booleanas Aleatórias como modelo de regulação de transcrição gênica. Além disso, a área de Biologia Sistêmica integra conhecimentos de biologia para entender como as partes de uma célula (genes, proteínas, etc), por exemplo, interagem entre si a fim de garantir o funcionamento e sobrevivência desta célula, ou seja, nesta área estudamos o funcionamento do sistema celular, ao invés de estudar os componentes individualmente (Higa (2012)).

Segundo Kitano (2002), podemos dividir o estudo de Biologia Sistêmica em quatro níveis:

1. Estrutura do sistema: inclui a rede de interações gênicas e vias metabólicas, assim como os mecanismos pelos quais tais interações modulam as propriedades físicas de estruturas intra e multicelulares.

2. Dinâmica do sistema: como o sistema se comporta no decorrer do tempo sob diversas condições;

3. Controle: mecanismos para controlar o estado de uma célula para evitar um comportamento indesejável e fornecer potenciais alvos terapêuticos para tratamento de doenças;

4. Projeto: estratégias para modificar e construir sistemas biológicos com propriedades desejadas.

Neste trabalho, focamos na Estrutura do Sistema e na Dinâmica do sistema.

\subsection{Redes de regulação gênica}

As atividades celulares são controladas pelos genes, através de uma complexa rede ainda desconhecida, que formam proteínas a partir do DNA (Ácido Desoxirribonucleico - em inglês Deoxyribonucleic Acid), ao longo de três fases principais: replicação do DNA, transcrição e tradução. A expressão gênica varia ao longo do tempo, de forma dinâmica, dependendo de como os genes se relacionam dentro desta rede. Tal rede é chamada Rede de Regulação Gênica (GRN - do inglês Gene Regulatory Network) e para seu estudo são usados diversas técnicas, incluindo modelos matemáticos e computacionais.

Diversos métodos de medição do nível de expressão gênica estão disponíveis, entre eles a Reação em Cadeia de Polimerase (PCR - do inglês Polymerase Chain Reaction) Liang e Pardee (1992), a Análise Serial de Expressão Gênica (SAGE - do inglês Serial Analysis of Gene Expression) (Velculescu et al. (1995)) e as medições de microarranjo (microarray) (Duggan et al. (1999); Huang (1999); Lipshutz et al. (1999); Schena et al. (1995); Shalon et al. (1996); Southern et al. (1999)). 
Além destas, uma técnica que tem ganhado destaque é o Sequenciamento Aleatório do Transcriptoma (WTSS - do inglês Whole Transcriptome Shotgun Sequencing), também conhecido como RNA-Seq (Marioni et al. (2008); Wang et al. (2009)). Apesar do enorme sucesso e dos grandes resultados das medições de microarray, a técnica de RNA-Seq é tida como uma provável substituta para os microarrays. Para maiores informações sobre RNA-Seq, veja os trabalhos de Marioni et al. (2008); Morin et al. (2008); Shendure et al. (2008). Tais técnicas conseguem gerar uma grande quantidade de dados com poucos experimentos. Além do estudo de expressão gênica (transcriptomics ou transcriptoma), outras áreas têm surgido, como Proteomas (do inglês proteomics, usando proteína) e Metabolomas (do inglês Metabolomics, através de metabólitos). Nosso estudo se baseia em dados obtidos através das medições de microarray.

Um problema bastante abordado em Biologia Sistêmica é a inferência de GRNs a partir de dados de expressão gênica. Esse problema é motivado pale premissa de que um estado funcional de um organismo celular é amplamente determinado pela expressão gênica, baseando-se no Dogma Central da Biologia Molecular (D'haeseleer et al. (1999)). Mas devido a complexidade e quantidade dos dados a serem estudados, normalmente modelos simplificados de GRNs são usados, a fim de facilitar o estudo e a experimentação. Existem diversos modelos de GRNs, entre modelos contínuos ou discretos, sendo usados de forma determinística ou estocástica.

O modelo discreto mais simples é o de Redes booleanas introduzido por Kauffman (1969). Posteriormente Shmulevich et al. (2002) modificou este modelo, incluindo incertezas, dando origem ao modelo de Redes booleanas Probabilísticas (PBN - do inglês Probabilistic Boolean Networks). Foi introduzido por Friedman et al. (2000) o modelo de Redes Bayesianas como uma ferramenta probabilística para identificação de dados regulatórios para reprodução de interações conhecidas. Entre os modelos contínuos podemos citar os modelos de equações diferenciais propostos por Goodwin (1963) e Wahde e Hertz (2000). Para maiores informações sobre os diversos modelos e um estudo comparativo, veja os trabalhos de Jong (2002) e Karlebach e Shamir (2008).

Neste trabalho, pretendemos focar no estudo de Redes booleanas (BN - do inglês Boolean Networks), provavelmente um dos modelos mais estudados. Este modelo, apesar de sua simplicidade, é capaz de representar através de sua dinâmica, assim como outros modelos, diversos fenômenos biologicamente significativos. Além disso, é possível obter diversos usos práticos, como a identificação de drogas para tratamento de câncer, através da inferência dos relacionamentos entre os genes a partir de dados experimentais como os perfis de expressão gênica (Huang (1999)). Pretendemos usar um caso particular de BNs chamada de Redes Booleanas Limiarizadas, onde tratamos apenas de estados discretos de forma determinística.

Aqui é importante notar que é pouco provável que a natureza seja ao mesmo tempo discreta, determinística e com comportamento binário, do contrário as células poderiam não sofrer mudanças e mutações ao longo do tempo. De um ponto de vista conceitual, é provável que a regularidade da função genética e as interações conhecidas sejam devidas a estabilidade auto organizada dos genes, que se modificaram ao longo do tempo até gerar tal estabilidade, através da existência de componentes estocásticos na célula que provocam mutações ao longo do tempo, possivelmente gerando novos tipos de célula. Do ponto de vista empírico, a suposição de apenas uma regra lógica por gene pode levar a conclusões incorretas quando inferindo essas redes a partir de medidas de expressão gênica, pois estas tipicamente tem ruídos de medição intrínsecos ao experimento, e o número de amostras é pequeno em relação ao número de genes a serem inferidos (Shmulevich et al. (2002)). Porém tal simplificação (de considerarmos apenas uma regra lógica) é útil para facilitar o estudo sem, no entanto, perder muitas das características principais, como a dinâmica e a representação das interações entre os genes.

Em uma PBN, a rede booleana é alterada a cada instante de tempo através da seleção de uma nova função booleana (Shmulevich et al. (2002)). Isto pode ser interpretado como se a natureza provocasse uma mudança da rede de regulação ao longo do ciclo de vida de uma célula. Apesar de modelar a incerteza inerente ao comportamento da Natureza, tal mudança não deve ocorrer de forma tão frequente (apesar de ser possível ajustar a distribuição de propabilidade para reproduzir o comportamento de não ocorrer mutações a todo momento). Assim, é útil limitar a troca 
da estrutura interna da rede de alguma forma. Por isso, Pal et al. (2005) propuseram as Redes booleanas Probabilísticas Sensíveis ao Contexto (cPBN - do inglês context-sensitive Probabilistic Boolean Network), onde a estrutura da GRN permanece fixa por um intervalo de tempo maior, até a ocorrência de um evento aleatório, como por exemplo uma mudança de contexto através de algum estimulo externo ou apenas uma mutação aleatória devido ao tempo. Podemos então, no modelo, representar tal mudança de contexto por uma variável booleana com probabilidade $q$ pequena de que tal fenômeno ocorra. Ao ocorrer tal mudança de contexto o sistema selecionaria então uma nova função booleana. Aqui vale lembrar que segundo a Teoria da Evolução as mutações não ocorrem diretamente relacionadas a mudanças de contexto, mas ainda assim a cPBN é uma ferramenta util para o estudo de redes gênicas.

\subsection{Objetivos}

Os modelos e técnicas de BN comumente usados para inferência de redes gênicas costumam usar algoritmos probabilísticos e heurísticas baseadas em conhecimentos biológicos, a priori, como base. Uma técnica ainda não aplicada é a estruturação como um Problema de Satisfação de Restrições (CSP - do inglês Constraint Satisfaction Problem) (Russell e Norvig (2002); Tsang (1993)), uma área de estudo com origem no campo de Inteligência Artificial, em que técnicas gerais aplicáveis a diversos tipos de problemas podem ser usadas sem algoritmos específicos do domínio do problema, dependendo unicamente da forma como o problema é estruturado, e resolvê-lo através de Programação de Restrições, a partir de características encontradas no problema em questão. Neste contexto, Programação de Restrições deve ser interpretado de forma análoga a Programação Linear ou Programação Dinâmica, e não como em uma linguagem de programação propriamente dita.

Neste trabalho vamos estudar e identificar algumas destas características inerentes ao problema de Inferência de Redes Gênicas. Vamos estruturar tais características como um CSP, e aplicar a Programação de Restrições para encontrar famílias de redes consistentes com os dados de entrada do algoritmo. Aqui, uma rede é chamada de consistente se ela reproduz como parte da sua dinâmica os dados de entrada do algoritmo, observados experimentalmente. No caso do problema de inferência de redes gênicas, os dados de entrada são uma pequena fração da dinâmica (uma série temporal de perfis de expressão gênica) de alguma rede desconhecida que desejamos encontrar.

Vamos ainda estudar o comportamento dinâmico de tais soluções, identificando famílias menores e de alguma forma mais consistentes com os dados de entrada e com o comportamento esperado da natureza, restringindo assim às soluções possivelmente melhores, sem necessariamente utilizarmos técnicas de otimização combinatória pela inexistência a priori de uma função critério ou utilidade, além de comparar a topologia e dinâmica de tais soluções com a topologia e dinâmica de redes artificiais de validação.

Apesar de já existirem trabalhos de inferência de redes gênicas através de consistência com dados de entrada (Higa et al. (2010, 2011, 2012)), tais trabalhos não se preocuparam de forma mais detalhada com o comportamento dinâmico e com a topologia das redes inferidas. Este trabalho é portanto importante por analisar e comparar a topologia e o quão próximas as redes inferidas estão de uma rede biológica.

\subsection{Organização}

Este trabalho está organizado da seguinte maneira:

- No Capítulo 2 discutiremos os conceitos biológicos necessários, a fim de fornecer bases ao entendimento do problema. Vamos falar um pouco mais sobre o problema de inferência de redes gênicas, e sobre os diversos modelos disponíveis, com uma revisão bibliográfica que discute mais a fundo tais modelos. Apresentamos também o modelo de redes booleanas de forma mais detalhada, em especial o modelo de redes booleanas limiarizadas. Vamos discorrer 
também sobre o Problema de Satisfação de Restrições, e algumas das diversas técnicas para resolver problemas usando o CSP;

- Já no Capítulo 3 vamos falar sobre o algoritmo proposto, modelando a inferência de redes booleanas limiarizadas como um CSP, e como filtrar as diversas redes consistentes com os dados de entrada em um conjunto mais significativo, e de maior interesse para testes em laboratório por um biólogo.

- Falamos no Capítulo 4 da implementação das ferramentas, sobre os modelos de redes artificiais usadas para validação, e como as redes foram simuladas e validadas. Falamos ainda dos resultados experimentais, tanto para as duas redes artificiais geradas para validação quanto para a rede biológica artificial da levedura (Saccharomyces cerevisiae).

- Por último, no Capítulo 5 discutiremos nossas conclusões, e daremos algumas perspectivas de trabalhos futuros. 


\section{Capítulo 2}

\section{Revisão teórica}

Neste capítulo faremos uma introdução teórica de alguns conceitos que serão úteis ao longo do texto.

\subsection{Conceitos biológicos}

Uma célula biológica é um sistema extremamente complexo, possuindo diversos mecanismos internos, como apoptose, divisão e diferenciação celular. Todo esse funcionamento é regido pelo código genético contido no DNA. E um gene é uma fração do DNA, sendo um conjunto de um ou mais genes responsável pela codificação de uma proteína, que são longas cadeias de moléculas de aminoácidos. Proteínas diferentes possuem funções bioquímicas completamente diferentes. A tradução do código genético em proteínas é feita pelo sistema de síntese proteica da célula.

\subsubsection{Expressão gênica}

O processo na qual a informação codificada por gene é utilizada para síntese do produto gênico (por exemplo um RNA funcional ou proteína), é chamado de expressão gênica, e é realizado em toda célula viva conhecida, de procariotos e eucariotos, e ocorre nos seguintes passos: transcrição, divisão do RNA, tradução e modificação pós-traducional da proteína.

Cada proteína é sintetizada de forma controlada, sendo a expressão dos genes um processo auto regulado. Existem várias etapas neste processo, como a síntese do RNA mensageiro (mRNA - do inglês messenger $R N A$ ) na fase de transcrição, e a síntese proteica durante a tradução. Dizemos que um gene está expresso quando sua sequencia correspondente do DNA é transcrita para o RNA.

Uma fita de RNA é formada por uma cadeia de fosfatos e açucares, com uma base nitrogenada ligada à uma molécula de açúcar. Temos as seguintes bases nitrogenadas formando uma fita de RNA: adenina (A), citosina (C), guanina $(\mathrm{G})$ e timina (T). Cada fita possui duas pontas, e orientadas de forma antiparalela e ligadas por pontes de hidrogênio, formam uma molécula de DNA. Uma delas é chamada de fita codificante (coding strand), e armazena a informação genética, enquanto que outra fita, chamada de fita molde (do inglês template strand) serve como modelo para a produção de RNA. O genoma, a informação hereditária de um organismo celular, é representada pelo DNA.

Em células de organismos procariotos, a transcrição do RNA gera o mRNA, pronto para o processo de tradução. Em eucariotos, por sua vez, o pre-mRNA que é transcrito, passando depois por uma série de modificações para se tornar um mRNA maduro. Geralmente, o pre-mRNA é formado por segmentos alternados de íntrons, palavra derivada do termo intragenic region, e éxons. Uma modificação importante que ocorre é conhecida como splicing, que consiste em remover os íntrons e unir os éxons, formando o mRNA. Assim, quando um gene é transcrito, dizemos que este gene está expresso, caso contrário ele está inibido.

A fase conhecida como tradução ocorre após o splicing, e é quando o mRNA carrega a a informação para a produção de proteínas, e é realizada fora do núcleo celular. O mRNA possui duas pontas que não codificam proteína, 5' UTR e 3' UTR (do inglês untranslated region), e uma região 
que codifica proteína, conhecida como CDS (do inglês Coding Sequence). O código genético para a produção de proteínas é codificado em forma de códons, onde cada códon é formado por uma tripla de nucleotídeos. Cada tripla codifica um entre os 20 possíveis aminoácidos. Sabemos que um aminoácido pode ser codificado por mais do que uma tripla de nucleotídeos. Uma explicação mais completa e detalhada pode ser encontrada em Alberts et al. (2007).

Para determinação do nível de expressão gênica vamos utilizar dados a partir da medição de microarrays de DNA. Estes experimentos são normalmente efetuados em lâminas de vidro, que contém pequenas quantidades de DNA dispostos em cavidades, formando uma matriz de pontos.

\section{DNA microarrays}

A tecnologia de medição de microarray, que permite a medição do nível de transcrição de um grupo de genes, foi relatada pela primeira vez por Schena et al. (1995), e em um genoma eucarioto completo (Saccharomyces cerevisiae) pela primeira vez por Lashkari et al. (1997).

Para executar a técnica, duas fitas de DNA são hibridizadas através da propriedade de complementaridade entre nucleotídeos. Assim, um gene conhecido é amplificado através de PCR, e em seguida uma certa quantidade de DNA correspondente a este gene é fixada em uma lamina, normalmente de vidro ou plastico, em um spot. Podem ser preenchidos milhares de spots, sendo então possível analisar a expressão de milhares de genes de uma vez.

A enzima conhecida como transcriptase reversa é então usada para gerar cDNA (do inglês complementary DNA) a partir do mRNA. Os cDNAs são marcados com um corante fluorescente (fluoróforo). Se um determinado mRNA estiver presente, seu cDNA correspondente marcado irá se ligar por hibridização à sua cadeia complementar na lâmina. Após a hibridização, as lâminas são lavadas para remover os cDNAs não hibridizadas, e a através de um processo de análise da intensidade do brilho dos spots ao estimular o fluoróforo com luz, é possível medir o nível de expressão do gene correspondente. Esse processo é chamado de single-channel, por usar apenas um corante. As matrizes indicam o nível relativo de hibridizações. Assim, elas não indicam realmente o nível de abundância de um transcrito, mas a abundância relativa quando comparado com outras amostras ou condições quando processados na mesma experiência. As ferramentas mais comuns para

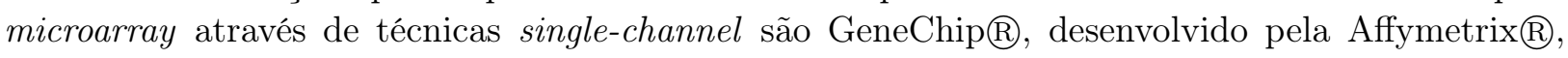
Bead Chip $\AA$ da empresa Illumina $\AA$, os arrays single-channel da empresa Agilent $\AA$, e os arrays CodeLink $($ desenvolvidos pela Applied Microarrays@. Chamamos então tais suportes de chip. Um ponto forte da técnica single-channel é que uma amostra aberrante não afeta os dados de outras amostras, pois cada chip é exposto a uma única amostra.

Além da técnica single-channel, podemos usar a técnica double-channel, onde temos duas laminas com cDNA, usadas para comparação de duas fontes distintas de mRNA. Neste caso, uma amostra fonte é marcada com corante vermelho (em geral, cianina 5, ou Cy5), e uma amostra de referência é marcada com corante verde (normalmente cianina 3, ou Cy3). Essas lâminas são então imersas em uma solução de citoplasma celular, onde moléculas de mRNA presentes se unem, através de mecanismos de afinidade química, às moléculas de cDNA. Tal união é chamada hibridização. Elas são então misturadas e hibridizadas em uma mesma lamina, o que é conhecido como hibridização competitiva. Um spot com brilho vermelho mostra então um gene expresso na amostra de teste, enquanto um spot com brilho verde mostra um gene expresso na amostra de referência. Se o gene estiver expresso nas duas amostras, o spot tem brilho amarelado. A Figura 2.1 mostra um esquema do procedimento de microarray double-channel.

A análise dos spots envolve processamento de imagem, analise de variabilidade e avaliação da qualidade, sendo o objetivo final extrair o sinal de cada spot e gerar uma matriz numérica contendo as intensidades dos sinais. Em geral, as linhas correspondem aos genes e as colunas correspondem aos experimentos de microarrays (Datta e Dougherty (2007)). Em teoria, um experimento deste poderia medir perfeitamente o nível de expressão dos genes em estudo, mas sabemos que existem na prática ruídos, que surgem no preparo da amostra, na rotulação, na hibridização, na extração do brilho, entre outros. Assim, devem ser usadas algumas abordagens para quantificar e tratar os ruídos, como os trabalhos de Chen et al. (2002), Kerr et al. (2000) ou Lee et al. (2000). Além 


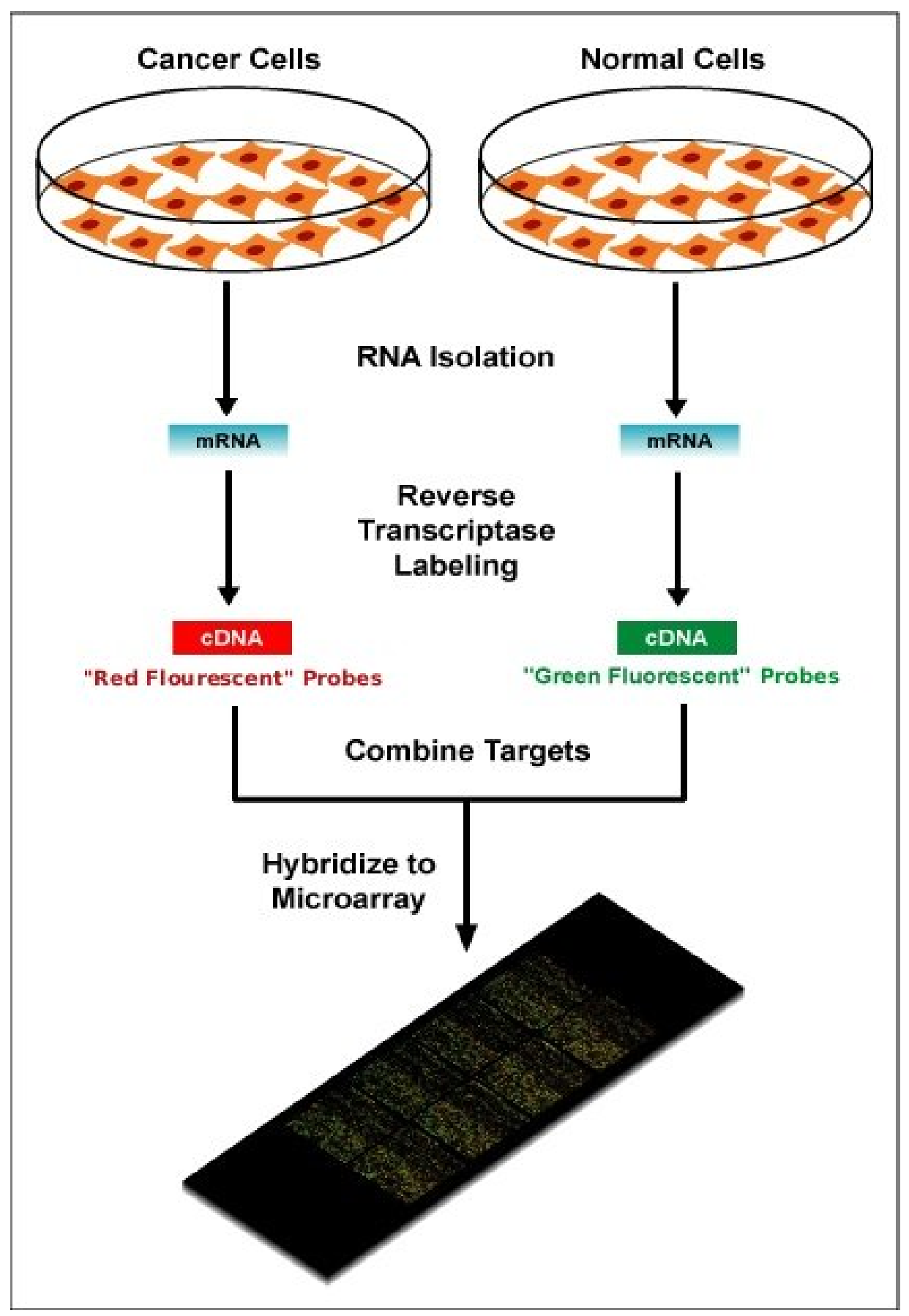

Figura 2.1: Esquema ilustrando os passos de um experimento de microarray (double-channel). Fonte: Wikipedia (2012a). 
disso, como normalmente os estudos de dados de microarray envolve a comparação de expressão gênica em microarrays distintos, é necessário que seja feita a normalização dos dados. Para isso, são usadas técnicas de normalização como apresentadas por Smyth e Speed (2003), Quackenbush et al. (2002) ou Yang et al. (2002).

Um lado negativo de técnicas single-channel é que, quando comparado com sistemas twochannel, são necessários duas vezes mais microarrays para comparação dentro de um mesmo experimento. Para comparações entre as técnicas one-channel e two-channel, veja os trabalhos de Patterson et al. (2006) e Woo et al. (2004). Veja também os trabalhos de Lönnstedt e Speed (2002), Smyth (2004) e Yang e Speed (2002) para mais informações sobre técnicas one-channel.

Os dados de expressão gênica providos por microarrays podem ser basicamente de dois tipos: independentes ou temporais. Nos dados independentes, uma amostra não possui uma relação de tempo com as outras. Por exemplo, um experimento em que vários microarrays são obtidos, um de cada paciente com câncer. Por outro lado, o procedimento de medições de microarray pode ser repetido ao longo do ciclo de vida de uma célula, separando-se uma cultura de células em frações e submetendo cada uma dessas frações ao procedimento em intervalos regulares, já que este é um experimento destrutivo. Após o processamento das imagens temos então uma série temporal do nível de expressão de um enorme número de genes. Os dados temporais representam uma análise das expressões ao longo do tempo. Neste trabalho, utilizamos apenas dados temporais; estes dados capturam uma visão mais completa do sistema do que dados estacionários (Higa (2012)).

\subsection{Inferência de Redes Gênicas}

Os modelos de GRNs nos ajudam a estudar os fenômenos biológicos mais facilmente. Assim, determinar tais interações, ao menos que parcialmente, é um problema de extrema importância.

O uso de dados provenientes, dentre outras técnicas, de microarrays para tentar determinar o relacionamento entre os genes é um problema conhecido como engenharia reversa, uma tarefa bastante desafiadora, onde estudamos os dados a fim de determinar as interações físicas do sistema. O problema é que para GRNs, em muitos casos não é possível a determinação precisa da estrutura, já que a quantidade de amostras de dados em relação ao número de genes normalmente é bastante restrita, e ruídos na medição interferem no processamento.

Nos modelos discretos de GRNs, dos quais estamos interessados no modelo de BN, o valor das variáveis representa o nível de expressão de cada gene, e o estado do sistema é representado por um vetor de estado de cada gene. A cada variável está associada uma função que determina o próximo estado, isto é, o nível de concentração da proteína no instante seguinte a partir do valor atual do vetor de estado.

Normalmente, técnicas de inferência visam determinar uma única rede em que se acredita representar corretamente a natureza. A questão é que o problema inverso é geralmente mal posto: diversas redes podem ter um comportamento que gera como parte de sua dinâmica, no nosso caso, uma série temporal idêntica à observada experimentalmente. O problema se torna ainda mais complicado pela escassez de dados e por possível ruído nos dados. Assim, visamos gerar e analisar diversas redes que poderiam gerar tal série temporal observada. Para isso, vamos usar o modelo de Redes Booleanas Limiarizadas, descritas na Seção 2.3, aplicando tal problema ao arcabouço do Problema de Satisfação de Restrições, descrito na Seção 2.4, e estudando a dinâmica das redes encontradas no Capítulo 4.

Apesar de estar diretamente ligado ao problema de inferência de Redes Gênicas, nossa meta não é inferir uma única rede e afirmar que está é a correta. Neste trabalho estamos interessados em algo que possa ser usado posteriormente como suporte para testes em laboratório. Assim, pretendemos gerar diversas redes consistentes com os dados de entrada, sem considerar que uma destas é, de fato, a rede correta, para em seguida efetuar algumas análises sobre esses resultados.

O processo é baseado em Redes booleanas e séries temporais. A seguir, definimos tais conceitos. 


\section{$2.3 \quad$ Redes Booleanas}

O modelo de Redes booleanas é o modelo discreto mais simples de GRN. Uma Rede booleana $G(X, F)$ é definida como um conjunto $X=x_{1}, x_{2}, \ldots, x_{n}$ de $n$ variáveis booleanas e um conjunto $F=f_{1}, f_{2}, \ldots, f_{n}$ de $n$ funções booleanas, com $x_{i}=\{0,1\}, i=1,2, \ldots n$ (Higa et al. (2010); Kauffman (1969); Li et al. (2004); Shmulevich et al. (2002)). O valor da variável $x_{i}$ no instante de tempo $t+1$ é determinado por uma função booleana $f_{i}:\{0,1\}^{k_{i}} \rightarrow 0,1$ dependente dos valores das variáveis $x_{j_{1}}^{(i)}, x_{j_{2}}^{(i)}, \ldots, x_{j_{k}}^{(i)} \in X$ no instante $t$. Existem, portanto, $k_{i}$ variáveis associadas (adjacentes) a variável $x_{i}$. No caso de GRN chamaremos as variáveis de genes, $x_{i}$ de gene alvo e os $k_{i}$ genes associados a $x_{i}$ de preditores de $x_{i}$. Se $x_{i}=0$, dizemos que o gene $x_{i}$ está inibido ou desligado. De forma análoga, se $x_{i}=1$, dizemos que $x_{i}$ está expresso ou ligado. Assim,

$$
x_{i}(t+1)=f_{i}\left(x_{j_{1}}^{(i)}(t), x_{j_{2}}^{(i)}(t), \ldots, x_{j_{k_{i}}}^{(i)}(t)\right) .
$$

Para simplificar a computação, consideramos que os estados de todos os genes são atualizados de forma síncrona pelas funções de $F$ (Huang (1999); Kauffman (1993); Wuensche (1998)). O estado da rede no instante $t$ é um vetor binário $\mathbf{s}(t)=\left(x_{1}(t), \ldots, x_{n}(t)\right)$, também chamado perfil de atividade gênica (GAP - do inglês Gene Activity Profile) (Huang (1999); Shmulevich et al. (2002)). Assim, para o caso de BNs, temos $2^{n}$ estados, rotulados $\mathbf{s}_{0}, \ldots, \mathbf{s}_{2^{n}-1}$. Este modelo é determinístico, dado que para cada gene $x_{i}$, apenas uma função booleana rege seu funcionamento. A transição sequencial entre tais estados representa a dinâmica da rede.

Devido ao número finito de estados e ao comportamento determinístico, alguns estados podem ser visitados de forma cíclica. Estes estados serão chamados de atratores, e os estados fora do atrator serão chamados de estados transientes. A união dos estados transientes com o atrator correspondente é chamada de bacia de atração. Uma transição sequencial de um estado transiente em direção ao atrator é chamada de trajetória. Apesar do grande número de GAPs parecer impedir uma analise computacional, simulações efetuadas por Kauffman (1993) mostram que para BNs onde a maioria das funções booleanas tem uma pequena quantidade de preditores, apenas um pequeno número de GAPs correspondem a atratores (Shmulevich et al. (2002)). Como normalmente a maioria dos GAPs são, portanto, estados transientes, mas os caminhos até os atratores é normalmente bastante curto, o sistema não é comumente encontrado nesses estados, a menos que o sistema seja perturbado. A Figura 2.2 representa a dinâmica de uma rede com quatro genes, e portanto $2^{4}=16$ estados. Nesta figura, os estados "0000", "0101" e "1000" são os atratores, e o restante dos estados são os chamados de estados transientes. Uma árvore, como a formada pelos estados "0100" e "1000", é chamada de bacia de atração. Neste exemplo temos apenas atratores pontuais, isto é, com apenas um estado, mas podemos ainda ter ciclos atratores, compreendidos por mais de um estado. A transição "1101", "1100", "1110", "0000" e "0000" representa uma trajetória.

\subsubsection{Rede Booleana Limiarizada}

Neste trabalho estamos interessados em tratar uma simplificação deste modelo, conhecido como Redes Booleanas Limiarizadas (TBN, do inglês thresholded Boolean network). Neste modelo, a função booleana $f_{i}$ é definida de acordo com uma matriz de regulação $\mathbf{A}_{n \times n} \operatorname{com} a_{i j}=\{-1,0,1\}, i, j=$ $1, \ldots, n$, a qual estamos interessados em inferir, e o valor dos genes $x_{j_{i}}$, isto é, os genes $x_{j}$ preditores do gene $x_{i}$, no instante $t$, para $j=1,2, \ldots, n$, de acordo com a Equação 2.1: 


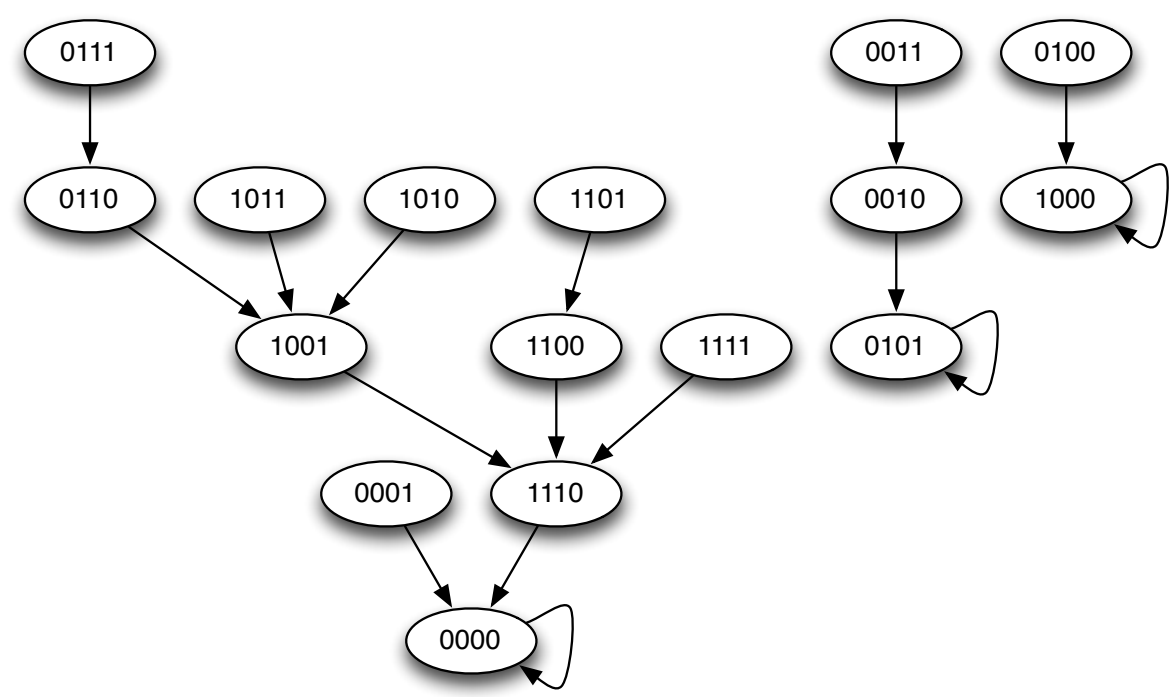

Figura 2.2: Diagrama representando a dinâmica de uma rede com quatro genes e 16 estados.

$$
x_{i}(t+1)= \begin{cases}1, & \text { se } \sum_{j=1}^{n} a_{i j} x_{j}(t)>\tau, \\ x_{i}(t), & \text { se } \sum_{j=1}^{n} a_{i j} x_{j}(t)=\tau \\ 0, & \text { se } \sum_{j=1}^{n} a_{i j} x_{j}(t)<\tau\end{cases}
$$

Onde $\tau$ é um limiar pré-determinado. Dizemos que $x_{j}$ induz $x_{i}$ se $a_{i j}=1$ e que $x_{j}$ reprime $x_{i}$ se $a_{i j}=-1$. Para os casos onde $a_{i j}=0$, não existe relacionamento entre os genes $x_{j}$ e $x_{i}$. No caso em que $\tau=0$, chamamos de Rede Booleana Restrita (RBN, do inglês Restricted Boolean Network), modelo proposto por Li et al. (2004).

Chamamos o somatório $\sum_{j=1}^{n} a_{i j} x_{j}(t)$ de entrada de $x_{i}$ no instante $t$. Além da regulação definida pela matriz $\mathbf{A}$, cada gene $x_{i}$ pode possuir um comportamento de auto inibição, assumindo o valor 0 se sua entrada é nula, isto é, se não existem genes $x_{j}$ regulando o gene $x_{i}$, adicionamos uma regulação de inibição de $x_{i}$ para $x_{i}$. Podemos observar que nem toda função booleana pode ser representada pela Equação 2.1, e por isso a rede booleana é chamada de "Restrita". Assim, uma rede Restrita é um caso particular de uma rede limiarizada. Além disso, podemos notar também que a entrada de cada gene $x_{i}$ depende unicamente da $i$-ésima linha da matriz $\mathbf{A}$.

\subsubsection{Série consistente}

Assumindo que os dados de expressão gênica foram gerados por um sistema biológico, e assim desconsiderando ruído ou erro de medição, seja $S=\mathbf{s}(1), \mathbf{s}(2), \ldots, \mathbf{s}(m)$ um conjunto de $m$ GAPs que definem uma série temporal produzida por uma rede booleana, com $\mathbf{s}(t) \in\{0,1\}^{n}$, para $t=$ $1, \ldots, m$. Quando uma rede produz uma série temporal idêntica à série dada, dizemos que esta rede é consistente com os dados. É claro que diversas redes diferentes podem produzir uma mesma série temporal, ou seja, podem existir diversas redes consistentes com uma dada série. É possível gerar, de forma ingênua, todas as redes através de enumeração, como proposto por Lau et al. (2007). Neste trabalho usamos algumas propriedades das TBNs a fim de evitar tal processo.

Vamos introduzir o CSP, e em seguida retornar a formalização do problema e a forma como iremos inserir o problema ao arcabouço do CSP. 


\subsection{Problema de Satisfação de Restrições}

Diversos problemas podem ser resolvidos por busca em um espaço de estados. Tais buscas podem usar heurísticas específicas do domínio do problema para acelerar a busca verificando a cada "solução" encontrada se esta é de fato uma solução do problema. Tais estados podem ser vistos como uma caixa preta, sem estrutura interna verificável, com estruturas de dados acessíveis apenas por rotinas específicas do problema. O problema de tais técnicas é que pequenas alterações no problema podem tornar o algoritmo inútil, sendo necessário a criação de novos algoritmos.

Os Problemas de Satisfação de Restrições (CSP - do inglês Constraint Satisfaction Problem), por outro lado, possuem características padronizadas para representação dos estados e teste de solução, de representação simples, que podem ser exploradas através do uso de algoritmos genéricos que podem ser usados para problemas de forma geral, ao invés de técnicas com conhecimentos específicos de domínio do problema. Assim, vamos estudar resumidamente algumas técnicas de CSP, que podem ser aplicadas para resolver problemas genéricos.

Um CSP é um problema composto de um conjunto de variáveis, cada qual associada a um dominio de valores possíveis, e um conjunto de restrições, que limitam os valores que as variáveis podem assumir simultaneamente. Além disso, alguns CSPs aceitam uma função objetivo a ser maximizada.

Formalmente, podemos definir o CSP como uma tupla $(A, D, C)$, onde $A=\left\{a_{1}, a_{2}, \ldots, x_{n}\right\}$ é o conjunto de variáveis, $D=\left\{D_{1}, D_{2}, \ldots, D_{n}\right\}$ é uma coleção de domínios, onde o domínio $D_{i}$ associado a variável $a_{i}$ é o conjunto de todos os valores possíveis de serem atribuídos para tal variável, e $C=\left\{C_{1}, C_{2}, \ldots, C_{m}\right\}$ é uma coleção de conjuntos de restrições, onde $C_{i}$ restringe valores que as variáveis de um subconjunto $A^{\prime} \subset A$ podem assumir simultaneamente. Uma solução de um CSP é uma atribuição, para toda variável $a_{i}$, de um valor de $D_{i}$, tal que todas as restrições de $C$ sejam satisfeitas (Russell e Norvig (2002); Tsang (1993)).

A solução de CSP sobre domínios finitos é feita através de algoritmos de busca, pela atribuição sistemática de valores para as variáveis e da verificação se as restrições são satisfeitas. As técnicas mais usadas são variações de backtracking, propagação de restrições e busca local. Nestas técnicas, uma variável é eleita através de alguma ordenação ou heurística, e após isso um valor é selecionado de seu domínio, sendo este valor selecionado também seguindo uma heurística ou ordenação específica para seleção de valor.

Seguem algumas definições que serão úteis ao longo do texto.

Atribuição Uma atribuição é um par variável-valor que representa a associação do valor à variável. Denotamos $\left\langle a_{i}, v\right\rangle$ a atribuição do valor $v$ à variável $a_{i}$. É claro que a atribuição só faz sentido se $v \in D_{i}$. Uma atribuição é consistente se não viola nenhuma restrição.

Atribuição $k$-composta Um estado ou atribuição $k$-composta é uma atribuição de $k$ valores a $k$ variáveis. Usamos $\left.\left\{\left\langle a_{1}, v_{1}\right\rangle,\left\langle a_{2}, v_{2}\right\rangle, \ldots,<a_{k}, v_{k}\right\rangle\right\}$ para denotar a atribuição dos valores $v_{1}, v_{2}, \ldots, v_{k}$ às variáveis $a_{1}, a_{2}, \ldots, a_{k}$ respectivamente. Dizemos então que para $k=|X|=n$, uma atribuição $n$-composta ou atribuição completa é uma atribuição de valor para cada variável de $A$.

Restrição Seja $S_{i}=a_{i_{1}}, a_{i_{2}}, \ldots, a_{i_{k}} \subset A$. Uma restrição em $S_{i}$ é um conjunto de atribuições compostas para as variáveis de $S_{i}$. Denotamos por $C_{S_{i}}$ as restrições no conjunto de variáveis $S_{i}$. Uma atribuição é consistente se não viola nenhuma restrição. Uma solução é uma atribuição $n$-composta que satisfaz todas as restrições, ou seja, uma atribuição completa e consistente. Assim, podemos ter atribuições $n$-compostas que não sejam soluções, e dizemos então que estas são atribuições falhas.

Dependendo dos requisitos da aplicação, podemos classificar os CSPs de acordo com as seguintes categorias (Tsang (1993)):

- CSPs onde se deseja encontrar alguma solução.

- CSPs onde se deseja encontrar todas as soluções. 
- CSPs onde se deseja encontrar a solução ótima, onde o ótimo é definido de acordo com algum domínio de conhecimento.

A seguir descreveremos de forma mais detalhada do funcionamento do CSP.

\subsubsection{Resolução de CSP}

Existem algumas formas de classificar as técnicas de resolução de CSP. Uma delas é a classificação em três categorias: redução do problema, busca da solução e por último síntese da solução (Tsang (1993)).

A redução do problema é uma classe de técnicas que visam transformar um CSP em problemas que são mais fáceis de resolver ou reconhecidamente insolúveis. Um problema $P$ é reduzido em um problema $P^{\prime}$ se eles são equivalentes, o domínio de cada variável de $P^{\prime}$ é um subconjunto do domínio da variável equivalente em $P$ e o conjunto de restrições em $P^{\prime}$ é pelo menos tão restritivo quanto as restrições de $P$. Dois CSPs são ditos equivalentes se têm o mesmo conjunto de variáveis e as mesmas soluções. Assim, reduzir um problema significa remover das restrições as atribuições compostas que não aparecem nas tuplas de soluções. Isso é feito basicamente de duas formas: removendo do domínio das variáveis valores que não aparecem nos resultados e estreitando ainda mais as restrições para que menos atribuições compostas as satisfaçam.

A técnica mais básica de busca para solução de um CSP é através de simples backtracking. Nesta, a operação básica é selecionar uma variável e atribuir a esta um valor de cada vez, tomando cuidado para que o valor selecionado seja consistente com os valores escolhidos até então para variáveis anteriormente tratadas. Se o valor escolhido não satisfaz alguma restrição, um novo valor é escolhido. Se não existem, para a variável atual, mais valores possíveis, então a atribuição da variável anterior é revisitada, e um novo valor é selecionado para tal variável. Toda solução deve ser uma atribuição completa, e portanto aparecer na profundidade $n$ da árvore de busca. Assim, a profundidade máxima da árvore é $n$. Por isso, algoritmos de Busca Em Profundidade (DFS - do inglês Depth First Search) são comuns para resolução de CSP.

A síntese de solução pode ser vista como algoritmos de busca que exploram múltiplos ramos da árvore de busca simultaneamente. Também pode ser vista como uma redução do problema na qual é criada a restrição para o conjunto de todas as variáveis, e então reduzida para o conjunto que contém todas as soluções. A ideia básica da síntese de soluções é criar atribuições viáveis para conjuntos cada vez maiores de variáveis, até que complete para o conjunto de todas as variáveis. A característica distintiva da síntese de soluções é que as soluções são geradas construtivamente.

Geralmente, as respostas encontradas por tais técnicas são de fato soluções para os problemas reais. Além disso, diversos algoritmos de resolução de CSP encontram todas as respostas possíveis. Existem, porém, problemas intratáveis, que usam relaxações de uma ou mais técnicas. Assim, é possível encontrar apenas algumas respostas, ou até mesmo algumas respostas aproximadas.

\section{Tipos de restrição}

Uma das características do CSP é que existem diversos tipos padronizados de restrição. Com isso, podemos criar técnicas genéricas para resolver tais restrições. A seguir, veremos algumas delas.

O tipo mais simples de restrição é a restrição unária, na qual se restringe o valor de uma variável a um único valor, um intervalo ou a um conjunto de valores de seu domínio. Tal restrição pode ser facilmente eliminada por pré processamento, removendo do domínio desta variável todos os valores conflitantes.

Uma restrição binária relaciona duas variáveis, por exemplo, $x \neq y$. Imagine que desejamos colorir um mapa dos estados das regiões Sul, Sudeste e Centro-oeste do Brasil, de forma que dois estados vizinhos não tenham a mesma cor. Para modelarmos este problema como um CSP, definimos as variáveis como os estados, e existe uma restrição entre dois estados se estes possuem uma fronteira em comum. Neste caso, $A=\{R S, S C, P R, S P, R J, E S, M G, G O, M S, M T\}$ é o conjunto de variáveis, o domínio de cada variável seria um conjunto de cores, por exemplo, 
$D=\{$ verde, amarelo, azul, branco $\}$, e nossas restrições seriam do tipo $x_{i} \leq x_{j}$ se $x_{i}$ e $x_{j}$ representam estados que possuem uma fronteira em comum. Neste caso, temos a modelagem como um CSP apenas com restrições binárias. Um CSP que contém apenas restrições binárias pode ser facilmente visualizado como um grafo de restrições. Um grafo é uma tupla $(V, E)$, onde $V$ é um conjunto de nós e $E \subset(V \times V)$ é um conjunto de arcos. No grafo de restrições, os nós representam variáveis e os arcos representam restrições. (Russell e Norvig (2002); Tsang (1993)). Veja na Figura 2.3 o grafo de restrições para o problema da coloração do mapa do Brasil.

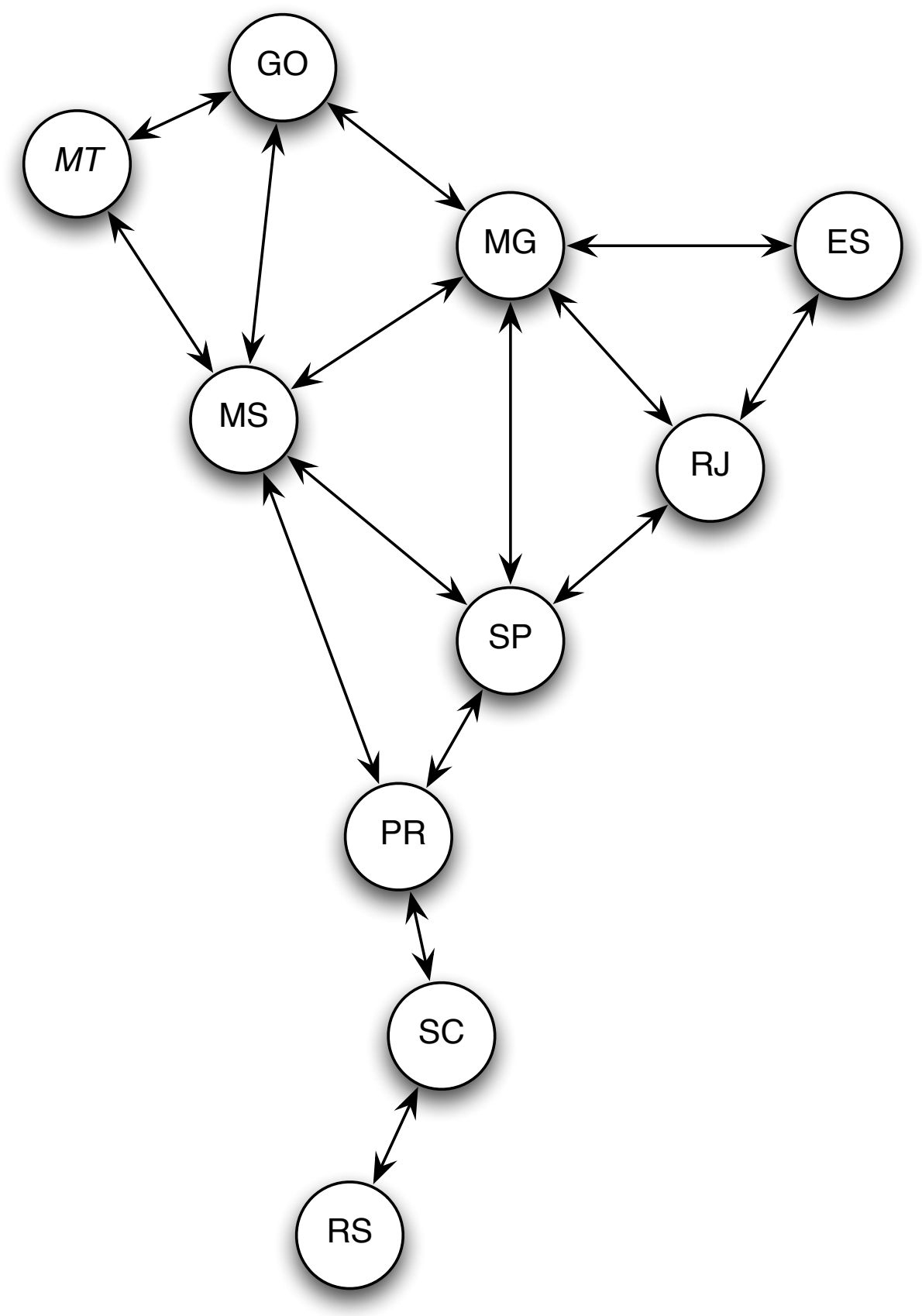

Figura 2.3: Um grafo de restrições, exibindo as variáveis (estados) e as restrições (fronteiras) para o problema de colorir o mapa do Brasil.

Problemas que envolvem restrições com mais de dois elementos devem ser representados como um hipergrafo de restrições, e não como um grafo de restrições como descrito anteriormente. Hipergrafos são generalizações de grafos, na qual uma aresta é substituída por uma hiperaresta, que pode relacionar mais de duas variáveis. Porém, através do uso de variáveis auxiliares, podemos reduzir todo CSP com restrições não binárias em um CSP apenas com restrições binárias (Russell e Norvig 
(2002)). Além disso, existem algoritmos especiais para solução de restrições lineares, em que as variáveis aparecem associadas a equações lineares.

As restrições definidas até agora eram restrições absolutas, sendo que se uma delas não é satisfeita podemos, de forma indesejável, excluir potenciais soluções. Podemos associar custos às variáveis, definindo assim restrições de preferência sobre os valores. Por exemplo, podemos preferir colorir $S P$ de branco, e $R J$ de verde. Associamos então um custo de 2 pontos as outras cores além de branco para $S P$ e verde para $R J$, mantendo custo de 1 ponto para estas cores. A violação destas restrições não necessariamente define uma falha, mas pode gerar uma solução inferior.

Certos casos de restrições ocorrem com frequência e podem ser manipulados por algoritmos especiais. Um exemplo de tais restrições é all-diff, onde todas as variáveis envolvidas devem possuir valores distintos duas a duas. Uma forma simples de detectar inconsistências all-diff funciona assim: se existem $m$ variáveis envolvidas na restrição com $n$ valores possíveis para todas, se $m>n$, então existe uma inconsistência. Isso leva ao seguinte algoritmo: primeiro remova todas as variáveis com um único valor e remova do domínio das variáveis adjacentes valores inconsistentes com esta atribuição. Repita enquanto houverem variáveis semelhantes. Se um domínio vazio é encontrado ou existem mais variáveis que valores possíveis, então uma inconsistência foi detectada.

\section{Tipos de variáveis}

A forma mais simples de CSP é com variáveis discretas e domínio finito. Se o tamanho máximo do domínio de qualquer variável é $d$, então o número de atribuições completas (não necessariamente respeitando as restrições) é $O\left(d^{n}\right)$, exponencial no número de variáveis. Dentre os tipos de CSP de domínio finito temos o CSP-Booleano, cujas variáveis assumem valores Verdadeiro ou Falso. E um dos casos especiais do CSP-Booleano é o problema $S A T$, o problema de determinar se existe uma determinada valoração que satisfaça uma determinada fórmula booleana. Tal problema foi o primeiro a ser identificado como pertencente à classe de complexidade NP-Completa. Logo, não esperamos que exista uma solução de CSP em tempo, no pior caso, menor que exponencial. Na maioria dos casos práticos, porém, é possível resolver problemas muito maiores que algoritmos mais genéricos de busca (Russell e Norvig (2002)).

\section{Busca da Solução}

Todo CSP tem como propriedade importante a comutatividade. Um problema é comutativo se a ordem da aplicação de um conjunto de ações não altera o resultado final. Assim, não importa a forma como atribuímos valores para uma variável, as possíveis soluções serão as mesmas (apesar de poderem vir fora de ordem se não for um problema de otimização). Todo algoritmo de busca para CSP gera sucessores considerando atribuições possíveis para uma única variável em cada nó da árvore de busca. Assim, o número de folhas é $d^{n}$. Sem esta propriedade, poderíamos usar, de forma ingênua, um algoritmo de busca em largura. Neste caso, teríamos um fator de ramificação no nível mais alto igual a $n d$ ( $n$ variáveis com $d$ possíveis valores), $(n-1) d$ no segundo nível e assim por diante, gerando $n ! d^{n}$ folhas, um número exponencialmente maior que o número de soluções.

Assim, a forma básica de busca de uma solução de um CSP é através de busca em profundidade com backtracking, onde é atribuído um valor para uma variável de cada vez, e caso uma variável não possua mais valores permitidos no domínio, é efetuado o backtracking. Veja Figura 2.4.

O Algoritmo BacktrackingRecursivo (algoritmo 1) exibe uma forma simples de efetuar o backtracking. As funções Seleciona-Variavel-Nao-Atribuida e ValoresordenadosNoDominio podem ser usadas para implementar as heurísticas mencionadas ao longo do texto. A partir dele podemos fazer três perguntas (Russell e Norvig (2002)):

1. Qual a ordem da escolha das variáveis devemos seguir para atribuição?

2. Quais as implicações da atribuição atual para as variáveis não atribuídas?

3. O que fazer quando o caminho falha (atingimos um estado sem valores válidos para atribuição)? Podemos evitar repetir tal falha no futuro? 


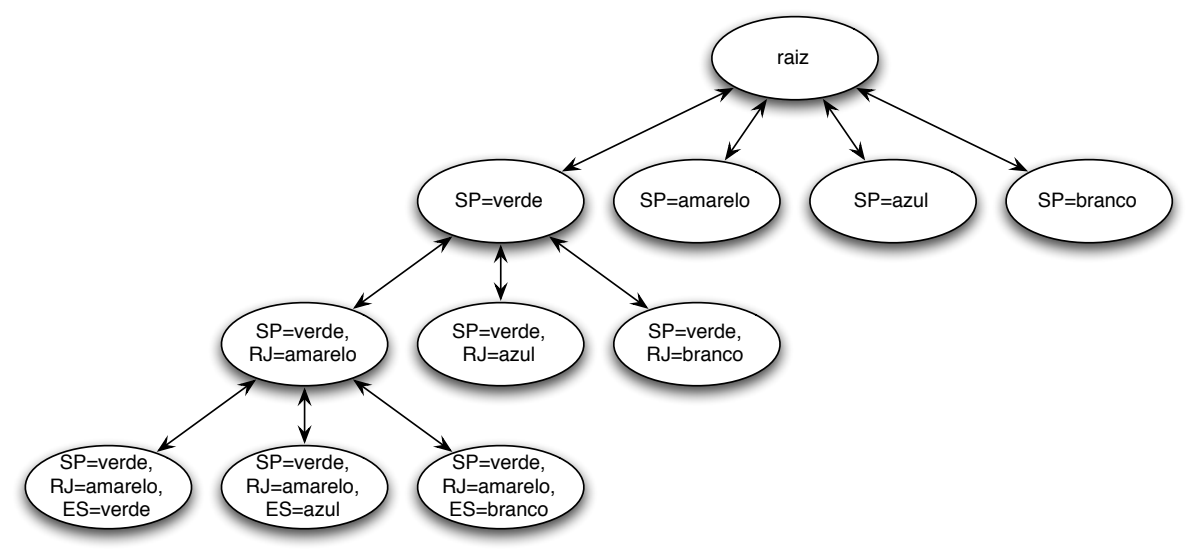

Figura 2.4: Parte da árvore de busca por simples backtracking para o problema da coloração dos estados do Brasil.

Ao iniciar a resolução do CSP, devemos de alguma forma selecionar uma variável para atribuição. Existem diversas heurísticas para tal seleção. Como não temos, a princípio, uma ordenação das variáveis, podemos então começar selecionando a variável envolvida no maior número de restrições. Esta é conhecida como heurística de grau. Isto porque, ao atribuir um valor para esta variável, aumentamos a restrição em um maior número de variáveis, diminuindo a ramificação em escolhas futuras e o aumento no número de folhas.

Uma segunda opção de escolha de variável é a heurística conhecida como Variável Mais Restrita (MCV - do inglês Most Constrained Variable), ou "fail-first". Nesta, escolhemos, dentre as variáveis disponíveis como próxima opção de escolha, a que tenha o menor domínio. Assim, inconsistências de atribuição de valores para esta variável são detectadas mais rapidamente, podando a árvore de busca e eliminando buscas desnecessárias.

Após escolher uma variável, devemos escolher qual a ordem de atribuição de valores para esta variável. Existem diversas heurísticas para seleção do valor. Dentre estes podemos citar (Russell e Norvig (2002); Schulte et al. (2010); Tack (2009)):

- Valor Menos Restritivo: escolhe um valor que restrinja menos as escolhas subsequentes de valores para variáveis adjacentes no grafo de restrições, permitindo assim mais flexibilidade na escolha para outras variáveis

- Aleatório: atribui um valor aleatório dentre os valores possíveis permitidos, mantendo a consistência

- Menor/Maior Valor: Assume o menor/maior valor disponível do domínio da variável.

Vale observar que a ordenação da escolha dos valores só é importante se estamos interessados em encontrar apenas uma ou parte das soluções. Se desejamos encontrar todas as soluções, devemos verificar todos os valores dos domínios, não importando assim a ordenação. Neste caso, a única alteração será na ordem em que as respostas são encontradas.

\section{Backjumping}

O algoritmo mais simples de backtracking segue uma política simples quando uma inconsistência é encontrada: volta um nível e tenta outro valor, e por isso é chamado de backtracking cronológico, pois a decisão mais recente é revisitada. Uma forma mais eficiente é voltar tudo até o conjunto de variáveis que causou o conflito, chamado conjunto conflito. Em geral é o conjunto de variáveis com valor previamente atribuído que são conectados com uma variável $x$ por restrições.

Backjumping é a técnica de retornar a variável do conjunto conflito que teve um valor atribuído mais recentemente. Isto é facilmente implementado modificando o algoritmo de backtracking para 


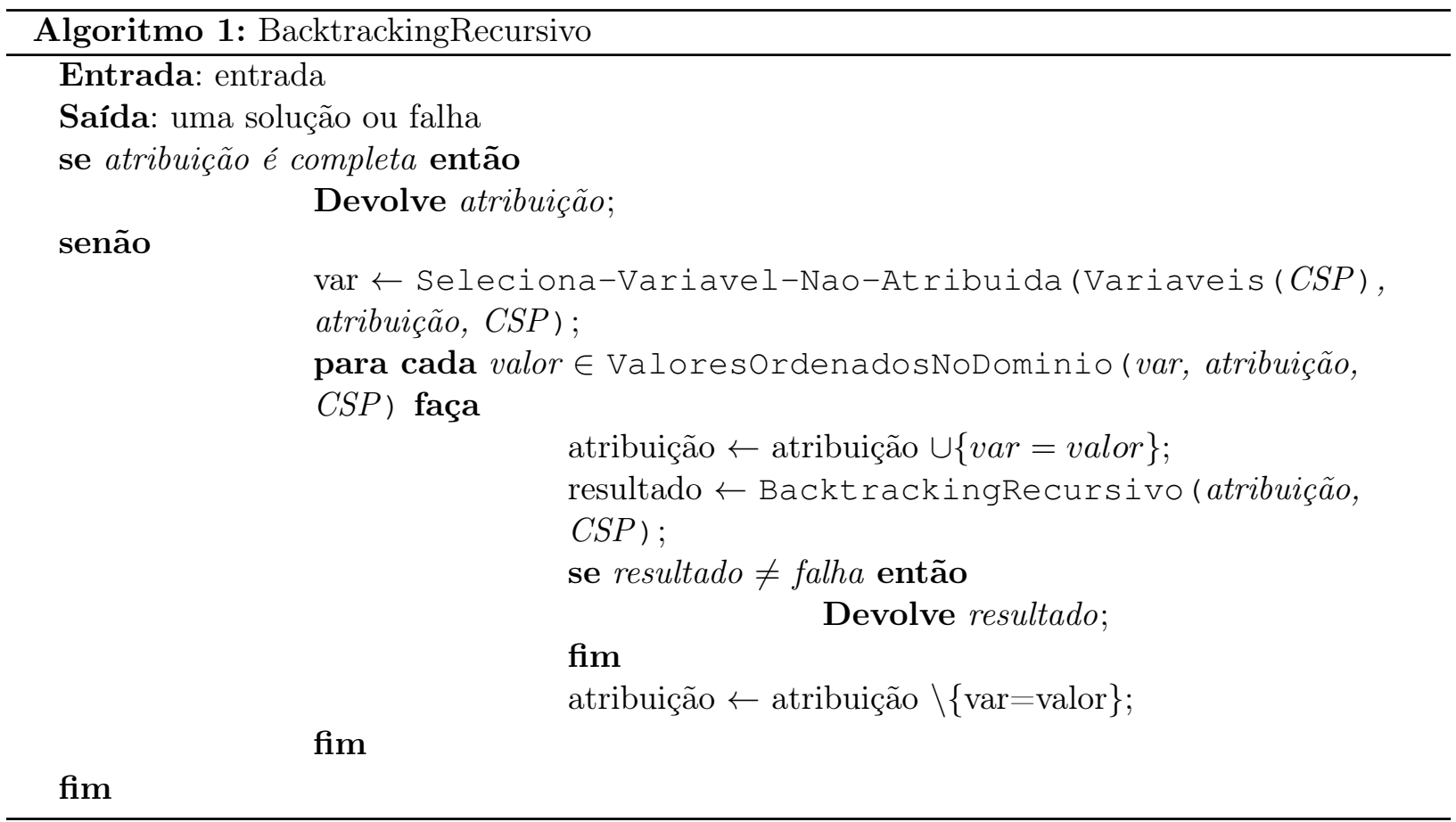

que ele mantenha o conjunto conflito enquanto procuramos por valores para atribuição. Se um valor viável não é encontrado, o algoritmo retorna ao elemento mais recente do conjunto conflito que indique falha.

Chamamos de conjunto conflito de uma variável o conjunto de variáveis que podem tornar uma atribuição inválida para tal variável. Backjumping é a técnica de retornar a variável do conjunto conflito que teve um valor atribuído mais recentemente. Isto é facilmente implementado modificando o algoritmo de backtracking para que ele mantenha o conjunto conflito enquanto procuramos por valores para atribuição. Se um valor viável não é encontrado, o algoritmo retorna ao elemento mais recente do conjunto conflito que indique falha.

Digamos que, ao selecionar o valor a ser atribuído a uma variável $a_{i}$, removemos um valor do domínio de uma variável $a_{j}$. Devemos então adicionar $a_{i}$ ao conjunto conflito de $a_{j}$. Além disso, quando o último valor é removido do domínio de $a_{j}$, as variáveis no conjunto conflito de $a_{j}$ devem ser adicionadas ao conjunto conflito de $a_{i}$. Assim, ao chegar a atribuição de $a_{j}$, sabemos para onde efetuar o backtracking, caso este seja necessário.

Seja $a_{j}$ a variável atual, e seja conf $\left(a_{j}\right)$ seu conjunto conflito. Se todo valor de seu domínio atual provoca uma falha, efetuamos o backjump para a variável $a_{i}$ mais recente em conf $\left(a_{j}\right)$, e atribuímos

$$
\operatorname{conf}\left(a_{i}\right) \leftarrow \operatorname{conf}\left(a_{i}\right) \cup \operatorname{conf}\left(a_{j}\right) \backslash\left\{a_{i}\right\}
$$

Esta técnica, conhecida como Conflict-directed backjumping, nos leva novamente ao ponto na árvore que causou o conflito, mas não nos proíbe de causar o mesmo conflito futuramente em outro ramo da árvore. Algumas implementações contém técnicas de aprendizagem de restrições, que adiciona uma restrição para evitar que este conflito ocorra novamente.

\section{Verificação Prematura}

Uma forma de melhorar o uso das restrições é a técnica chamada de verificação prematura (do inglês forward checking) (Russell e Norvig (2002)).

Após escolher o valor de uma variável $a_{i}$, olhamos todas as variáveis $a_{j}$ que são adjacentes a $a_{i}$ no grafo de restrições, e removemos de seus domínios os valores inconsistentes com a escolha 
do valor de $a_{i}$. Podemos visualizar a verificação prematura como uma forma eficiente de computar incrementalmente a informação que a heurística MCV precisa para ser executada.

\section{Propagação de Restrições}

O problema da verificação prematura é que ela olha apenas as variáveis adjacentes no grafo de restrição, não olhando muito adiante nas escolhas das atribuições. Podemos estender a verificação prematura, verificando iterativamente não apenas as variáveis adjacentes no grafo de restrições, mas todas as variáveis. Chamamos a propagação das implicações de uma restrição em outras variáveis de Propagação de Restrições (Russell e Norvig (2002); Tack (2009)).

Para exemplificar a Propagação de Restrições, vamos usar como exemplo o jogo Sudoku, provavelmente um dos problemas de combinatória mais conhecidos da atualidade (Tack (2009)).

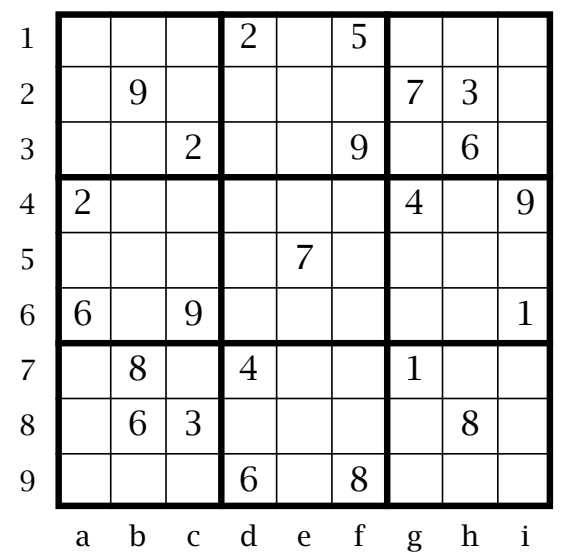

\begin{tabular}{|c|c|c|c|c|c|c|c|c|}
\hline & 7 & 8 & 2 & 6 & 5 & 9 & 1 & 4 \\
\hline 5 & 9 & 6 & 8 & 1 & 4 & 7 & 3 & 2 \\
\hline 1 & 4 & 2 & 7 & 3 & 9 & 5 & 6 & 8 \\
\hline 2 & 1 & 7 & 3 & 8 & 6 & 4 & 5 & 9 \\
\hline 8 & 5 & 4 & 9 & 7 & 1 & 6 & 2 & 3 \\
\hline 6 & 3 & 9 & 5 & 4 & 2 & 8 & 7 & 1 \\
\hline 7 & 8 & 5 & 4 & 2 & 3 & 1 & 9 & 6 \\
\hline 4 & 6 & 3 & 1 & 9 & 7 & 2 & 8 & 5 \\
\hline 9 & 2 & 1 & 6 & 5 & 8 & 3 & 4 & 7 \\
\hline
\end{tabular}

Figura 2.5: Um jogo de Sudoku a esquerda, e sua solução a direita (figura adaptada de Tack (2009)).

O jogo consiste de uma matriz $9 \times 9$, que deve ser preenchida com números de 1 até 9 de forma que toda linha, coluna e cada um dos nove blocos $3 \times 3$ contenha exatamente os números de 1 a 9, sem repetições. O jogo começa com a matriz parcialmente preenchida, de modo que exista apenas uma única solução. A Figura 2.5, extraída de Tack (2009), exibe um jogo típico de Sudoku à esquerda, e sua solução à direita.

O modo mais simples de modelar o Sudoku como um CSP é identificar cada um dos 81 campos como uma variável. Cada variável $v_{i}$, para $v \in\{a, b, \ldots, i\}$ e $i \in\{1,2, \ldots, 9\}$ pode assumir qualquer valor do domínio $D_{i}=\{1, \ldots, 9\}$. Temos 27 restrições, cada uma dizendo que cada linha, coluna ou bloco 9times 9 deve assumir exatamente os números entre 1 e 9. Cada restrição é, portanto, uma instância da restrição all-diff.

Suponha que desejamos escolher uma variável do bloco inferior esquerdo da Figura 2.5. É fácil perceber que o domínio da variáveis não atribuídas dentro deste bloco não pode incluir os valores $\{3,6,8\}$, pois estes já foram atribuídos as variáveis $b_{7}, b_{8}, c_{8}$, respectivamente. Olhando as restrições e os valores atribuídos, podemos remover do domínio das variáveis $a_{7}, a_{8}, a_{9}, c_{7}, c_{9}$ o valor $\{2\}$, que já foi atribuído às variáveis $a_{4}$ e $c_{3}$. Assim, só nos resta atribuir $\left\langle b_{9}, 2\right\rangle$. Este processo de inferência é a Propagação de Restrições. Assim, a propagação de restrições restringe um número muito maior de variáveis a cada iteração, diminuindo a chance de ocorrer uma falha e diminuindo a quantidade de backtracking.

Para implementarmos a Propagação de restrições, vamos introduzir o conceito de arco-consistência, que provê um método rápido de propagar a restrição de forma mais forte que a verificação prematura.

Um arco é uma aresta direcionada no grafo de restrições. Suponha que duas variáveis $a_{i}$ e $a_{j}$ sejam adjacentes no grafo de restrições. $\mathrm{O}$ arco entre elas é dito consistente se, para todo valor $v_{i}$ de $a_{i}$, existe algum valor $v_{j}$ de $a_{j}$ que é consistente com $v_{i}$. Caso seja detectado um valor que cause 
inconsistência, este valor pode ser removido do domínio, evitando falhas futuras. A verificação de arco-consistência pode ser feita como pré processamento no começo do processo de busca ou como um passo de propagação como a verificação prematura depois de cada atribuição. Em todo caso, o processo deve ser repetido até que não existam mais inconsistências. Isto porque, sempre que um valor é removido do domínio de uma variável para remover uma inconsistência, uma nova inconsistência pode surgir em arcos apontando para essa variável.
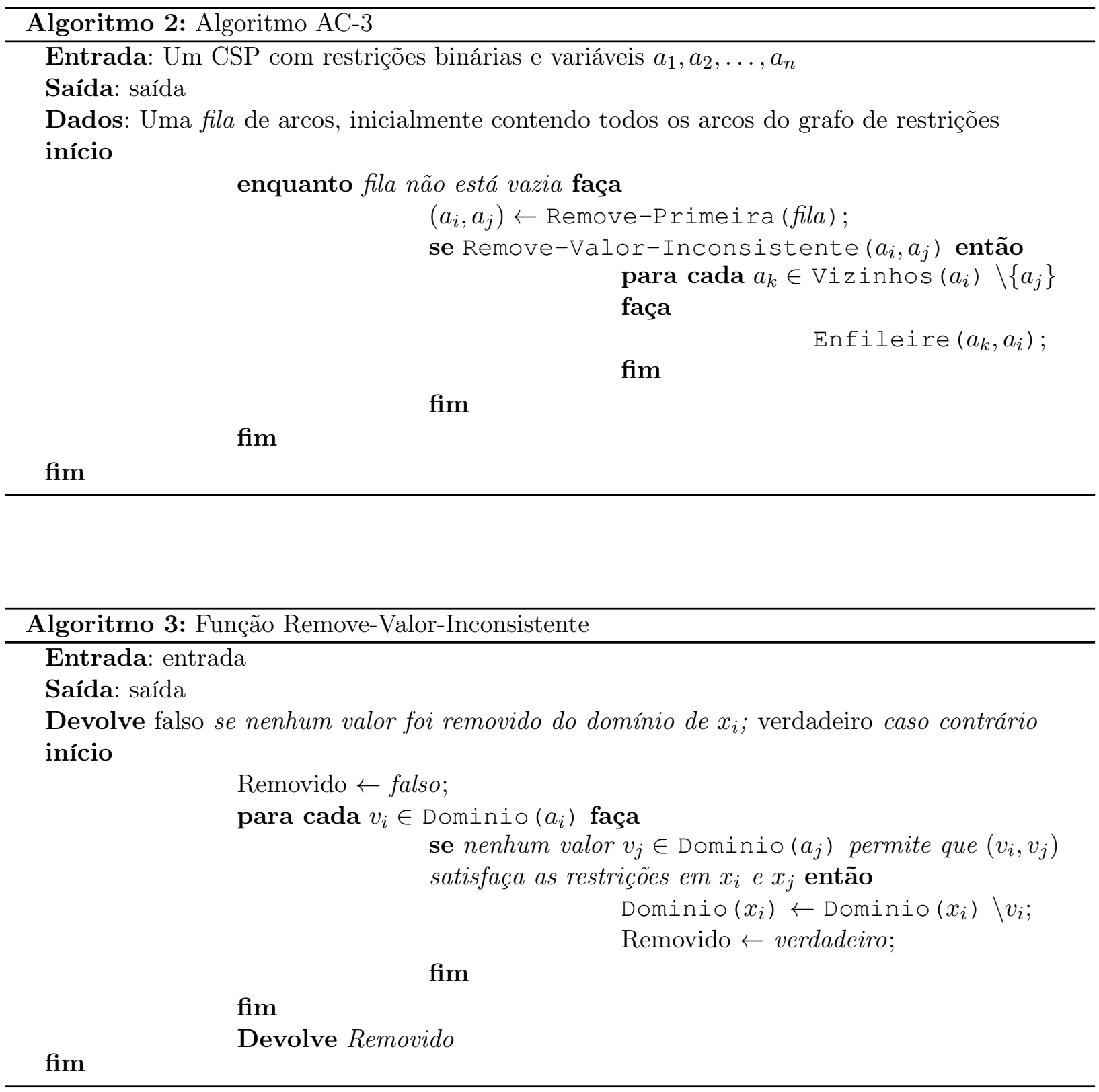

O Algoritmo AC-3 (algoritmo 2), devido a Mackworth (1977), recebe um CSP binário, com variáveis $\left\{a_{1}, a_{2}, \ldots, a_{n}\right\}$, e mantém uma fila para controlar os arcos a terem a consistência verificada. Cada arco $\left(a_{i}, a_{j}\right)$ é removido da fila e analisado. Se valores precisam ser removidos do domínio de $a_{i}$, então todo arco $\left(a_{k}, a_{i}\right)$ deve ser inserido na fila e analisado. Um CSP tem no máximo $O\left(n^{2}\right)$ arcos. Cada arco pode ser reinserido na fila $d$ vezes, pois $a_{i}$ tem no máximo $d$ valores possíveis de serem removidos. A verificação da consistência de um arco pode ser feita em tempo $O\left(d^{2}\right)$. Então para o algoritmo AC-3, o tempo de pior caso tem ordem $O\left(n^{2} d^{3}\right)$. Apesar de ser mais custoso que a verificação prematura, o tempo vale a pena.

Como o CSP inclui o problema $S A T$ como um caso especial, não esperamos encontrar um 
algoritmo polinomial que decida se CSP é consistente. Assim, arco-consistência pode não revelar todas as inconsistências. Como a Propagação de restrições é uma técnica incompleta, CSP-solvers que se baseiam nesta técnica costumam intercalar tais propagações com técnicas de busca local. Assim, um CSP-solver baseado nessa técnica propaga as restrições enquanto puder, e quando não for mais possível, divide o problema em problemas menores, que são então resolvidos recursivamente (Tack (2009)).

\section{Outras técnicas baseadas no grafo de restrições}

Nesta seção veremos algumas formas de explorar a representação do CSP como um grafo de restrições. Tal representação demonstra a estrutura do problema, e isso nos permite identificar técnicas para encontrar soluções de forma mais rápida.

Um CSP é constituído de subproblemas independentes se o grafo de restrições é desconexo. Assim, cada componente corresponde a um $C S P_{i}$. Se o estado $S_{i}$ é uma solução de $C S P_{i}$, então bigcup $_{i} S_{i}$ é solução de CSP $=\bigcup_{i} C S P_{i}$.

Suponha que cada $C S P_{i}$ tenha $c$ variáveis de um total de $n$, com $c$ constante. Existem $\frac{n}{c}$ subproblemas, cada um sendo resolvido em tempo $O\left(d^{c}\right)$. Assim, o total é $O\left(d^{c} \frac{n}{c}\right)$, linear em $n$. Sem isso, é $O\left(d^{n}\right)$, exponencial em $n$.

Subproblemas completamente independentes são raros, sendo normalmente uma grande componente conexa do grafo de restrições. Dentre estes, o caso mais simples é quando o grafo de restrições do CSP forma uma árvore, e duas variáveis são relacionadas por uma única restrição (existe, assim, no máximo um caminho entre duas variáveis no grafo de restrição).

Considere o seguinte algoritmo:

1. Escolha qualquer variável como raiz da árvore, e ordene as variáveis da raiz para as folhas de modo que todo nó pai preceda seus filhos na ordenação. Rotule as variáveis $a_{1}, \ldots, a_{n}$. Assim, toda variável, exceto a raiz, contém apenas um pai.

2. Para $j$ de $n$ até 2 , aplique a técnica de arco-consistência para o arco $\left(a_{i}, a_{j}\right)$, onde $a_{i}$ é pai de $a_{j}$, removendo valores do domínio de $a_{i}$, se necessário.

3. Para $j$ de 1 até $n$, atribua um valor para $a_{j}$ consistente com o valor atribuído para $a_{i}$, com $a_{i}$ pai de $a_{j}$.

É fácil verificar que o passo 3 não requer backtracking, pois o CSP é caminho consistente. Além disso, ao aplicar a arco-consistência de forma reversa, garantimos que valores removidos do domínio de um variável não afetam a consistência de arcos já processados. O algoritmo descrito acima resolve para uma árvore em $O\left(n d^{2}\right)$, linear no número de variáveis.

Com um algoritmo eficiente para resolver este caso, seria interessante de alguma forma reduzir grafos mais genéricos em árvore. Podemos fazer isto basicamente de duas formas: removendo vértices ou através da decomposição em árvore.

Para remover vértices do grafo de restrições de um CSP, atribuímos valor para uma variável de modo que o restante do grafo de restrições seja uma árvore. O valor atribuído é removido do domínio de variáveis adjacentes, assim como valores inconsistentes com o valor atribuído a esta variável. Isto leva ao algoritmo algoritmo 4 mais genérico:

Neste algoritmo, $S$ é chamado de cycle cutset, pois é o conjunto de nós que, ao ser removido, remove todos os ciclos do grafo. Se $c=|S|$, o tempo é $O\left(d^{c}(n-c) d^{2}\right)$. Se o grafo já é uma árvore, então $c=0$, e portanto muito vantajoso. Porém se $c$ é alto, aproximando-se de $(n-2)$, encontrar o menor cycle cutset é NP difícil. Essa abordagem algorítmica é chamada de cutset conditioning (Russell e Norvig (2002)).

Cada subproblema é então resolvido independentemente. Se um subproblema não tem solução, então o problema inteiro também não tem. Após encontrar as soluções dos subproblemas, a solução global segue: 


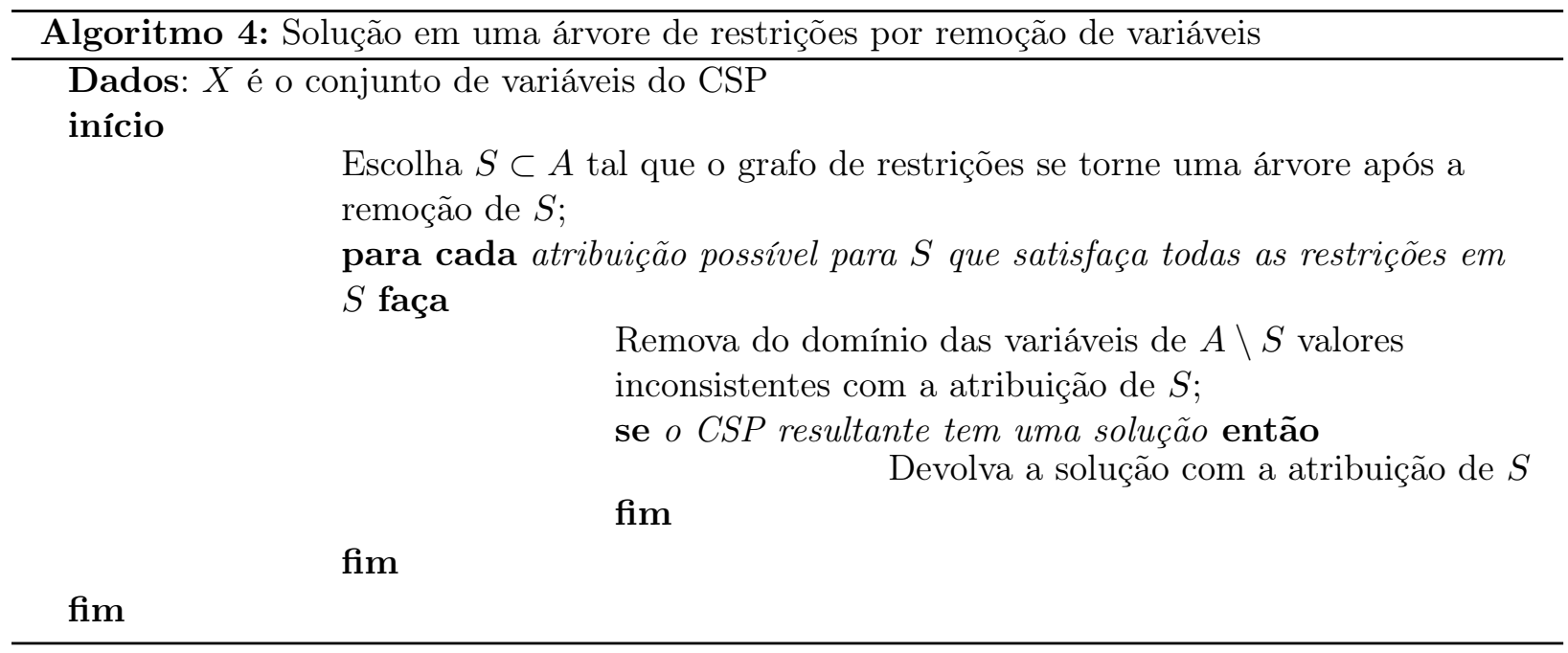

- Visualizamos cada subproblema como uma mega variável cujo domínio é o conjunto de todas soluções para o subproblema

- Resolvemos então as restrições entre subproblemas com o algoritmo de árvore anterior. As restrições entre os subproblemas força que as soluções devem ser consistentes nas variáveis compartilhadas entre dois subproblemas.

Grafos de restrição admitem muitas decomposições, mas devemos procurar decomposições com problemas menores possíveis. A largura da árvore é $w=1-|C|$, onde $C$ é o tamanho do maior subproblema. Se o grafo tem árvore de largura $w$ e nos é dado tal árvore, o problema pode ser resolvido em tempo $O(n d(w+1))$. Mas encontrar a decomposição é NP-difícil. 


\section{Capítulo 3}

\section{Algoritmo de inferência}

Normalmente a inferência de redes gênicas não leva em conta a consistência com dados de entrada ou a dinâmica da rede. Nosso trabalho consiste em implementar um algoritmo que encontra redes consistentes com os dados de entrada. Após a inferência e simulação destas redes, analisamos o comportamento dinâmico de cada rede inferida, filtrando redes possivelmente de maior interesse para testes práticos em laboratório.

Para a inferência de redes, construímos um algoritmo constituído de dois passos principais:

- Identificação de redes consistentes com a série temporal de entrada.

- Simulação da dinâmica e filtragem de soluções.

A seguir discutiremos a modelagem do problema.

\subsection{Restrições}

Para modelarmos o problema de inferir soluções consistentes como um CSP, definimos $A=a_{i j}$, onde $a_{i j}$ representa a influência do gene $j$ sobre o gene $i$. Além disso, para toda variável, seu domínio é $D=\{-1,0,1\}$

Através da análise das séries temporais, Higa et al. (2010) criaram um algoritmo iterativo para encontrar famílias de soluções consistentes com uma série temporal dada, sendo que tal algoritmo consiste de três passos principais. Usando então o arcabouço do CSP, durante a execução desse trabalho, criamos uma extensão deste algoritmo, convertendo cada um dos três passos em um conjunto de restrições. Tal extensão foi então usada no artigo Higa et al. (2011). A seguir, descrevemos cada conjunto de restrição, que juntos representam parcialmente as relações entre os genes.

Vale lembrar aqui, conforme descrevemos na Subseção 2.3.1, que a entrada de cada gene $x_{i}$ depende apenas da $i$-ésima linha da matriz A. Conforme visto na Seção 2.4.1, podemos então modelar nosso problema de inferir famílias de TBN consistentes com a série temporal em subproblemas independentes - inferir apenas uma linha de cada vez, ao invés da matriz inteira. Sem esta restrição, poderíamos ingenuamente modelar nosso problema com $n^{\prime}=n^{2}$ variáveis, uma para cada célula da matriz de regulação. Assim, teríamos um problema com tempo $O\left(3^{n^{\prime}}\right)=O\left(3^{n^{2}}\right)$, muito maior que exponencial. Com esta propriedade, podemos então modelar $n$ problemas (um para cada linha $i$ da matriz A) de $n$ variáveis (uma para cada coluna $j$ da linha $i$, ou seja, $a_{i j}$ ), com $O\left(3^{n}\right)$. Assim, temos $n$ problemas, cuja solução de cada um é uma linha da matriz de regulação.

\subsubsection{Primeiro conjunto de Restrições}

Para determinar o primeiro conjunto de restrições, analisamos três estados consecutivos da série temporal, digamos $\mathbf{s}(t-1), \mathbf{s}(t)$, e $\mathbf{s}(t+1)$. Considere a Tabela 3.1, que contém a série temporal de uma rede com quatro genes, e cinco GAPs. 
Tabela 3.1: Exemplo de série temporal

\begin{tabular}{ccccc}
\hline $\mathbf{s}(t)$ & $x_{1}(t)$ & $x_{2}(t)$ & $x_{3}(t)$ & $x_{4}(t)$ \\
\hline & & & & \\
1 & 1 & 1 & 0 & 0 \\
2 & 1 & 0 & 0 & 0 \\
3 & 1 & 0 & 1 & 0 \\
4 & 1 & 0 & 1 & 1 \\
5 & 0 & 0 & 1 & 1 \\
& & & &
\end{tabular}

Podemos notar aqui que se dois estados consecutivos $\mathbf{s}(t-1)$ e $\mathbf{s}(t)$ diferem de apenas um único gene $x_{k}$, então qualquer gene $x_{i}$ que muda de estado de $\mathbf{s}(t)$ para $\mathbf{s}(t+1)$ é diretamente regulado por $x_{k}$. Olhando para os estados $\mathbf{s}(1)$ e $\mathbf{s}(2)$ da tabela, podemos observar que apenas o gene $x_{2}$ mudou seu valor de 1 para 0 . Olhando então para $\mathbf{s}(2)$ e $\mathbf{s}(3)$ vemos que $x_{3}$ mudou para 1 . Seguindo então o modelo de TBN, esta mudança foi causada, necessariamente, pelo gene $x_{2}$. É fácil perceber que $x_{2}$ inibe $x_{3}$ em $t=1$, e ao mudar seu valor para 0 em $t=2$, permite a $x_{1}$ ativar $x_{3}$ em $t=3$. Podemos então fazer a seguinte proposição:

Proposição 3.1. Sejam $\mathbf{s}(t-1), \mathbf{s}(t)$ e $\mathbf{s}(t+1)$ três estados consecutivos de uma TBN. Se $\mathbf{s}(t-1)$ e $\mathbf{s}(t)$ diferem de um único gene $x_{k}$, então para cada gene $x_{i}$ tal que $x_{i}(t) \neq x_{i}(t+1)$, temos que $x_{k}$ regula diretamente $x_{i}$, isto é, $a_{i k} \neq 0$.

Prova: Suponha que $\mathbf{s}(t-1)$ e $\mathbf{s}(t)$ diferem por apenas um gene $x_{k}$, e que existe pelo menos um gene $x_{i}$ tal que $x_{i}(t) \neq x_{i}(t+1)$. Como $x_{i}(t) \neq x_{i}(t+1)$, os somatórios $\sum_{j} a_{i j} x_{j}(t-1)$ e $\sum_{j} a_{i j} x_{j}(t)$ tem valores diferentes. Dado que apenas $x_{k}$ é o único gene que possui valores diferentes em $\mathbf{s}(t-1)$ e $\mathbf{s}(t)$, esta diferença deve obrigatoriamente ser causada por $x_{k}$. Assim, $a_{i k} \neq 0$.

\subsubsection{Segundo conjunto de Restrições}

Para gerar o segundo conjunto de restrições, observamos dois estados consecutivos na série temporal, $\mathbf{s}(t)$ e $\mathbf{s}(t+1)$. Aqui podemos fazer uma observação importante: desconsiderando fatores externos e de acordo com o modelo utilizado neste trabalho, apenas genes expressos no instante $t$ podem ativar genes no instante $t+1$. Isso pode ser observado da Equação 2.1. Apesar dos genes ativos nos darem pista de quais genes estão regulando determinado gene, isso não nos indica o tipo de relacionamento. A Equação 2.1 pode, no entanto, nos ajudar a determinar o tipo de regulação. Suponha por exemplo que um gene $x_{i}$ muda seu estado do valor 0 no instante $t$ para 1 no instante $t+1$. Podemos então deduzir que a entrada de $x_{i}$ no instante $t$ é positiva, e que apenas genes ativos são responsáveis pela entrada positiva. Seguindo esta lógica, podemos gerar um conjunto de restrições lineares usando os genes ativos, de modo que a entrada do gene $x_{i}$ no instante $t$ seja coerente com o valor de $x_{i}$ no instante $t+1$. Segue então a seguinte proposição.

Proposição 3.2. Para cada gene $x_{i}$, podemos gerar restrições para variáveis $a_{i j}$ coerentes com a transição de $x_{i}(t)$ para $x_{i}(t+1)$ de acordo com a Tabela 3.2

Prova: Vamos provar o primeiro tipo de restrição da Tabela 3.2, isto é, se $x_{i}(t)=0$ e $x_{i}(t+1)=0$, então $\sum_{j: x_{j}(t)=1} a_{i j} \leq 0$. De acordo com a Equação 2.1, temos duas opções. A primeira é que a entrada de $x_{i}$ no instante $t$ é $0\left(\sum_{j} a_{i j} x_{j}(t)=0\right)$, e portanto o valor de $x_{i}(t+1)=x_{i}(t)$. O segundo caso é se a entrada de $x_{i}$ no instante $t$ é negativa, o que desligaria o gene $x_{i}$ em $t+1$ se este tivesse valor 1 , mas não muda quando este tem valor 0 . Se considerarmos apenas os genes $x_{j}(t)=1$, podemos então rescrever esta restrição como $\sum_{j: x_{j}(t)=1} a_{i j} \leq 0$. Seguindo a mesma lógica, podemos provar as outras restrições da Tabela 3.2. 
Tabela 3.2: Restrições de transição de estados

$$
x_{i}(t) \quad x_{i}(t+1) \quad \text { Restrição para } a_{i j}
$$

$\begin{array}{ccc}0 & 0 & \sum_{j: x_{j}(t)=1} a_{i j} \leq 0 \\ 0 & 1 & \sum_{j: x_{j}(t)=1} a_{i j}>0 \\ 1 & 0 & \sum_{j: x_{j}(t)=1} a_{i j}<0 \\ 1 & 1 & \sum_{j: x_{j}(t)=1} a_{i j} \geq 0\end{array}$

Considere, por exemplo, o instante $t=3$ da Tabela 3.1. Nesse instante, apenas os genes $x_{1}$ e $x_{3}$ estão ativos, logo, são os únicos que contribuem para a entrada de cada um dos outros genes. Se considerarmos $x_{4}$, podemos observar que seu valor mudou de 0 para 1. De acordo com a Equação 2.1, a entrada deve ser positiva, isto é $\sum_{j=1}^{4} a_{4 j} x_{j}(3)>0$. Devemos ter então que $a_{41}+a_{43}>0$. Assim, nenhuma das duas variáveis podem assumir valor -1 , e não podem assumir ao mesmo tempo o valor 0. Aplicando esse procedimento a todas os genes, podemos gerar o segundo conjunto de restrições.

\subsubsection{Terceiro conjunto de restrições}

Para gerar o último conjunto de restrições, consideramos dois pares de estados consecutivos na série temporal. Sejam $t_{1}$ e $t_{2}$ dois pontos distintos da série temporal:

$$
\mathbf{s}(1) \rightarrow \cdots \rightarrow \mathbf{s}\left(t_{1}\right) \rightarrow \mathbf{s}\left(t_{1}+1\right) \rightarrow \cdots \rightarrow \mathbf{s}\left(t_{2}\right) \rightarrow \mathbf{s}\left(t_{2}+1\right) \rightarrow \cdots \mathbf{s}(m) .
$$

Suponha ainda que $\mathbf{s}\left(t_{1}\right)$ e $\mathbf{s}\left(t_{2}\right)$ são muito similares. A diferença entre $\mathbf{s}\left(t_{1}+1\right)$ e $\mathbf{s}\left(t_{2}+1\right)$ deve ser causada pelos genes diferencialmente expressos em seus predecessores. Por exemplo, suponha que $\mathbf{s}\left(t_{1}\right)$ e $\mathbf{s}\left(t_{2}\right)$ difiram em um único gene:

$$
\mathbf{s}\left(t_{1}\right)=\left(\begin{array}{l}
1 \\
0 \\
1 \\
0
\end{array}\right), \mathbf{s}\left(t_{2}\right)=\left(\begin{array}{l}
1 \\
0 \\
1 \\
1
\end{array}\right) .
$$

E que suas sucessões sejam:

$$
\left(\begin{array}{l}
1 \\
0 \\
1 \\
0
\end{array}\right) \rightarrow\left(\begin{array}{l}
0 \\
0 \\
0 \\
0
\end{array}\right), \ldots,\left(\begin{array}{l}
1 \\
0 \\
1 \\
1
\end{array}\right) \rightarrow\left(\begin{array}{l}
1 \\
1 \\
1 \\
1
\end{array}\right)
$$

Então a diferença entre $\mathbf{s}\left(t_{1}+1\right)$ e $\mathbf{s}\left(t_{2}+1\right)$ neste caso deve ser causada pela diferença de $x_{4}$. $\mathrm{O}$ procedimento se baseia em comparações deste tipo para encontrar restrições.

Vamos considerar o gene $x_{1}$ do nosso exemplo. Ele foi inibido no primeiro par de estados e não mudou no segundo par. Seja $I$ a entrada total originada pelos genes com expressão similar em $\mathbf{s}\left(t_{1}\right)$ e $\mathbf{s}\left(t_{2}\right), M$ a entrada gerada por $x_{4} \mathrm{em} \mathbf{s}\left(t_{1}\right)$ e $\bar{M}$ ser a entrada gerada por $x_{4} \mathrm{em} \mathbf{s}\left(t_{2}\right)$. Para explicar a mudança de $x_{1}$ entre os dois pares devemos ter: 


$$
\left\{\begin{array}{l}
I+M<0 \\
I+\bar{M} \geq 0
\end{array}\right.
$$

Se $a_{i j}$ representa a influência do gene $x_{j}$ sobre o gene $x_{i}$, podemos então calcular $I, M$ e $\bar{M}$ como segue:

$$
\begin{gathered}
I=\left(a_{11} a_{12} a_{12}\right) \cdot\left(\begin{array}{c}
1 \\
0 \\
1
\end{array}\right)=a_{11}+a_{13}, \\
M=a_{14} \cdot 0=0, \\
\bar{M}=a_{14} \cdot 1=a_{14} .
\end{gathered}
$$

Logo,

$$
\left\{\begin{array} { l } 
{ I + M < 0 , } \\
{ I + \overline { M } \geq 0 }
\end{array} \Rightarrow \left\{\begin{array} { l } 
{ a _ { 1 1 } + a _ { 1 3 } + 0 < 0 } \\
{ a _ { 1 1 } + a _ { 1 3 } + a _ { 1 4 } \geq 0 }
\end{array} \Rightarrow \left\{a_{14}>0 .\right.\right.\right.
$$

Isto implica que a entrada $a_{14}$ da matriz de regulação deve ter valor 1.

Se $\mathbf{s}\left(t_{1}\right)$ e $\mathbf{s}\left(t_{2}\right)$ diferem em mais de um gene, ainda assim podemos gerar as restrições de regulação. De fato, este passo tenta construir um sistema de inequalidades com as entradas de cada gene para uma combinação de dois pares consecutivos. Mais formalmente podemos fazer a seguinte afirmação:

Proposição 3.3. Sejam $t_{1}$ e $t_{2}$ dois instantes de tempo diferentes da série temporal. A transição de estados de $x_{i}\left(t_{1}\right)$ para $x_{i}\left(t_{1}+1\right)$ e de $x_{i}\left(t_{2}\right)$ para $x_{i}\left(t_{2}+1\right)$ gera restrições para variáveis $a_{i j}$ de acordo com a Tabela 3.3

Prova: Vamos provar a primeira restrição da Tabela 3.3, isto é, se $x_{i}\left(t_{1}\right)=1, x_{i}\left(t_{1}+1\right)=0, x_{i}\left(t_{2}\right)=$ 0 e $x_{i}\left(t_{2}+1\right)=1$, então

$$
\sum_{j: x_{j}\left(t_{1}\right)=1 \text { e } x_{j}\left(t_{2}\right)=0} a_{i j}-\sum_{j: x_{j}\left(t_{2}\right)=1 \text { e } x_{j}\left(t_{1}\right)=0} a_{i j}<0 .
$$

Considerando a transição de estados de $x_{i}\left(t_{1}\right)$ para $x_{i}\left(t_{1}+1\right)$, pela Proposição 3.3 , temos que $\sum_{j: x_{j}\left(t_{1}\right)=1} a_{i j}<0$. Da teoria dos conjuntos, podemos escrever o conjunto de genes ativos no instante $t_{1}, A\left(t_{1}\right)=j: x_{j}\left(t_{1}\right)=1$, como dois conjuntos disjuntos:

$$
A\left(t_{1}\right)=\left\{j: x_{j}\left(t_{1}\right)=1 \text { e } j: x_{j}\left(t_{2}\right)=0\right\} \cup\left\{j: x_{j}\left(t_{1}\right)=1 \text { e } j: x_{j}\left(t_{2}\right)=1\right\} .
$$

Assim,

$$
\sum_{j: x_{j}\left(t_{1}\right)=1} a_{i j}=\sum_{j: x_{j}\left(t_{1}\right)=1 \mathrm{e} x_{j}\left(t_{2}\right)=0} a_{i j}
$$

De forma análoga, temos, da transição de $x_{i}\left(t_{2}\right)=0$ para $x_{i}\left(t_{2}+1\right)=1$,

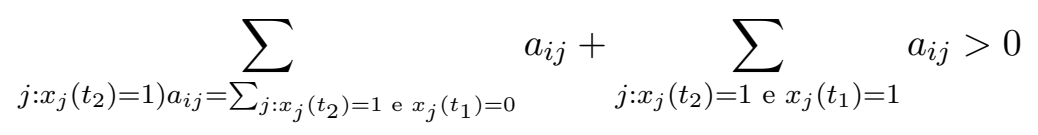

Subtraindo as duas inequalidades, temos 


$$
\begin{aligned}
& x_{i}\left\{t_{1}\right\} \rightarrow x_{i}\left\{t_{1}+1\right\} \quad x_{i}\left\{t_{1}\right\} \rightarrow x_{i} t_{1}+1 \quad \text { Restrição para } a_{i j}
\end{aligned}
$$

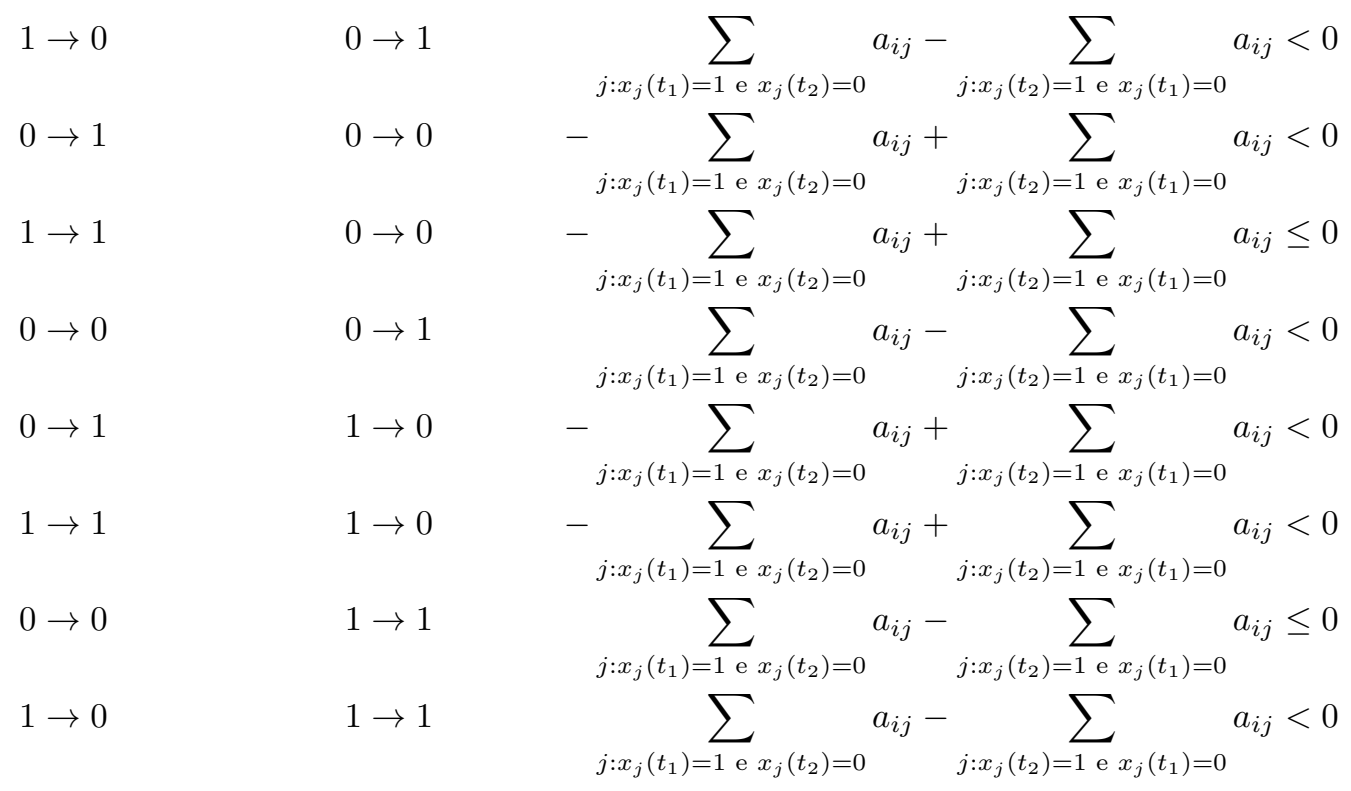$$
\sum_{j: x_{j}\left(t_{1}\right)=1 \text { e } x_{j}\left(t_{2}\right)=0} a_{i j}-\sum_{j: x_{j}\left(t_{2}\right)=1 \text { e } x_{j}\left(t_{1}\right)=0} a_{i j}<0 .
$$

As outras restrições podem ser obtidas de forma similar.

O segundo passo do algoritmo é simular a dinâmica de redes gênicas construídas a partir das soluções consistentes encontradas pelo CSP. A seguir vamos discutir sobre a construção das redes e a simulação da dinâmica.

\subsection{Simulação da dinâmica}

Para cada linha $r_{i}$ da matriz de regulação, o solver construído de acordo com a Seção 4.1 gera uma coleção $R_{i}=\left\{r_{i 1}, r_{i 2}, \ldots, r_{i m}\right\}$ de soluções consistentes com a série temporal. Cada linha consistente $r_{i k}=\left(a_{i 1}^{k}, a_{i 2}^{k}, \ldots, a_{i n}^{k}\right) \in R_{i}$ contém $n$ entradas $a_{i j}^{k}$, cada uma correspondendo a um tipo de relação entre os genes $x_{j}$ e $x_{i}$ (ativação, inibição ou sem regulação).

Para simular a dinâmica, precisamos antes construir a rede a ser simulada a partir das soluções consistentes encontradas no passo anterior.

\subsubsection{Critérios de geração das redes}

Após a execução do solver para a série temporal de entrada, temos um conjunto de soluções possíveis para cada linha da matriz de regulação. Precisamos então construir uma matriz específica com base em tais soluções de acordo com algum critério. Para isso, nosso algoritmo escolhe uma linha $r_{i} \in R_{i}, i=1, \ldots n$ para construção de uma rede consistente com a série de entrada, e a rede construída é então simulada para analise do comportamento dinâmico. Para isso escolhemos sete critérios de seleção de linhas consistentes dos conjuntos de soluções, por serem modelos de redes conhecidos e potencialmente modelos de redes biológicas. São eles: 


\section{1 - Redes aleatórias}

Sabendo que $R$ é uma coleção de soluções consistentes, para cada linha $r_{i}$ da matriz de regulação, escolhemos aleatoriamente uma solução da coleção de soluções, com igual probabilidade para cada escolha.

\section{2 - Redes esparsas}

Uma das crenças da Biologia é que as redes de regulação gênicas são esparsas, ou seja, cada gene tem poucos preditores, e atua como preditor de poucos genes. Assim, nesse caso, escolhemos linhas de $R_{i}$ com um pequeno número de valores diferentes de zero, ou seja, linhas da matriz de regulação que representem poucas regulações sobre o gene $x_{i}$. Assim, para $i=1,2, \ldots, n$, escolhemos,

$$
r_{i} \in\left\{r_{i k}: \sum_{j=1}^{n}\left(a_{i j}^{k}\right)^{2}=\min \left(\sum_{j=1}^{n}\left(a_{i j}^{l}\right)^{2}, l=1,2, \ldots, m\right), k=1,2, \ldots m\right\} .
$$

Experiências preliminares mostraram que seleções de acordo com a Equação 3.6 costumam gerar redes com muitos genes sem preditores ou genes com apenas um preditor e que não são, por sua vez, preditores de outros genes. Ou seja, redes com genes com grau de entrada zero e grau de saída diferente de zero, ou genes com grau de entrada diferente de zero, mas com grau de saída zero. Tais experiências preliminares mostraram que se existe um grande número de genes dessa forma em uma rede, a mesma tende a ser bastante instável, com muitas bacias pequenas, e sem uma bacia grande. Assim, para dar alguma liberdade ao quão esparsa a rede é, selecionamos também seguindo a Equação 3.7

$$
r_{i} \in\left\{r_{i k}: \sum_{j=1}^{n}\left(a_{i j}^{k}\right)^{2} \leq\left[\min \left(\sum_{j=1}^{n}\left(a_{i j}^{l}\right)^{2}, l=1,2, \ldots, m\right)+1\right], k=1,2, \ldots m\right\} .
$$

Isso nos dá redes bastante esparsas (dentro do possível, já que dependemos do número mínimo de preditores em cada solução encontrada), com alguma flexibilidade do número de preditores. Chamamos essas redes de esparsa com um grau de liberdade

\section{3 - Redes densas}

Em contraponto ao caso acima, selecionamos matrizes tal que para $i=1,2, \ldots, n$

$$
r_{i} \in\left\{r_{i k}: \sum_{j=1}^{n}\left(a_{i j}^{k}\right)^{2}=\max \left(\sum_{j=1}^{n}\left(a_{i j}^{l}\right)^{2}, l=1,2, \ldots, m\right), k=1,2, \ldots m\right\} .
$$

Da mesma forma como no critério anterior, optamos por dar alguma flexibilidade a densidade da rede, considerando conectividade, isto é, o número de preditores, entre o máximo e o máximo menos um. Assim, selecionamos também de acordo com a Equação 3.9:

$$
r_{i} \in\left\{r_{i k}: \sum_{j=1}^{n}\left(a_{i j}^{k}\right)^{2} \geq\left[\max \left(\sum_{j=1}^{n}\left(a_{i j}^{l}\right)^{2}, l=1,2, \ldots, m\right)-1\right], k=1,2, \ldots m\right\} .
$$

Assim como no caso de redes esparsas, chamamos essas redes de redes densas com um grau de liberdade.

\section{4 - Redes com número de preditores limitados}

Segundo Kauffman (1969), uma rede teria entre 2 e 3 preditores para estar na fronteira entre a ordem e o caos, região em que se acredita estar as redes gênicas. Assim, limitamos o número de preditores entre dois valores $a$ e $b$, ou seja 


$$
r_{i} \in\left\{r_{i k}: a \leq \sum_{j=1}^{n}\left(a_{i j}^{k}\right)^{2} \leq b, k=1,2, \ldots m\right\} .
$$

Neste trabalho fizemos experiências com alguns valores predefinidos, que serão descritos mais adiante, mas a implementação construída permite variação dos valores por meio de parâmetros.

\section{5 - Hub de entrada}

Outra crença difundida é a de que as redes gênicas seguem um modelo livre de escala, com o grau dos genes, isto é, o número de preditores e de genes preditos, seguindo uma distribuição de lei de potência, na forma $P(k) k^{-\gamma}$, de acordo com Barabasi e Albert (1999) e Albert e Barabási (2000), como indicam também os trabalhos de Jeong et al. (2000) e Huang (1999). Como trabalhamos com redes com número de genes baixo (nossos experimentos foram feitos em redes com 11 genes), não é possível verificar se a rede segue uma lei de potência. Assim, sorteamos aleatoriamente com distribuição uniforme um gene que terá grau de entrada alto, com vários genes atuando como preditores do gene sorteado. O restante dos genes seguem a seleção esparsa. Ao selecionar a possível linha $r_{i}$ para compor a matriz de regulação, se a linha atual a ser selecionada é a do gene hub, selecionamos aleatoriamente de acordo com:

$$
r_{i} \in\left\{r_{i k}: \sum_{j=1}^{n}\left(a_{i j}^{k}\right)^{2}=\max \left(\sum_{j=1}^{n}\left(a_{i j}^{l}\right)^{2}, l=1,2, \ldots, m\right), k=1,2, \ldots m\right\} .
$$

Do contrário, selecionamos aleatoriamente de acordo com

$$
r_{i} \in\left\{r_{i k}: \sum_{j=1}^{n}\left(a_{i j}^{k}\right)^{2} \leq\left[\min \left(\sum_{j=1}^{n}\left(a_{i j}^{l}\right)^{2}, l=1,2, \ldots, m\right)+1\right], k=1,2, \ldots m\right\} .
$$

Isso nos dá redes com um gene com conectividade alta, isto é, um grande número de preditores, e o restante com conectividade baixa.

\section{6 - Hub de saída}

Neste caso, análogo ao caso anterior, o gene escolhido atuará como preditor de muitos genes. Novamente o restante dos genes segue um modelo esparso. Aqui, escolhemos tentando seguir um modelo livre de escala (sem garantia pelo tamanho da rede), acreditando que alguns são genes chave, atuando como grandes preditores. Assim, as linhas são selecionadas da seguinte maneira: para cada linha $r_{i}$ da matriz de regulação, com probabilidade $p=0,9$ (parametrizável), selecione uma linha $r_{i}=\left(a_{i 1}, a_{i 2}, \ldots, a_{i n}\right)$ tal que $a_{i j} \neq 0$, onde $j$ é o gene hub, do contrário selecione uma linha $r_{i}$ tal que:

$$
r_{i} \in\left\{r_{i k}: \sum_{j=1}^{n}\left(a_{i j}^{k}\right)^{2} \leq\left[\max \left(\sum_{j=1}^{n}\left(a_{i j}^{l}\right)^{2}, l=1,2, \ldots, m\right)+1\right], k=1,2, \ldots m\right\}
$$

\section{7 - Hub de saída com número de preditores limitados}

Neste caso, unimos duas crenças da Biologia, a de que existe um gene chave atuando como preditor, e de que o número de genes preditos ou de preditores não deve ultrapassar um limite mínimo e máximo. Assim, para cada linha $r_{i}$ da matriz de regulação, com probabilidade $p=0,9$ (parametrizável), selecione uma linha $r_{i}=\left(a_{i 1}, a_{i 2}, \ldots, a_{i n}\right)$ tal que $a_{i j} \neq 0$, onde $j$ é o gene hub, e com probabilidade $q=1-p$ selecione uma linha $r_{i}$ tal que: 


$$
r_{i} \in\left\{r_{i k}: a \leq \sum_{j=1}^{n}\left(a_{i j}^{k}\right)^{2} \leq b, k=1,2, \ldots m\right\} .
$$

Para cada critério de construção de redes descritos acima acima, construímos um conjunto de redes a partir das soluções consistentes geradas pelo solver. Efetuamos então a simulação da dinâmica para cada rede construída, e coletamos dados para filtragem e analise, além da comparação dos resultados entre os critérios de construção. A seguir descreveremos mais detalhes sobre esse processo.

\subsubsection{Critérios de ordenação e escolha}

O número de TPBs consistentes com a entrada pode ser muito alto, mas estamos interessados apenas em redes que fazem sentido biológico. A questão é: como identificar essas redes analisando sua dinâmica? Segundo Kauffman (1993) e Li et al. (2004), redes estáveis são aquelas que possuem um pequeno número de atratores e um deles com uma bacia de atração grande. Apesar da bacia ser grande, apenas um pequeno número de estados fazem parte de um atrator. Tais estados que não fazem parte do atrator (chamados de estados transientes) não são biologicamente significativos. Por outro lado, os estados que fazem parte do atrator podem representar um tipo de célula ou um estágio (diferenciação, proliferação ou apoptose).

Para cada critério de construção de redes gênicas a partir das linhas consistentes com a entrada do solver, o algoritmo de simulação gera um número parametrizável de redes a serem simuladas, a fim de fazer uma filtragem estatística. Para cada simulação, coletamos o número atratores e o tamanho de cada bacia de atrator. Vamos descrever em seguida como selecionar as redes de acordo com sua dinâmica.

\section{Entropia}

Entropia é uma grandeza da termodinâmica que determina a quantidade de energia não disponível para conversão em trabalho, determinando assim o "grau de desordem" de um sistema. O conceito foi introduzido por Clausius (1850). Boltzmann (1877) mostrou como expressar a entropia em termos de probabilidades associadas à configurações microscópicas de um sistema, vindo depois a ser conhecido como Entropia de Boltzmann-Gibbs (Boltzmann (1974)). Para mais informações, veja Clausius (1867); Lopes (2011); Tsallis (2009).

A forma discreta dessa entropia é dada como segue:

$$
H_{B G}=-k \sum_{i=1}^{W} p_{i} \log p_{i}
$$

Onde $k$ é a constante de Boltzmann, e $p_{i}$ corresponde as probabilidades das $W$ configurações microscópicas possíveis, satisfazendo:

$$
\sum_{i=1}^{W} p_{i}=1
$$

A entropia foi aplicada por Shannon (2001) na Teoria da Informação, e utilizada para determinar a quantidade de informação contida em uma determinada fonte, assim como para graduar a incerteza de um conjunto de dados. Nesse caso, usamos $k=1$.

Considere uma variável indicadora $I$ que pode assumir um valor booleano $R=\{0,1\}$. Neste trabalho, essa variável indica se um estado pertence ou não a determinada bacia de atração. Assim como na entropia de Boltzmann-Gibbs, a entropia de Shannon é definida em termos das probabilidades possíveis da ocorrência desta variável aleatória $P(I)$ :

$$
H(I)=-\sum_{i \in I} P(i) \log P(i),
$$


tal que

$$
\sum_{i \in I} P(i)=1
$$

Considere agora uma TBN qualquer do espaço de redes geradas para simulação para um dos critérios de escolha, digamos $\mathbf{A}$.

Sejam $\mathcal{A}_{1}, \mathcal{A}_{2}, \ldots, \mathcal{A}_{w}$ os atratores desta rede, com as respectivas bacias de atração $\mathcal{B}_{1}, \mathcal{B}_{2}, \ldots, \mathcal{B}_{w}$. Denotamos $\left|\mathcal{A}_{i}\right|$ o número de estados de $\mathcal{A}_{i}$, e $\left|\mathcal{B}_{i}\right|$ o número de estados da bacia $\mathcal{B}_{i}$ correspondente. Assim, a probabilidade de um estado desta rede estar em uma bacia $\mathcal{B}_{i}, i=1,2, \ldots, w$ é dada por:

$$
P\left(Y_{i}=1\right)=\frac{\left|\mathcal{B}_{i}\right|}{\sum_{j=1}^{w}\left|\mathcal{B}_{i}\right|=2^{n}},
$$

onde $Y_{i}$ é a variável booleana aleatória que denota o fato de um estado arbitrário estar em $\mathcal{B}_{i}\left(Y_{i}=1\right)$. Neste trabalho, $\sum_{j=1}^{w}\left|\mathcal{B}_{i}\right|=2^{n}$. Com estas probabilidades podemos calcular a entropia seguindo a Equação 3.10:

$$
H_{\mathbf{A}}=-\sum_{i=1}^{w} P\left(Y_{i}=1\right) \log \left[P\left(Y_{i}=1\right)\right] .
$$

Neste caso, a entropia atinge o valor máximo quando todas as bacias têm o mesmo tamanho, mas neste trabalho procuramos o caso oposto, ou seja, uma única bacia grande, e possivelmente uma ou mais bacias pequenas, logo, procuramos minimizar a entropia. 


\section{Capítulo 4}

\section{Resultados}

Nesta seção descreveremos o procedimento experimental para validação do algoritmo. Começaremos descrevendo as implementações, e em seguida as experiências feitas. Discutiremos os resultados na próxima seção.

\subsection{Implementação}

Implementamos as restrições do modelo descrito em Seção 3.1 utilizando a biblioteca Gecode, e com isto criamos um solver, utilizado nas experimentações.

Escolhemos tal ferramenta, entre outras razões, por ser:

- Aberta, é altamente extensível, suporta a criação de novas estratégias de propagação, ramificação e mecanismos de busca, além da criação de novos tipos de domínio de variáveis. Além disso, essa biblioteca permite a integração com outros sistemas e linguagens, como Lisp, Haskell, Ruby e Java

- Livre, distribuída sob licença MIT com implementação, exemplos e documentação de código fonte aberto e disponível para download.

- Portável, o Gecode é implementado em $\mathrm{C}++$ seguindo cuidadosamente os padrões da linguagem, rodando em diversos sistemas e configurações de máquina.

- Acessível, vem com diversos exemplos e uma extensa documentação de referência sobre o funcionamento, modelagem e extensão da base disponível.

- Eficiente, Gecode oferece uma excelente performance em relação ao uso de memória e ao tempo de execução.

- Paralelizável, permite o uso de vários processadores de múltiplos núcleos, obtendo vantagem na busca em paralelo.

O Gecode é uma biblioteca para criação de solvers através da Programação de Restrições, e utiliza variáveis de domínio finito, como visto em Seção 2.4.1, baseado em propagação de restrições como visto na Seção 2.4.1 e busca exaustiva. Tem uma abordagem que usa técnicas e ferramentas avançadas a partir de técnicas clássicas de Inteligência Artificial, Linguagens de Programação e algoritmos eficientes de Pesquisa Operacional. Além disso, foram desenvolvidos algoritmos especiais para diversos tipos de restrições globais, que são conjuntos de restrições comuns que aparecem com frequência em CSP (Tack (2009)). Dentre estes, possui algoritmos específicos para tratamento de restrições lineares, como citado na Seção 2.4.1, e que nos permitem implementar facilmente as restrições vistas nas seções anteriores. Além desses algoritmos para restrições de equações lineares, a variável a qual será atribuído um valor é escolhida de forma aleatória, assim como o valor que será atribuído para tal variável a partir de seu domínio. 
A criação das redes artificiais foi feita em Python ${ }^{1}$ usando a distribuição Enthought Python Distribution $^{2}$ (ou EPD), versão 7.2, acadêmica de 64bits, utilizando o pacote NetworkX ${ }^{3}$, versão 1.6. Python também foi utilizado para gerar os gráficos com os dados, utilizando os pacotes $S c i P y^{4}$ e $N u m P y^{5}$ incluídos na EPD. A construção das redes inferidas a partir das soluções consistentes geradas pelo solver construído com Gecode também foi feita em Python.

As imagens foram geradas usando as ferramentas OmniGraffle ${ }^{6}$ versão 5.3.6, OmniGraffle for $i P a d^{7}$ e Graphviz versão 2.28 de arquivos exportados em formato $\operatorname{dot}^{9}$ das redes geradas usando o NetworkX.

\subsection{Implementação em CUDA}

Simular a dinâmica da rede significa, para cada estado possível $\left(2^{n}\right.$ estados para uma rede com $n$ genes), identificar qual o próximo estado e a qual bacia de atração tais estados pertencem.

É possível perceber da Equação 2.1 que só dependemos do estado atual para descobrir o próximo estado. Assim, é fácil acelerar essa computação através de técnicas de programação paralela. Além disso, a identificação de atratores pode ser vista como um problema de coloração de componentes, um problema computacionalmente intensivo e subconjunto do problema de coloração de grafos (Hawick e Leist (2010)). Precisamos aqui identificar a qual atrator pertence determinado estado (o equivalente a determinar qual cor podemos atribuir a determinado componente do grafo).

Uma das técnicas de programação paralela é através do uso de Unidades de Processamento Gráfico (GPU - do inglês Graphical Processing Unit) com o uso de GPGPU (do inglês Generalpurpose computing on graphics processing units). Estas têm revitalizado o estudo de computação paralela por possuírem uma arquitetura poderosa a um custo acessível. Para utilização de GPGPU, algumas plataformas e ferramentas de programação tem sido criadas. Dentre estas, uma das mais difundidas é a CUDA ${ }^{\mathrm{TM}}$ (do inglês Compute Unified Device Architecture), desenvolvida pela empresa NVIDIA@, ou a tecnologia concorrente OpenCL ${ }^{\mathrm{TM}}$, desenvolvida pela Apple Inc. ${ }^{\mathrm{TM}}$ e mantida pelo Khronos Group ${ }^{\mathrm{TM}}$.

Neste trabalho usamos uma implementação feita por Ferreira (2010 - Trabalho em andamento) do algoritmo proposto por Hawick e Leist (2010) para identificação das bacias de atração através da técnica de coloração de componentes. Como não focaremos mais em técnicas de programação paralela, veja o referido artigo para maiores informações.

Nossos experimentos foram feitos em uma GPU NVIDIA GeForce GT330M com 512Mb de VRAM, em um MacBook Pro6,2, com processador Intel Core i7 com clock de 2,66GHz com dois núcleos e $8 \mathrm{~Gb}$ de mamória RAM. Por possuir a tecnologia Hyper-threading ativada, o sistema operacional consegue rodar até quatro threads simultaneas, como se o processador possuísse quatro núcleos. A GPU GT330m possui 48 núcleos CUDA, podendo rodar até 512 threads simultaneas, com um clock de 1,1GHz. Em testes iniciais rodando nos quatro núcleos do processador (sem utilizar CUDA), o tempo total de simulação de uma rede com onze genes era de aproximadamente $3 \mathrm{~s}$. Com a implementação em CUDA, obtivemos uma redução para em média 9ms para simulação e 30ms para executar o algoritmo de colocação de componentes, mostrando que é bastante util usar GPGPU para esse tipo de problema. Álém disso, a programação de GPGPU é um trabalho bastante complexo, e diversas otimizações na implementação podem ser feitas, levando a tempos ainda menores.

Fizemos também alguns testes para redes com 20 genes, levando em média 3s para simular a dinâmica e colorir os comoponentes. Mas é importante notar que, segundo Hawick e Leist (2010),

\footnotetext{
${ }^{1}$ http://www.python.org/

${ }^{2}$ http://enthought.com/

${ }^{3}$ http://networkx.lanl.gov/

${ }^{4}$ http://www.scipy.org/

${ }^{5}$ http://numpy.scipy.org/

${ }^{6}$ http://www.omnigroup.com/products/omnigraffle/

${ }^{7}$ http://www.omnigroup.com/products/omnigraffle-ipad/

${ }^{8}$ http://www.graphviz.org/

${ }^{9}$ http://www.graphviz.org/Documentation.php
} 
por limitações da implementação do padrão CUDA disponível até o ano de 2010 (com capacidades computacionais versões 1.0 até 1.3), as placas disponíveis até então poderiam colorir grafos contendo até $2^{27}$ arcos, devido a limitações no endereçamento de memória de textura, pois o algoritmo usa 4 bytes por arco, limitando o algoritmo a endereçar no máximo 512Mb de VRAM. A memória de textura é um método provisionado (do inglês cached) de acesso a uma área designada da memória global, o que melhora o tempo de acesso das threads às informações armazenadas. Como o grafo de transição de estados que representa a dinâmica da rede é aproximadamente uma árvore, possuindo precisamente $2^{n}$ arcos, onde $n$ é o número de genes, já que temos apenas um ciclo de atração por componente, então, na implementação do padrão CUDA disponível na GPU em questão, poderiamos simular redes com até 27 genes, com tempo relativamente baixo.

\subsection{Redes aleatórias}

Diversos modelos de topologia de redes aleatórias tem sido estudados, especialmente modelos inspirados em redes reais de grande escala. Por exemplo, redes celulares foram estudadas por Jeong et al. (2000), além do modelo clássico de redes aleatórias propostas por Erdős e Rényi (1959). Para uma discussão mais completa sobre redes aleatórias, veja Rodrigues e Travieso (2007).

Neste trabalho, usamos duas variações para aplicação direta no nosso contexto, das redes ErdốsRényi e da das Redes Direcionadas Livre de Escala. O primeiro foi escolhido por ser um modelo clássico de redes aleatórias, enquanto o segundo foi escolhido por tratar de redes livres de escala, que recentemente tem ganhado destaque por modelarem bem diversos comportamentos físicos e biológicos. A seguir descreveremos mais tais redes e as modificações feitas.

\subsubsection{Redes Erdős-Rényi}

O primeiro modelo escolhido para uso como rede de validação foi o modelo clássico de redes aleatórias propostas por Erdốs e Rényi (1959), conhecidas por redes Erdôs-Rényi, ou ER.

O modelo clássico considera a topologia de uma rede com $n$ genes possíveis e $m$ regulações, escolhido aleatoriamente dentre uma das $\left(\begin{array}{c}\left(\begin{array}{c}n \\ 2\end{array}\right) \\ m\end{array}\right)$ redes possíveis, escolhida considerando uma distribuição uniforme de probabilidade. Aqui, o grau médio (número de regulações) de cada gene é dado por $\langle d\rangle=\frac{2 m}{n}$.

Uma outra forma de construção de redes ER é definida para uma rede com $n$ genes e uma probabilidade $0<p<1$ de conectar pares de genes. Neste modelo, para $n \rightarrow \infty$, o grau médio para cada gene é dado por $\langle d\rangle=p(n-1)$. Para construção de redes ER e garantir o grau médio $\langle d\rangle$ semelhantes entre os genes, podemos adotar uma distribuição de probabilidade fixa $P$ de uma regulação ocorrer entre dois genes $x_{i}$ e $x_{j}$ tal que (Lopes (2011)):

$$
P\left(v_{i} \leftrightarrow v_{j}\right)=\frac{d}{n-1} .
$$

Neste trabalho foi usada uma extensão com arestas orientadas implementada no pacote NetworkX Hagberg et al. conforme o algoritmo abaixo:

1. Crie um grafo direcionado $G$ com $n$ vértices

2. Crie uma lista $E$ de arcos, com os $P=(n, 2)=\frac{n !}{(n-2) !}$ possíveis arcos existentes do grafo direcionado completo

3. Para todo arco $e \in E$, com probabilidade $p$ adicione $e$ ao grafo direcionado $G$

4. Devolva o grafo orientado $G$ 
Aqui vale notar que se $p \geq 1$, o grafo será completo, e quanto menor o valor de $p$, mais esparso será o grafo. O grafo então retornado pelo algoritmo pode então ser considerado a rede gênica, com $n$ genes e as regulações adicionadas no passo 3 do algoritmo.

Neste trabalho, estamos interessados que a rede não só tenha orientação, mas que a orientação represente o tipo de regulação, ou seja, se a regulação é de inibição ou ativação. Assim, na nossa implementação, após gerarmos a rede e a representando uma matriz de adjacência $\mathbf{A}$ (onde $a_{i j} \in\{0,1\}$ representa a existência um arco de $j$ para $i$ ), iteramos sobre todos os arcos, e com probabilidade $p=0,5$ alteramos para $a_{i j}=-1$, representando assim uma inibição.

\subsubsection{Redes Direcionadas Livres de Escala}

Para a segunda comparação, usamos o modelo de Rede Direcionada Livre de escala proposto por Bollobás et al. (2003).

Neste, começamos com uma rede direcionada, potencialmente com apenas um gene, e em passos de tempos discretos, adicionamos novas regulações, podendo ou não adicionar um novo gene em cada um desses passos. Para simplicidade, o modelo original proposto por Bollobás et al. (2003) permite laços (regulações de um gene ao próprio gene) e múltiplas regulações entre dois genes. Neste trabalho estamos interessados em potencialmente termos laços, mas não estamos interessados em múltiplas regulações entre dois genes. Assim, após a geração, removemos as regulações repetidas. A seguir descrevemos o processo básico devido a Bollobás et al. (2003).

Sejam $\alpha, \beta, \gamma, \delta_{\text {in }}, \delta_{\text {out }}$ números reais não negativos, com $\alpha+\beta+\gamma=1$. Seja $G_{0}$ uma rede direcionada inicial fixa, por exemplo um único vértice sem arcos, e seja $t_{0}$ o número de arcos de $t_{0}$. Fazemos $G\left(t_{0}\right)=G_{0}$, assim no instante $t$ a rede $G(t)$ tem exatamente $t$ arcos, e um número aleatória de vértices.

Dizemos que escolhemos um vértice $v$ de $G(t)$ de acordo com $d_{\text {out }}+\delta_{\text {out }}$ significa escolher $v$ tal que $\operatorname{Pr}\left(v=v_{i}\right)$ é proporcional a $d_{\text {out }\left(v_{i}\right)}+\delta_{\text {out }}$, isto é $\operatorname{Pr}\left(v=v_{i}\right)=\left(d_{\text {out }}\left(v_{i}\right)+\delta_{\text {out }}\right) /\left(t+\delta_{\text {out }} n(t)\right)$. De forma análoga, escolher $v$ de acordo com $d_{i n}+\delta_{\text {in }}$ significa escolher $v$ tal que $\operatorname{Pr}\left(v=v_{i}\right)=\left(d_{i n}\left(v_{i}\right)+\right.$ $\left.\delta_{i n}\right) /\left(t+\delta_{i n} n(t)\right)$, onde $d_{i n}\left(v_{i}\right)$ e $d_{o u t}\left(v_{i}\right)$ são os graus de entrada e saída de $v_{i}$, respectivamente, medidos do grafo $G(t)$.

A construção de $G(t+1)$ a partir de $G(t)$, para $t \geq t_{0}$ segue o seguinte procedimento:

1. Com probabilidade $\alpha$, adicione um vértice $v$ e um arco de $v$ para um vértice existente $w$, onde $v$ é escolhido de acordo com $d_{i n}+\delta_{i n}$;

2. Com probabilidade $\beta$, adicione um arco de um vértice existente $v$ para um vértice existente $w$, com $v$ escolhido de acordo com $d_{\text {out }}+\delta_{\text {out }}$, e $w$ escolhido de acordo com $d_{\text {in }}+\delta_{\text {in }}$;

3. Com probabilidade $\gamma$, adicione um vértice $w$ e um arco de $w$ para um vértice existente $v$, onde $w$ é escolhido de acordo com $d_{\text {out }}+\delta_{\text {out }}$;

Claramente as probabilidades $\alpha+\beta+\gamma=1$. Assumimos também que $\alpha+\gamma>0$, do contrário nenhum novo vértice seria adicionado.

É fácil visualizar que se $\alpha \gg \gamma$, a rede gênica será uma rede livre de escala, onde o gene com grau mais alto tem um grau de saída maior do que o grau de entrada. O inverso ocorre se $\alpha \ll \gamma$ : o grau de entrada do gene mais conectado é menor que o grau de saída. Além disso, quando $\beta$ é baixo (muito próximo de zero), poucos arcos ligam dois genes existentes: o resultado é que mais genes acabam não tendo preditores (grau de entrada zero) ou não predizendo nenhum gene (grau de saída zero).

Experiências preliminares nos mostraram que quando isso acorre, a rede é instável, gerando uma grande quantidade de bacias de atração pequenas, o que desejamos evitar. Assim, ao algoritmo inicial de Bollobás et al. (2003) adicionamos o seguinte passo: após a geração da rede, para cada gene com grau de saída zero, adicione uma regulação (arco) para um gene com grau de entrada zero. A principio isso poderia ser visto como um problema ou quebra das propriedades pretendidas com o algoritmo inicial, mas temos dois argumentos para tal modificação: primeiro, neste trabalho 
lidamos com redes pequenas (11 genes), onde é impossível verificar propriedades livres de escalas; segundo, mesmo que a rede cresça, como desejado no estudo de redes livres de escala, para $n \rightarrow \infty$, o impacto causado por essa adição de regulações, intuitivamente, não é significativo - apenas não teríamos mais genes não reguladores ou não regulados. É necessário uma argumentação formal mais detalhada, mas como não é o foco deste trabalho, deixamos como trabalhos futuros.

É importante notar que se $\delta_{\text {out }}=0$, genes adicionado com grau de saída zero (genes não reguladores) terão sempre grau de saída zero. O mesmo ocorre com $\delta_{i n}=0$ : genes não regulados desde a sua inclusão na rede não serão regulados. Assim, assumimos $\delta_{\text {out }}>0$ e $\delta_{\text {in }}>0$. Após testes empíricos, chegamos aos seguintes valores para os parâmetros do algoritmo: $\alpha=0,2, \beta=0,35, \gamma=$ $0,45, \delta_{\text {in }}=1, \delta_{\text {out }}=1$. Tais parâmetros foram usado a fim de minimizar o número de genes com grau de saída zero e genes com grau de entrada zero.

Para garantir que a rede seja conexa, após a geração da rede, buscamos genes sem regulação, isto é, grau de entrada zero. Para todos estes genes, adicionamos uma regulação de algum gene cujo grau de saída também seja zero. Se este segundo gene com grau de saída zero não existir, então sorteamos algum outro gene com igual probabilidade entre eles, e adicionamos uma regulação deste gene para o primeiro (cujo grau de entrada é zero). Fazemos isto para garantir que tal gene não regulado tenha alguma influência na rede.

Assim como no caso de redes ER, após a geração inicial de uma rede usando o algoritmo acima, na nossa implementação, as regulações são refeitas, escolhendo com probabilidade $p=0,5$ se é uma regulação de ativação ou inibição.

\subsubsection{Procedimento de simulação e validação}

Para validação, foram feitos dois conjuntos de experiências, um para cada tipo de rede: ErdốsRényi e Direcionadas livre de escala. Cada conjunto de experiências consistiu em gerar uma rede cuja dinâmica tivesse entropia relativamente baixa, que serviu como entrada para geração da série temporal usada como entrada do nosso algoritmo. Cada uma dessas redes foi então simulada, e a partir da simulação encontrada a maior bacia de atração (a bacia com o maior número de estados). A partir de um estado pertencente ao atrator desta bacia, procuramos uma trajetória (sequencia de estados da dinâmica), seguindo o seguinte algoritmo:

1. Considere variáveis para armazenar o tamanho do caminho igual a zero, o caminho vazio e o estado inicial nulo (o estado de todos os genes desligados)

2. Para $i=1$ até $i=n$

(a) Copie o estado de cada gene para um novo "estado temporário", invertendo o estado do gene $x_{i}$

(b) A partir deste "estado temporário", simule a dinâmica até encontrar o atrator, mantendo o caminho desde o estado

(c) Se o tamanho do caminho atual a partir do estado temporário for maior que o caminho mantido na variável do começo do algoritmo, substituir o caminho da variável pelo caminho atual, o tamanho do caminho da variável pelo tamanho do caminho atual, e o estado inicial pelo estado temporário

Ao final desse algoritmo, teremos um caminho relativamente grande, e que leva a um atrator, que será usado como série temporal. Não estamos necessariamente interessados de que tal caminho esteja na maior bacia de atracão, apesar disso ser interessante. Neste ponto, precisamos apenas de um caminho que faça parte da dinâmica de uma rede conhecida para validação. Mas como descrevemos anteriormente, as redes usadas para validação foram geradas tentando minimizar o número de bacias de atração e maximizar o tamanho de uma delas. Com isso, a chance do maior caminho estar em uma bacia pequena é reduzido. Também é importante notar aqui que o algoritmo acima busca um caminho tal que o estado de origem tenha distancia Hamming igual a um em relação 
ao estado atrator, tal como ocorre na rede de Li et al. (2004), que pode ser vista na Figura 4.21. Mas isso não garante um caminho longo, podendo até mesmo ter uma trajetória com tamanho um. Deixamos como trabalhos futuros analisar a viabilidade de caminhos mais longos para origem com distância Hamming maior que um.

Com base nesse maior caminho, geramos as soluções consistentes de acordo com as restrições descritas na Seção 3.1, e a partir destas, para cada critério de geração de redes descritas na Seção 3.2, geramos 1000 redes que foram então simuladas (sendo então geradas e simuladas um total de 11000 redes, já que alguns critérios de contrução de redes foram usados com variações de parâmetros). Destas, separamos $5 \%$ cuja dinâmica apresentasse a menor entropia.

\section{Critérios de validação}

Para validarmos nosso algoritmo, usamos uma técnica de comparação dinâmica e topológica das redes geradas pelo algoritmo com as redes artificiais usadas para geração das séries temporais. A técnica usada aqui foi apresentada em Dougherty (2007) (Lopes (2011))

\section{Medidas de similaridade Topológica}

Uma matriz de confusão (Kohavi e Provost (1998); Webb (2002)) é uma forma conveniente de tabular os dados a fim de avaliar a qualidade de um modelo. Vamos considerar que temos uma rede A ideal e uma rede B inferida, e as respectivas matrizes de regulação. Como primeiro critério de validação, vamos usar medidas de similaridade propostas por Dougherty (2007). Podemos computar as entradas da matriz de confusão com os seguintes significados: Verdadeiro Positivos (TP, do inglês True Positive), é a quantidade de regulações que existem na rede ideal A, e que foram identificadas na rede inferida B;Falso Positivos (FP, do inglês False Positive), número de regulações encontradas em B e que não existem em A; Verdadeiro Negativos (TN, do inglês True Negative), quantidade de regulações não encontradas em B que realmente não existem em A; e Falso Negativos (FN, do inglês False Negative), quantidade de regulações não encontradas em B, mas que existem em A. Veja a Tabela 4.1 para um exemplo de matriz de confusão. Na matriz de confusão, cada coluna representa os dados inferidos, enquanto as linhas representam os dados reais (Lopes (2011)).

Tabela 4.1: Exemplo de Matriz de Confusão

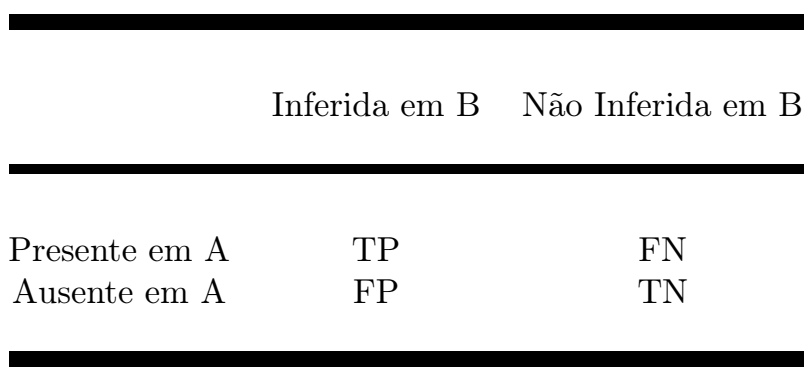

Uma das técnicas de validação de classificadores é conhecido como Espaço ROC (do inglês Receiver Operating Characteristic). Nesta seção iremos descrever um pouco seu funcionamento. Para maiores detalhes, veja Flach (2003), inclusive com uma extensão 3D do espaço ROC.

Uma escolha comum para analisar o espaço ROC é feita definindo o eixo $x$ como sendo a Taxa de Falso Positivos (FPR, do inglês False Positive Rate), e o eixo y como sendo a Taxa de Verdadeiro Positivos (TPR, do inglês True Positive Rate), também conhecida como Sensibilidade. Por definição, temos que

$$
T P R=\frac{T P}{T P+F N},
$$

e

$$
F P R=\frac{F P}{F P+T N} .
$$


Temos ainda a Especificidade, definida por

$$
\text { Especificidade }=S P C=\frac{T N}{N}=\frac{T N}{(F P+T N)}=1-F P R .
$$

No espaço ROC, o ponto $(0,1)$ representa o classificador ideal, enquanto o ponto $(1,0)$ representa um classificador que erra todas as predições. Já os pontos na diagonal ascendente $(0,0)-(1,1)$ representa um classificador totalmente aleatório, com $50 \%$ de chance de acertar a predição. Pontos acima dessa linha representam classificadores melhores que aleatório, enquanto pontos abaixo dessa linha representam classificadores piores que aleatório (Flach (2003)).

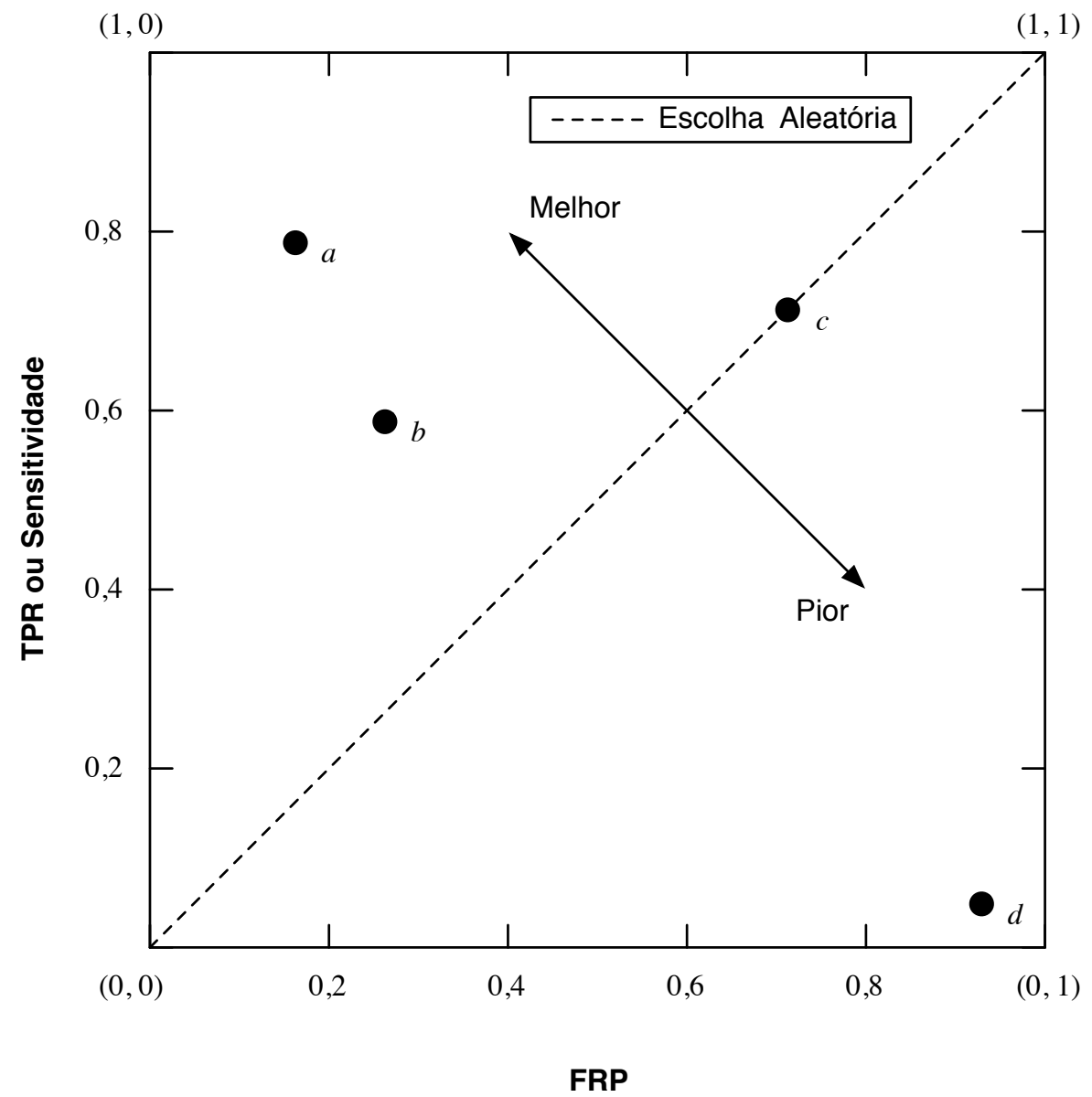

Figura 4.1: Exemplo de espaço ROC.

Veja por exemplo na Figura 4.1, que exibe um exemplo de espaço ROC, o método de classificação $a$ exibe o melhor poder preditivo, seguido pelos métodos $b$ e $c$. O ponto $c$ reside sobre a linha de escolha aleatória, e temos portanto $50 \%$ de chance desse ponto estar certo. O método do ponto $d$ tem o pior poder de predição, porém se o classificador for invertido (o equivalente a trocar as colunas da matriz de confusão, isto é, identificar TP como FN, e FP, como TN), seu poder de predição passa a ser melhor que o método do ponto $a$.

Considerando que as medidas Especificidade e Sensibilidade não são independentes entre si, quando utilizadas em conjunto é adequado utilizar sua média geométrica para representar o valor médio entre as medidas. A média geométrica é dada por:

$$
M G(X)=\sqrt[n]{x_{1}, x_{2}, \ldots, x_{n}}
$$

dessa forma, quando estas medidas são utilizadas em conjunto, a fim de produzir uma medida de similaridade entre duas redes $\operatorname{Similaridade}(A, B)$, é adotada neste trabalho uma média geométrica 
entre as medidas envolvidas, como por exemplo, no caso definido pela Equação 4.1 abaixo:

$$
\text { Similaridade }(A, B)=\sqrt{\text { Especificidade } \times \text { Sensibilidade }}
$$

É importante observar que ambas as taxas de arestas corretas e incorretas são consideradas pelas medidas da Equação 4.1, implicando que a similaridade máxima é obtida por valores destas medidas próximos a um.

\section{Medida de similaridade Lógica}

Podemos ainda validar o comportamento dinâmico da rede analisando apenas a entropia, como foi feito para selecionar as redes de maior interesse, mas isto não basta para termos uma rede mais próxima da ideal. Assim, podemos validar o comportamento lógico, seguindo a Distância baseada em Regra (do inglês Rule-Based Distance), como descrita por Dougherty (2007). Sejam A e B duas redes gênicas booleanas possuindo o mesmo conjunto de genes. Se denotarmos as funções de transição de estado por $f=\left(f_{1}, f_{2}, \ldots, f_{n}\right)$ e $g=\left(g_{1}, g_{2}, \ldots, g_{n}\right)$, respectivamente, já que existem, no nosso caso, $n$ genes e $2^{n}$ possíveis estados, a distancia é dada por

$$
\mu_{\text {fun }}(\mathbf{A}, \mathbf{B})=\frac{1}{n 2^{n}} \sum_{i=1}^{n} \sum_{j=1}^{2^{n}} I\left[g_{i}\left(\mathbf{x}_{k}\right) \neq f_{i}\left(\mathbf{x}_{k}\right)\right]
$$

onde $I$ denota a função indicadora $I[F]=1$ se $F$ é verdadeiro, do contrário $I[F]=0$, e $\mathbf{x}_{k}$ é um estado na dinâmica. Na Equação 4.2 , o somatório $\sum_{j=1}^{N} I\left[g_{i}\left(\mathbf{x}_{k}\right) \neq f_{i}\left(\mathbf{x}_{k}\right)\right]$ pode ser entendido como a distância Hamming do próximo estado, partindo de um mesmo estado nas duas redes. Considerando que as duas redes são determinísticas, se o valor dessa função é $\mu_{\text {fun }}(\mathbf{A}, \mathbf{B})=0$, então a tabela verdade das duas redes é idêntica. Desejamos então minimizar este valor.

\section{Medida de similaridade Dinâmica}

Além das medidas de similaridade topológica e lógica, como a ordenação das redes inferidas é feita levando-se conta apenas a entropia do tamanho das bacias da dinâmica da rede inferida, podemos calcular a distância da entropia da rede inferida em relação à rede ideal. Mas antes, devemos normalizar as entropias, e para isso devemos levar em consideração que a entropia é máxima se todas as bacias têm o mesmo tamanho. Assim, se $x$ é o número de bacias da dinâmica da rede em questão (ideal ou inferida) e $H$ a entropia do tamanho das bacias na dinâmica da mesma, então a entropia máxima pode ser encontrada por:

$$
H_{\text {max }}=-\sum_{i=1}^{x} p_{i} \log p_{i}=-\sum_{i=1}^{x} \frac{\frac{2^{n}}{x}}{2^{n}} \log \frac{\frac{2^{n}}{2^{n}}}{2^{n}}=-x\left(\frac{1}{x} \log \frac{1}{x}\right)=-\log \frac{1}{x}
$$

onde $n$ é o número de genes, e a entropia normalizada pode ser calculada como:

$$
\bar{H}=\frac{H}{H_{\max }} .
$$

Assim, a entropia normalizada atinge valor máximo $\bar{H}=1$ quando todas as bacias da rede inferida tem mesmo tamanho, e zero quando existe apenas uma bacia contendo todos os estados.

Podemos então calcular a distância $D_{\bar{H}}(\mathbf{A}, \mathbf{B})$ da entropia entre a rede real $A$ e a rede inferida $B$ de acordo com a Equação 4.5:

$$
D_{\bar{H}}(\mathbf{A}, \mathbf{B})=|\bar{H}(A)-\bar{H}(B)|,
$$

onde $\bar{H}(A)$ é a entropia normalizada da rede ideal, $\bar{H}(B)$ é a entropia normalizada da rede inferida, e $|\bar{H}(A)-\bar{H}(B)|$ é o valor absoluto da diferença. 


\section{Integração das similaridades}

Podemos validar as redes individualmente por cada uma das medidas descritas anteriormente. Mas apesar de termos três medidas de similaridade, isto pode não ser suficiente, tendo uma "boa dinâmica" considerando apenas a entropia das bacias ou a distância baseada em regra mas com uma topologia bastante diferente da rede ideal, ou uma rede com uma topologia um pouco mais próxima da ideal, sem no entanto ter uma boa dinâmica. Assim, criamos um parâmetro de forma a integrar esses resultados, a fim de escolher uma rede mais interessante de forma geral. Seja $c$ um critério de construção de rede. Seja ainda $\mu_{\text {fun }}^{c}(\mathbf{A}, \mathbf{B})$ a distância baseada em regra para o critério $c, D_{\bar{H}}^{c}(\mathbf{A}, \mathbf{B})$ a distancia da entropia para o critério $c$ e $\operatorname{Similaridade}^{c}(\mathbf{A}, \mathbf{B})$ a similaridade para o critério $c$, ambos comparando as redes $\mathbf{A}$ e $\mathbf{B}$. Então:

$$
S_{c}=\frac{D_{H}^{c}(\mathbf{A}, \mathbf{B})+\mu_{\text {fun }}^{c}(\mathbf{A}, \mathbf{B})-\text { Similaridade }^{c}(\mathbf{A}, \mathbf{B})}{3},
$$

onde $\mathbf{A}$ é a rede ideal, e a rede inferida é $\mathbf{B}$, selecionada de acordo com critério $c$.

Como desejamos diminuir a distancia baseada em regras e aumentar a similaridade entre as redes, alem de ter uma entropia mais próxima da ideal, a Equação 4.6 nos ajuda a encontrar uma rede mais interessante, levando em consideração os dois critérios. Desejamos, portanto, minimizar o valor de $S_{m}$.

\subsection{Resultados Experimentais}

Para validação construímos duas redes artificiais, a primeira seguindo o modelo Erdôs-Rényi direcionada, conforme descrito na Subseção 4.3.1, e a segunda seguindo o modelo livre de escala, de acordo com o algoritmo descrito na Subseção 4.3.2. A partir destas redes, geramos a série temporal de entrada do algoritmo de inferência. Realizamos ainda a inferência a partir da série temporal encontrada por Li et al. (2004) para a série da levedura. Todas as redes possuem 11 genes.

Conforme comentado na Subseção 4.3.3, após o processamento da série pelo solver, para cada critério de construção de rede descrito na Subseção 3.2.1, são geradas 1000 redes, que são então simuladas e ordenadas de acordo com a entropia do tamanho das bacias de atração. Dessas 1000 redes, filtramos $50(5 \%)$ com menor entropia, que são então consideradas boas redes candidatas para testes em laboratório por um biólogo.

A seguir descrevemos os resultados.

\subsubsection{Análise dos dados para redes DER e exemplos de redes inferidas}

Vamos agora ver alguns exemplos de redes inferidas e analisar com mais detalhes. Nesta sessão, analisaremos redes inferidas com dados obtidos a partir de uma rede aleatória artificial ideal, seguindo o modelo Erdôs-Rényi direcionado, ou DER (do inglês Directed Erdôs-Rényi). A rede ideal gerada é constituída de 11 genes.

A rede artificial ideal gerada foi simulada para identificação da maior bacia. A partir da maior bacia, identificamos o atrator e geramos o caminho a ser usado como série temporal seguindo o algoritmo descrito na Subseção 4.3.3. Vale lembrar que, conforme dissemos anteriormente, podemos ter uma série temporal muito pequena, o que pode ser insuficiente para inferência mais precisa das redes, por não ser possível identificar restrições suficientes, de acordo com a Seção 3.1. Veja na Figura 4.2 a rede artificial ideal gerada, e na Figura 4.3 sua dinâmica. A dinâmica desta rede tem $H=1,207$ e $\bar{H}=0,485$.

Começaremos analisando os dados da topologia e da dinâmica das redes inferidas usando os vários critérios de contrução de rede, descritos na Subseção 3.2.1. A Tabela 4.2 exibe os dados da topologia. Nesta tabela, a coluna $A C C$ indica a precisão dos dados inferidos, ou o quão próximo os 


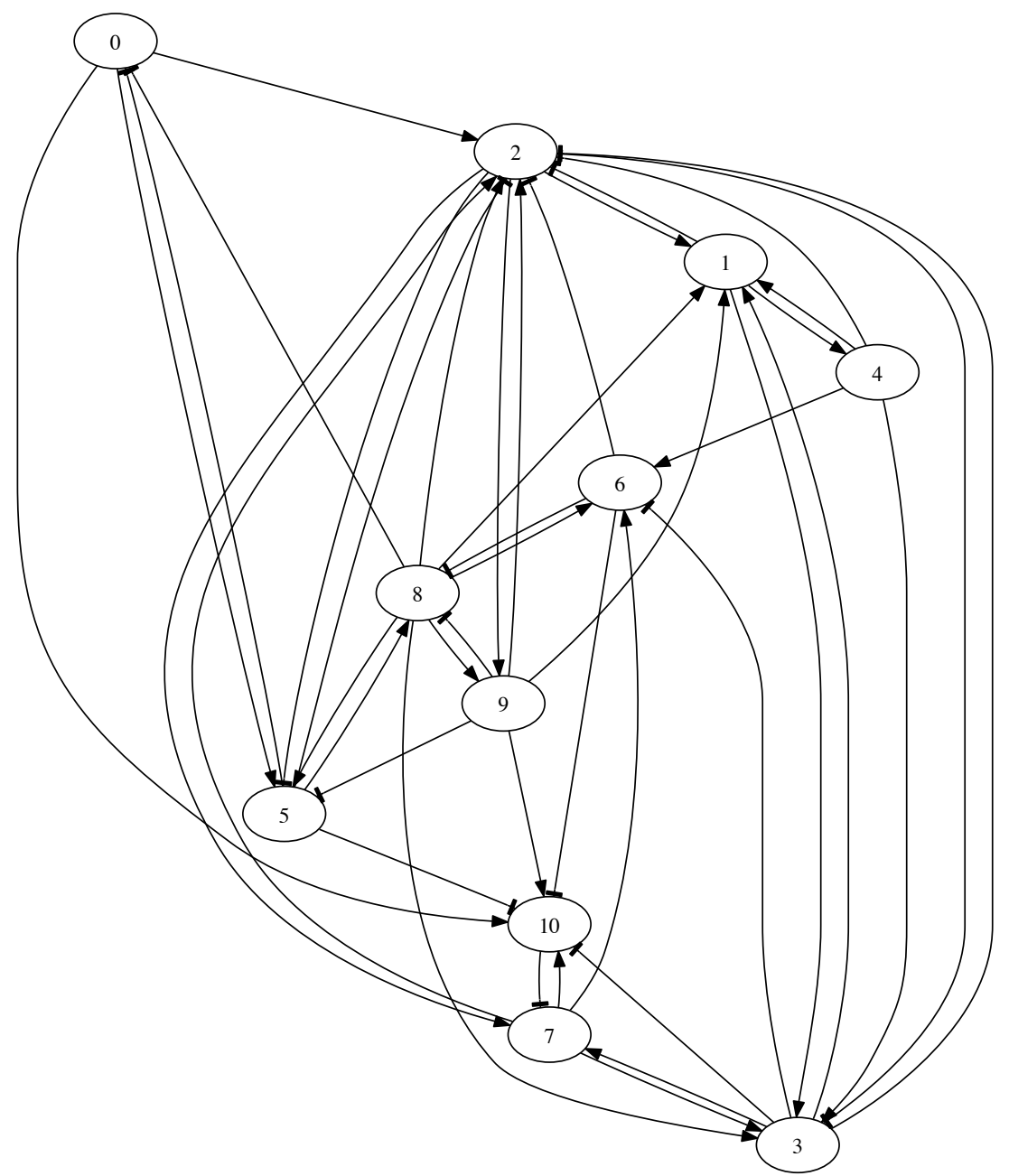

Figura 4.2: Rede Erdôs-Rényi direcionada, gerada artificialmente, usada para validação. A rede foi simulada para gerar a série temporal, que foi então usada no algoritmo. 


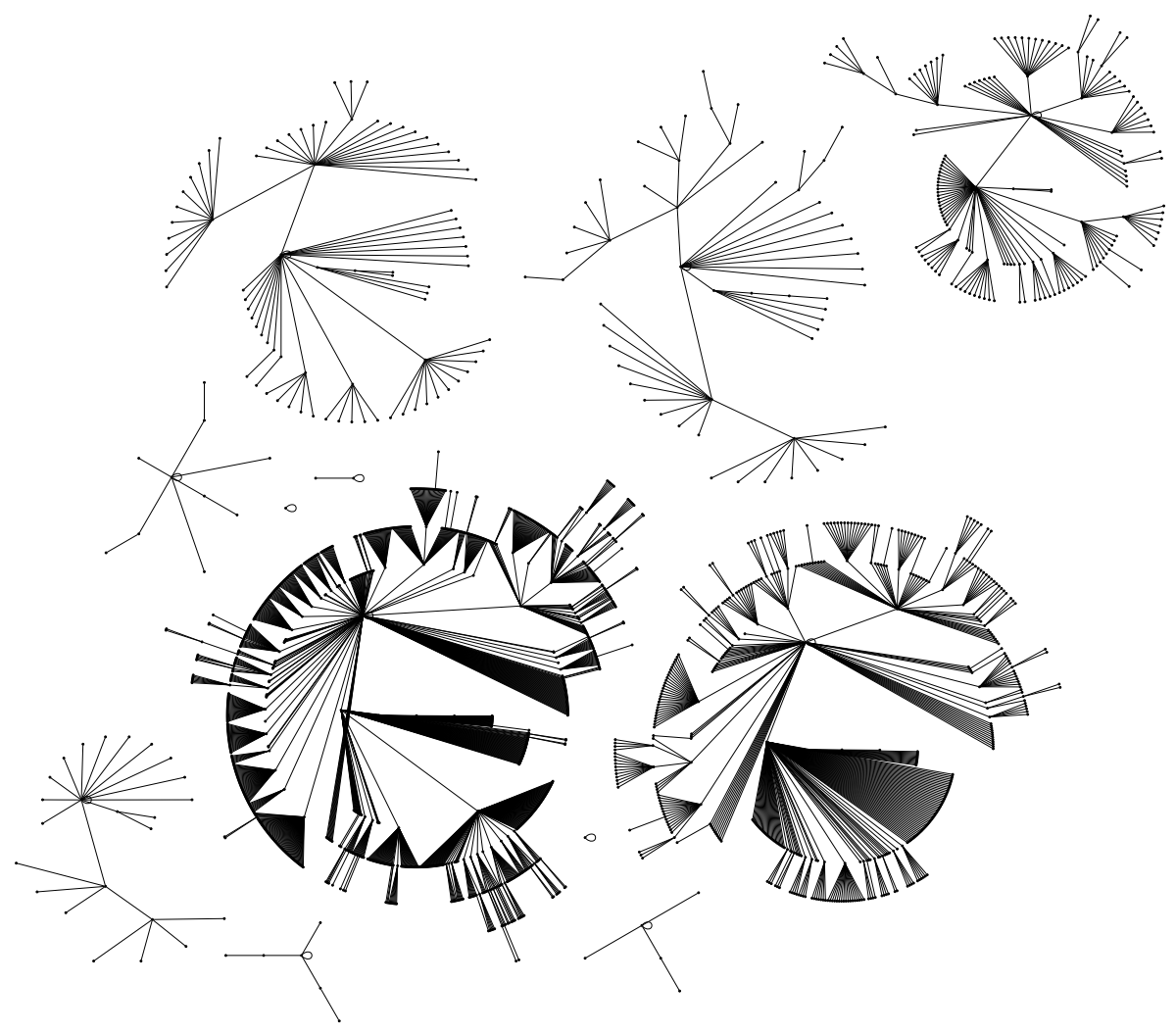

Figura 4.3: Dinâmica da rede Erdôs-Rényi direcionada, gerada artificialmente, que foi usada para validação. $A$ rede é exibida na Figura 4.2.

resultados inferidos estão próximos dos valores reais, e é definida como:

$$
A C C=\frac{(T P+T N)}{(P O S+N E G)},
$$

onde $P O S=T P+F N$ e $N E G=F P+T N$.

Conforme pode ser visto na Tabela 4.2, as redes com mais arestas, como redes densas e redes densas com um grau de liberdade, tem a maior taxa de acerto de TP, apresentando os maiores valores de TPR (pois o número de FN, com o excesso de regulações, é bastante baixo). Em compensação, com o excesso de regulações, acaba aumentando também os FP, aumentando assim o valor de FPR. Além disso, os dados destas redes apresentam os menores valores de precisão (coluna ACC). Com isso, as redes mais densas (incluindo as aleatórias) são as redes com a maior similaridade topológica, mas com a menor garantia de que a inferência das regulações está correta.

Já as redes inferidas com menos regulações, como redes esparsas, redes esparsas com um grau de liberdade, ou as redes com hub (principalmente hub de entrada), tem a menor similaridade topológica, apresentando uma média alta de FN. Apesar de acertarem também uma maior quantidade de TN, isso não é suficiente para diminuir o valor de FPR, pois a quantidade de FP também é relativamente alta.

Ainda de acordo com a Tabela 4.2, exceto pelas redes densas e redes densas com um grau de liberdade inferidas, todas as redes inferidas os valores médios de FPR maiores que TPR. Isso pode ser um indicativo de que os erros ocorrem com mais frequência que os acertos. Conforme pode ser visto na Figura 4.4, com exceção das redes inferidas usando critérios de redes densas e redes densas com um grau de liberdade, todas as outras estão abaixo da linha de escolha aleatória. Logo, estas redes erram a inferência das regulações mais do que acertam.

Vamos agora analisar os dados da dinâmica. A Tabela 4.4 exibe os dados. Nesta tabela, a entropia média foi calculada sobre os valores normalizados das entropias encontradas para cada rede, assim como a distância $D_{\bar{H}}(\mathbf{A}, \mathbf{B})$. 
Tabela 4.2: Médias dos dados de topologia das redes inferidas a partir da série gerada da rede DER da Figura 4.2

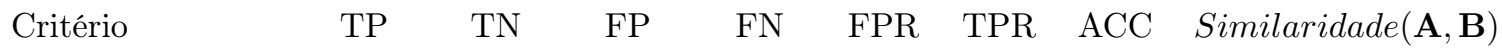

\begin{tabular}{|c|c|c|c|c|c|c|c|c|}
\hline Densa & 21,880 & 31,220 & 95,120 & 1,040 & 0,753 & 0,955 & 0,356 & 0,498 \\
\hline Densa - 1 & 20,200 & 34,860 & 88,140 & 5,180 & 0,717 & 0,797 & 0,371 & 0,482 \\
\hline Aleatória & 15,500 & 44,740 & 68,240 & 14,440 & 0,604 & 0,519 & 0,421 & 0,475 \\
\hline $\begin{array}{l}\text { Hub de saída-pred. lim.: }[2, \\
4]\end{array}$ & 8,540 & 59,980 & 31,420 & 29,000 & 0,344 & 0,227 & 0,531 & 0,463 \\
\hline Hub de saída & 7,040 & 59,660 & 34,420 & 30,100 & 0,366 & 0,189 & 0,508 & 0,461 \\
\hline Esparsa + 1 & 7,280 & 63,360 & 25,520 & 31,820 & 0,287 & 0,186 & 0,552 & 0,456 \\
\hline Hub de entrada & 8,460 & 60,640 & 31,640 & 29,240 & 0,343 & 0,224 & 0,532 & 0,456 \\
\hline Pred. limitados: $[2,4]$ & 6,380 & 64,720 & 23,240 & 33,240 & 0,264 & 0,161 & 0,557 & 0,453 \\
\hline Pred. limitados: $[2,3]$ & 6,040 & 64,760 & 22,660 & 33,780 & 0,259 & 0,151 & 0,556 & 0,446 \\
\hline Esparsa & 5,180 & 66,800 & 18,820 & 35,820 & 0,220 & 0,126 & 0,568 & 0,423 \\
\hline
\end{tabular}

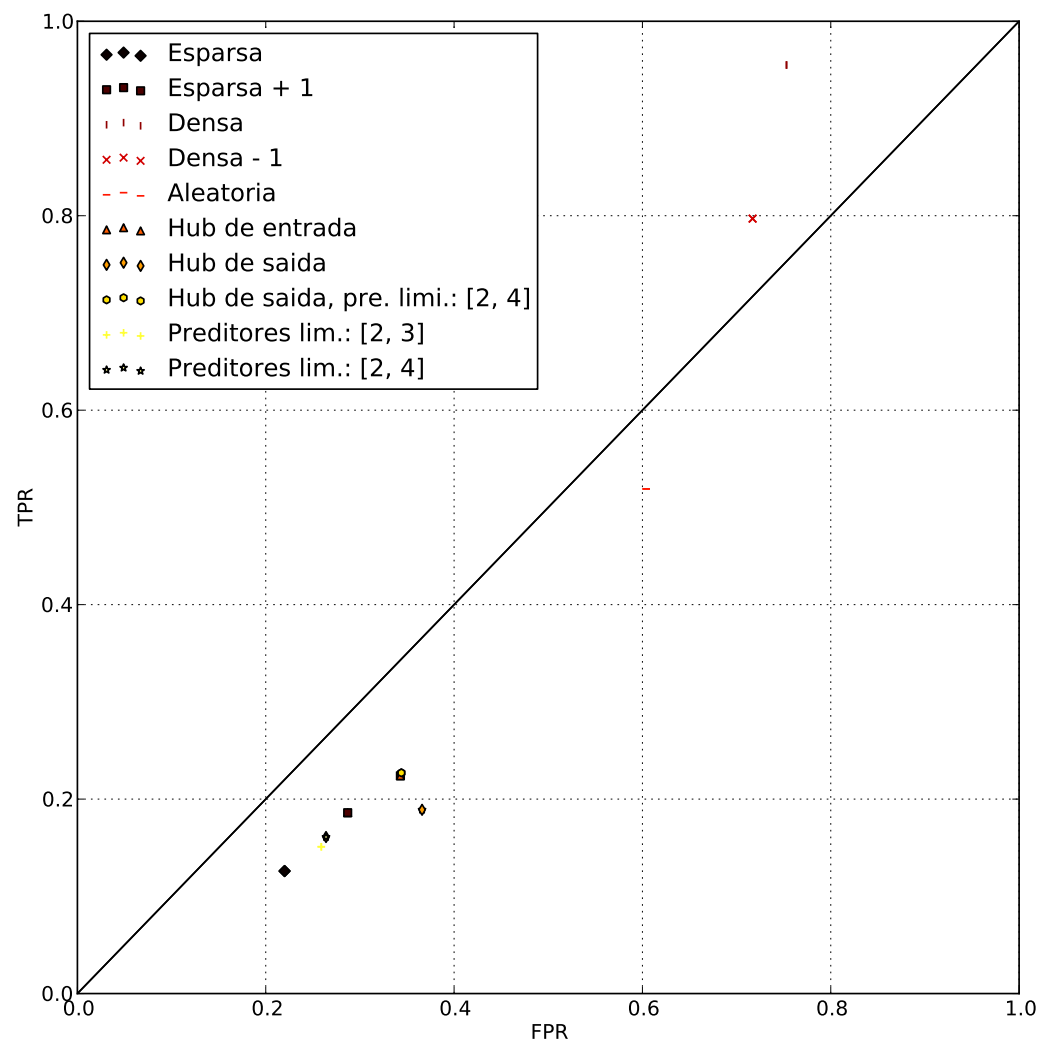

Figura 4.4: Espaço ROC para redes inferidas a partir da série temporal gerada da rede Erdôs-Rényi direcionada gerada artificialmente. Os pontos baixo da diagonal ascendente representam redes com taxa de falso positivo maior que a taxa de verdadeiro positivo, sendo então redes com topologia pior do que escolha aleatória (representada pela diagonal ascendente). Nesse caso, as redes densas têm maior taxa de acerto (compensada pelo acerto maior de verdadeiro positivo), mas prejudicado pela grande quantidade de falso positivo (por isso os pontos estão mais próximo do lado direito). Os valores são médias para dados de 50 redes com maior entropia do tamanho das bacias de atração. 
Podemos ver na Tabela 4.4 que a média $S_{c}=0,115$ é mínima para redes esparsas, puxada para baixo pela a distância baseada em regras, $\mu_{f u n}(\mathbf{A}, \mathbf{B})=0,312$ e pela distância da entropia ideal $D_{\bar{H}}(\mathbf{A}, \mathbf{B})$, mesmo que tenha a menor similaridade topológica, $\operatorname{Similaridade}(\mathbf{A}, \mathbf{B})=0,423$.

Tabela 4.3: Médias dos dados da dinâmica das redes inferidas a partir de série identificada para a rede DER da Tabela 4.4

\begin{tabular}{ccccc}
\hline Critério & & & & \\
& $D_{\bar{H}}(\mathbf{A}, \mathbf{B})$ & $\mu_{\text {fun }}(\mathbf{A}, \mathbf{B})$ & Similaridade $(\mathbf{A}, \mathbf{B})$ & $S_{c}$ \\
\hline & & & & \\
Esparsa & 0,233 & 0,312 & 0,423 & 0,115 \\
Hub de entrada & 0,344 & 0,382 & 0,456 & 0,139 \\
Densa & 0,412 & 0,485 & 0,498 & 0,142 \\
Densa - 1 & 0,418 & 0,475 & 0,482 & 0,142 \\
Aleatória & 0,418 & 0,452 & 0,475 & 0,147 \\
Esparssa + 1 & 0,367 & 0,362 & 0,456 & 0,154 \\
Pred. lim.: [2, 4] & 0,362 & 0,342 & 0,453 & 0,158 \\
Hub de saída, pred. lim. $[2,4]$ & 0,399 & 0,384 & 0,463 & 0,159 \\
Pred. lim.: [2, 3] & 0,371 & 0,333 & 0,446 & 0,161 \\
Hub de saída & 0,402 & 0,345 & 0,461 & 0,173 \\
& & & &
\end{tabular}

Vamos então analisar uma rede inferida usando critério de redes esparsas. A Figura 4.5 exibe a rede em questão. Para comparação, veja na Figura 4.2 a rede ideal, e na Figura 4.3 sua dinâmica. Essa rede foi selecionada por apresentar a menor média $\left(S_{c}=0,05\right)$ dentre as redes esparsas inferidas.

Conforme pode ser visto também na Figura 4.6, apenas uma transição foi identificada na dinâmica (linha vermelha). De fato, esta transição é exatamente a usada como entrada do algoritmo, como pode ser visto na Tabela 4.4. Como foi comentado anteriormente, esta série é muito curta para ser suficientemente representativa, mesmo assim foi capaz de inferir uma boa dinâmica, apesar da topologia prejudicada. A entropia da rede inferida é $H=0,718$ (e entropia normalizada $\bar{H}=0,346)$, a distância da entropia da rede ideal é $D_{\bar{H}}=0,14$, o valor de $\mu_{f u n}(\mathbf{A}, \mathbf{B})=0,396$ e Similaridade $(\mathbf{A}, \mathbf{B})=0,388$. Em relação a rede artificial ideal, essa rede tem $\mathrm{TP}=8, \mathrm{TN}=67$, $\mathrm{FP}=16, \mathrm{FN}=35, \mathrm{FPR}=0,193, \mathrm{TPR}=0,186$ e $\mathrm{ACC}=0,595$.

Tabela 4.4: Série usada como entrada para inferência de redes DER

\begin{tabular}{cccccccccccc} 
Instante & 1 & 2 & 3 & 4 & 5 & 6 & 7 & 8 & 9 & 10 & 11 \\
\hline & & & & & & & & & & & \\
1 & 0 & 1 & 0 & 1 & 1 & 0 & 1 & 1 & 1 & 1 & 0 \\
2 & 0 & 1 & 0 & 1 & 1 & 0 & 1 & 1 & 0 & 1 & 0 \\
\hline
\end{tabular}

A dinâmica da rede possui oito bacias, cujos tamanhos e atratores podem ser vistos na tabela Tabela 4.5 .

Outro fato importante é que, conforme pode ser visto na Figura 4.7, apesar dos valores médios de TPR e FPR estarem posicionados abaixo da linha de escolha aleatória, a rede esparsa com a menor média apresenta um dos ponto mais próximos do ponto $(0,1)$ ideal. Neste gráfico apresentamos as 50 redes filtradas com menor entropia ( $5 \%$ do total de 1000 inferidas) em preto, e o ponto vermelho apresenta a rede com menor média $S_{c}$. É claro então que a $\operatorname{Similardade}(\mathbf{A}, \mathbf{B})=0,388$, a mais alta em relação as outras redes esparsas inferidas, contribui bastante para diminuir a média. Assim, uma outra possibilidade de trabalho futuro seria incluir pesos aos valores de $\operatorname{Similardade}(\mathbf{A}, \mathbf{B})$, 


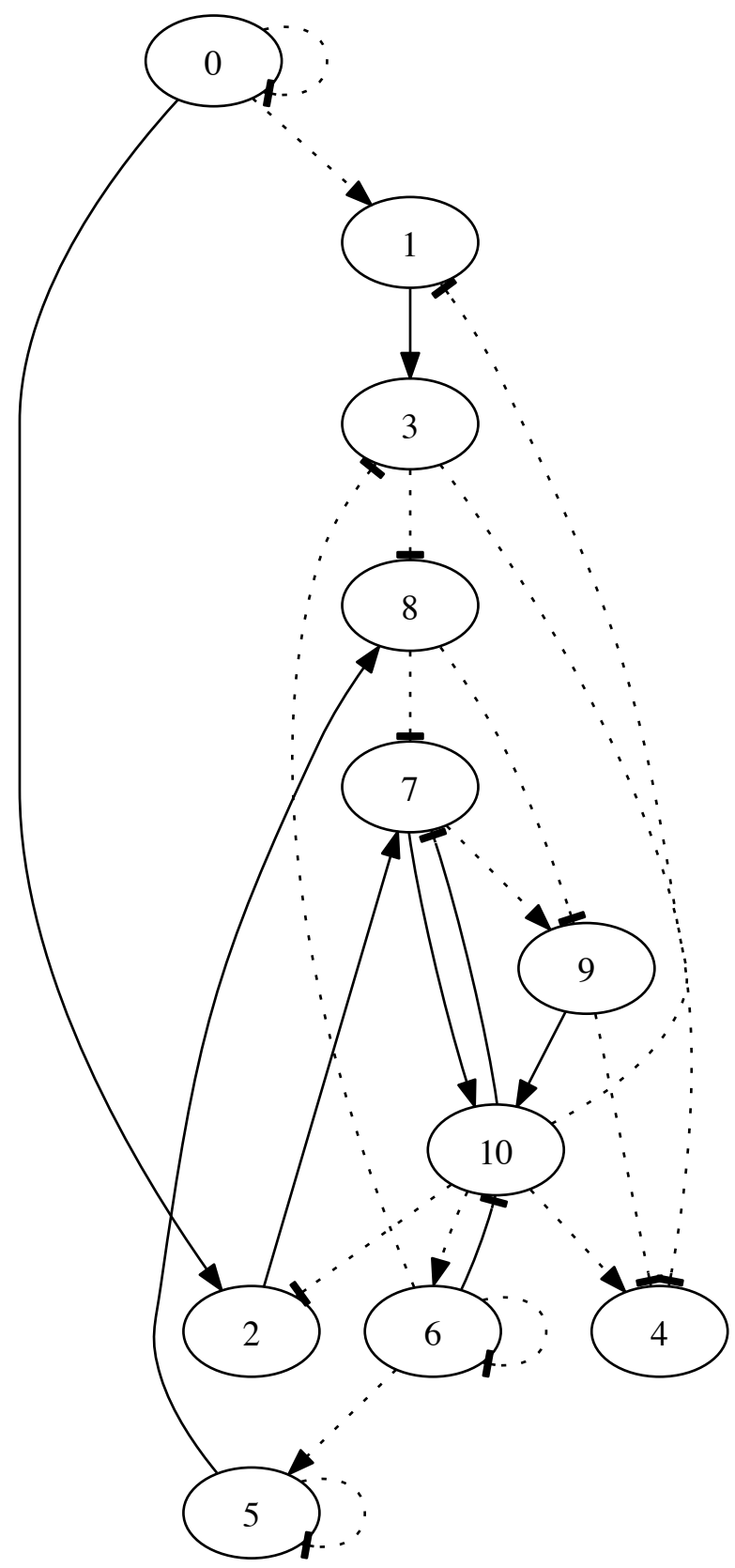

Figura 4.5: Rede inferida, usando critério de redes esparsas, com dados de uma rede Erdôs-Rényi direcionada. Essa rede foi escolhida por apresentar a menor média $\left(S_{c}=0,05\right)$. Linhas cheias representam TP, enquanto linhas pontilhadas representam FP (regulações incorretamente inferidas, por não existirem na rede ideal). 


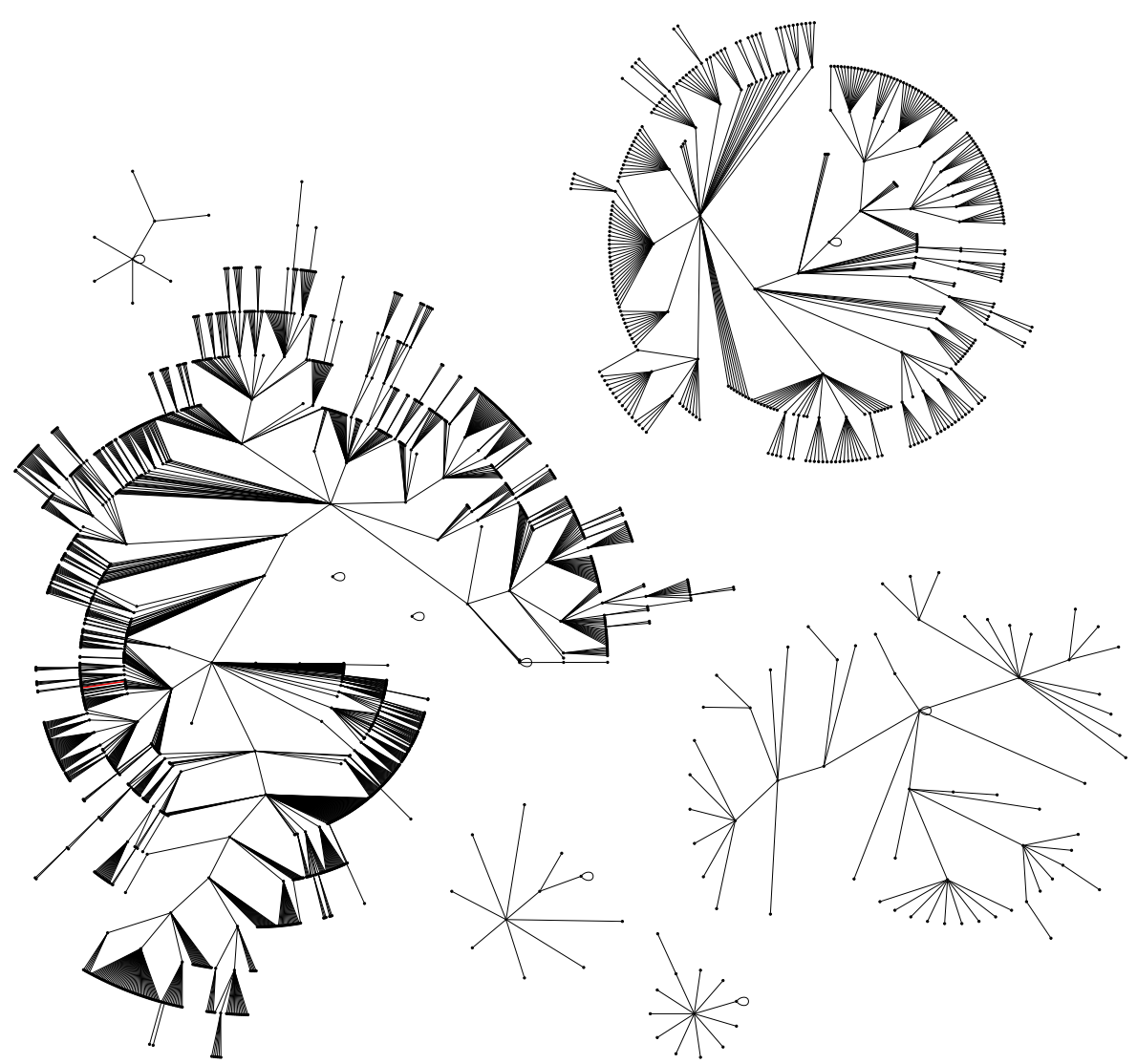

Figura 4.6: Dinâmica da rede esparsa inferida, exibida na Figura 4.5, a partir da série gerada a partir de uma rede Erdös-Rényi direcionada artificial. O caminho representado pelo arco vermelho representa a série temporal usada como entrada.

Tabela 4.5: Tamanho das bacias para rede esparsa inferida

\begin{tabular}{cccccccccccc}
\hline 1563 & 0 & 0 & 0 & 0 & 1 & 0 & 0 & 0 & 1 & 0 & 0 \\
387 & 0 & 0 & 0 & 0 & 0 & 0 & 0 & 0 & 1 & 0 & 0 \\
64 & 0 & 1 & 0 & 1 & 0 & 0 & 0 & 0 & 0 & 0 & 0 \\
13 & 0 & 0 & 1 & 0 & 0 & 0 & 0 & 0 & 1 & 0 & 0 \\
11 & 0 & 0 & 1 & 0 & 1 & 0 & 0 & 0 & 1 & 0 & 0 \\
8 & 0 & 0 & 0 & 1 & 0 & 0 & 0 & 0 & 0 & 0 & 0 \\
1 & 0 & 0 & 0 & 0 & 0 & 0 & 0 & 0 & 0 & 0 & 0 \\
1 & 0 & 0 & 0 & 0 & 1 & 0 & 0 & 0 & 0 & 0 & 0 \\
& & & & & & & & & & & \\
\hline
\end{tabular}


$\mu_{f u n}(\mathbf{A}, \mathbf{B})$ e $D_{\bar{H}}(\mathbf{A}, \mathbf{B})$.

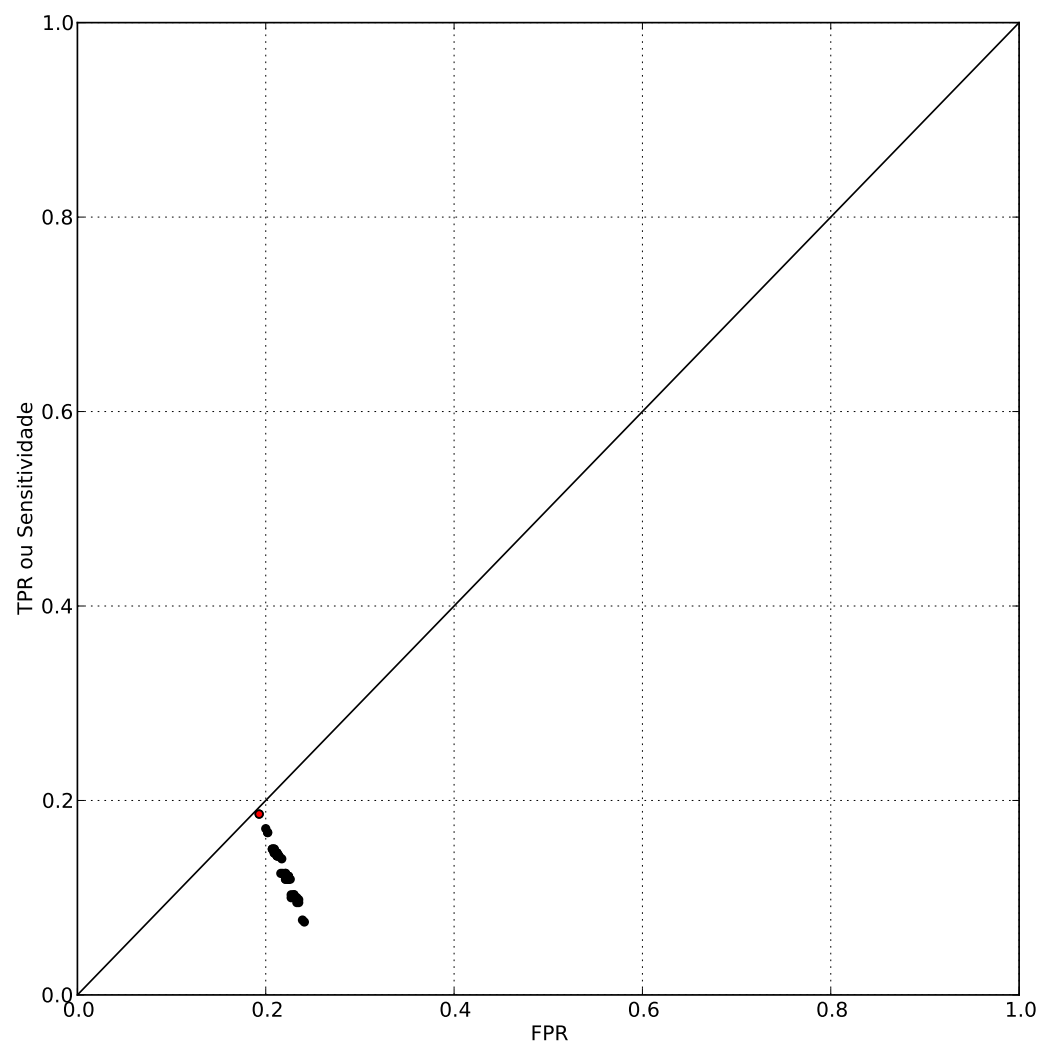

Figura 4.7: Espaço ROC com TPR e FPR das 50 redes esparsas inferidas a partir da série temporal extraída de uma rede Erdós-Rényi direcionada artificial.

Outro passo importante é entender a variação da entropia, já que a consideramos para identificar a dinâmica das redes. A Figura 4.8 exibe esses dados, para as redes inferidas a partir dos dados da Figura 4.2. Podemos verificar aqui que a entropia é distribuída igualmente em todos os casos. Nessa figura, o retângulo azul representa $50 \%$ dos valores centrais da amostra, a linha vermelha dentro do quadrado representa a mediana (valor numérico que separa a metade inferior da metade superior da amostra), enquanto os traços pretos sob e sobre as linhas tracejadas em azul representam o quartil inferior e o quartil superior, respectivamente. Temos então, dentro das barras superior e inferior, 99,3\% das amostras, enquanto o sinal + representa um valor extremo, discrepante da maioria dos valores. Os valores descritos no topo do gráfico representam a mediana. Apesar de pequenas variações da distribuição, o que varia mais é o valor da mediana. É importante afirmar aqui que os valores usados aqui para geração deste gráfico foram sobre as 1000 redes simuladas, e não sobre as 50 filtradas (Wikipedia (2012b)).

Ainda olhando todo o conjunto de redes simuladas, podemos olhar a entropia em um gráfico de linha, como na Figura 4.9. Neste gráfico, ordenamos as simulações pelo valor da entropia. Aqui, podemos verificar que a curva de crescimento apresenta uma forma semelhante entre os vários critérios, apesar da curva da entropia para rede densa crescer mais devagar, enquanto a curva para redes esparsas crescer mais rapidamente. Por outro lado, podemos ver que o restante dos critérios cresce de maneira bastante parecida, dificultando a escolha por uma em especial, usando apenas a entropia como critério. Outro ponto importante de notar deste gráfico é que, olhando apenas a entropia, seria mais interessante usar redes densas ou aleatórias, por possuírem entropia mais baixa. Mas o número excessivo de redes com entropia baixa nesse caso é justamente um fator de complicação, já que fica mais difícil filtrar num espaço de busca maior. Assim, redes com uma 


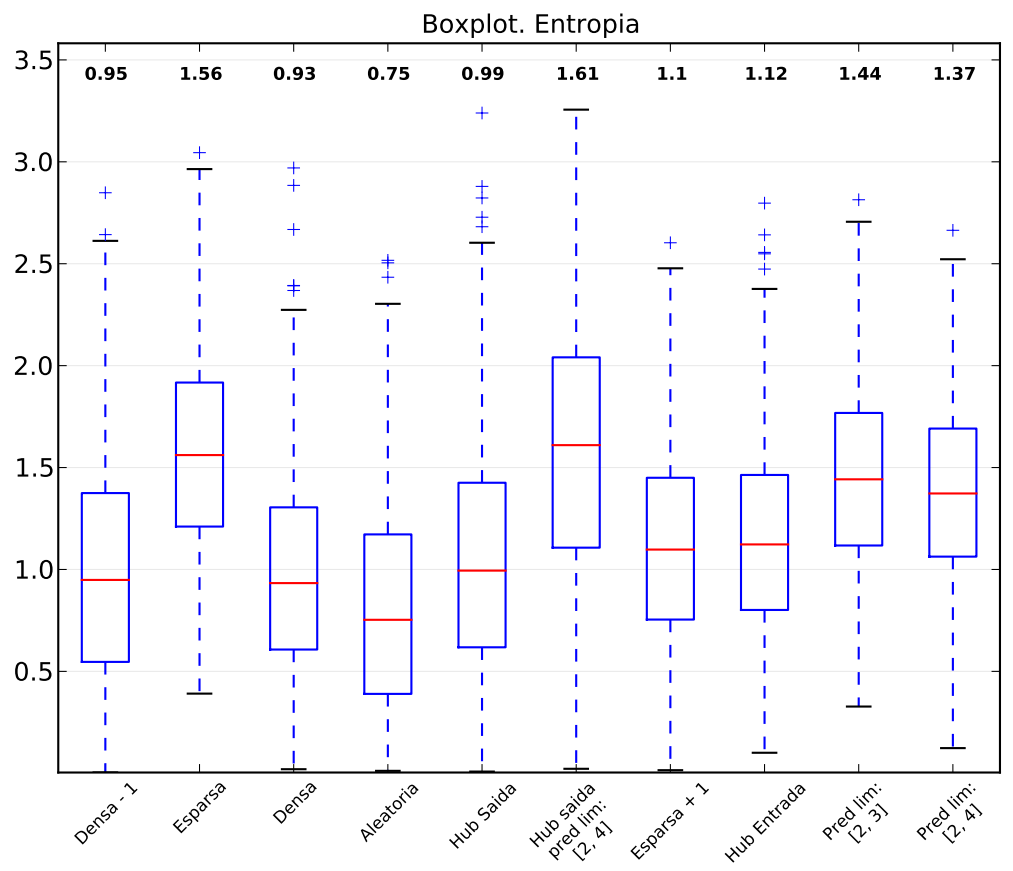

Figura 4.8: Distribuição das médias da entropia para redes inferidas a partir da rede da Figura 4.2. Os retângulos representam a distribuição $50 \%$ dos dados. A linha vermelha representa a mediana, cujo valor é apresentado sobre cada conjunto de dados.

maior similaridade topológica podem existir, mas com a seleção apenas pelo valor da entropia, acabaríamos excluindo tais redes.

Podemos também verificar que o tamanho da maior bacia está bastante relacionado com o valor da entropia. Na Figura 4.10 podemos ver que é quase inversamente proporcional ao valor da entropia. Podemos ver também que, apesar de não apresentar uma boa média $S_{c}$, redes aleatórias apresentam as maiores bacias, sendo assim possivelmente mais estáveis, seguidas de redes densas e redes com hub de saída.

Por último, podemos gerar o gráfico de linha para o número de bacias, que pode ser visto na Figura 4.11. Aqui, o crescimento é basicamente inverso ao apresentado na Figura 4.9. Como o gráfico apresenta um valor inteiro, aparecem os "degraus", pois diversas redes podem ter o mesmo número de bacias.

\subsubsection{Análise dos dados para redes livre de escala e exemplos de redes inferidas}

Nossa segunda experiência para validação foi feita com redes direcionadas livre de escala, geradas a partir do algoritmo apresentado na Subseção 4.3.2. Novamente foi gerada uma rede com onze genes, e identificada a série temporal usada como entrada conforme descrito na Subseção 4.4.1.

A Tabela 4.6 exibe os dados médios de interesse para analise da topologia. Conforme pode ser visto, novamente as redes densas apresentam a maior similaridade topológica, seguidas pelas redes densas com um grau de liberdade e pelas redes aleatórias. Novamente temos, como era de se esperar, um maior número de TP e um valor menor para a média de FN para redes densas, o que favorece o valor de TPR. Também temos a rede esparsa como inferida com a menor similaridade topológica. Apesar disso, a inferência é mais precisa para redes esparsas do que redes densas.

Vamos agora analisar as médias dos dados da dinâmica para redes inferidas. Veja a Tabela 4.7. Podemos ver aqui que novamente as redes esparsas possuem médias $S_{c}$ mais baixas, novamente devido aos valores baixos de $D_{\bar{H}}(\mathbf{A}, \mathbf{B})$ e $\mu_{f u n}(\mathbf{A}, \mathbf{B})$. Vale notar que distância da entropia média normalizada $D_{\bar{H}}(\mathbf{A}, \mathbf{B})=0,049$ é bem pequena nesse caso, com a rede com uma dinâmica bastante parecida. 


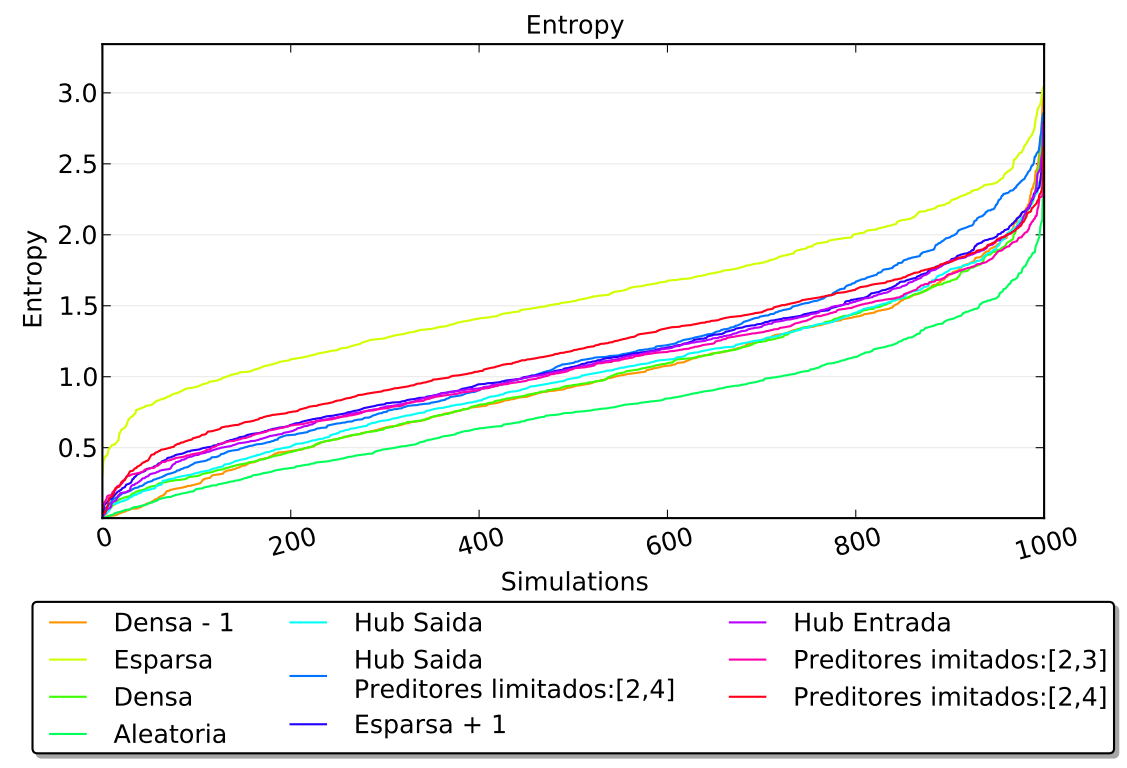

Figura 4.9: Crescimento do valor da entropia para cada critério de construção de redes, a partir de uma rede ER direcionada. Aqui as redes foram ordenadas de forma crescente pelo valor da entropia. Cada linha representa 1000 redes simuladas para cada critério de construção de redes para simulação.

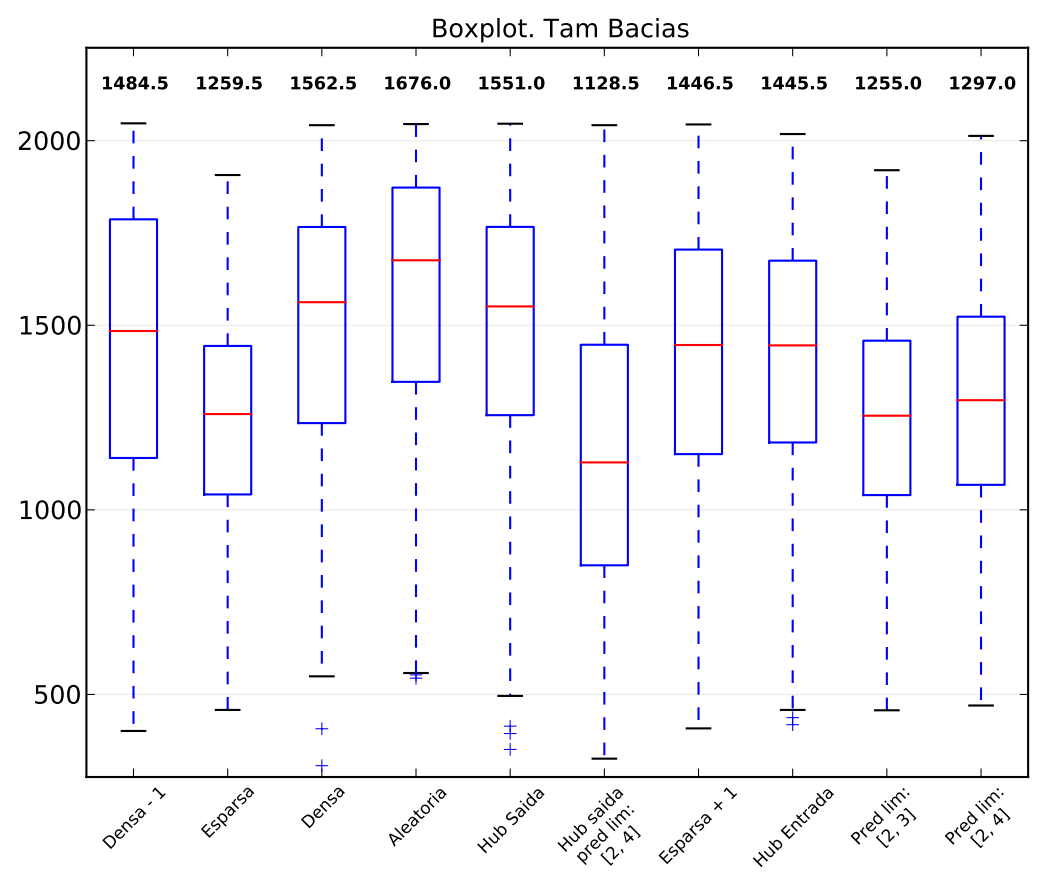

Figura 4.10: Distribuição das médias do tamanho da maior bacia das redes inferidas da série da Tabela 4.4, extraída de uma rede Erdôs-Rényi direcionada, para cada critério de construção de redes. 


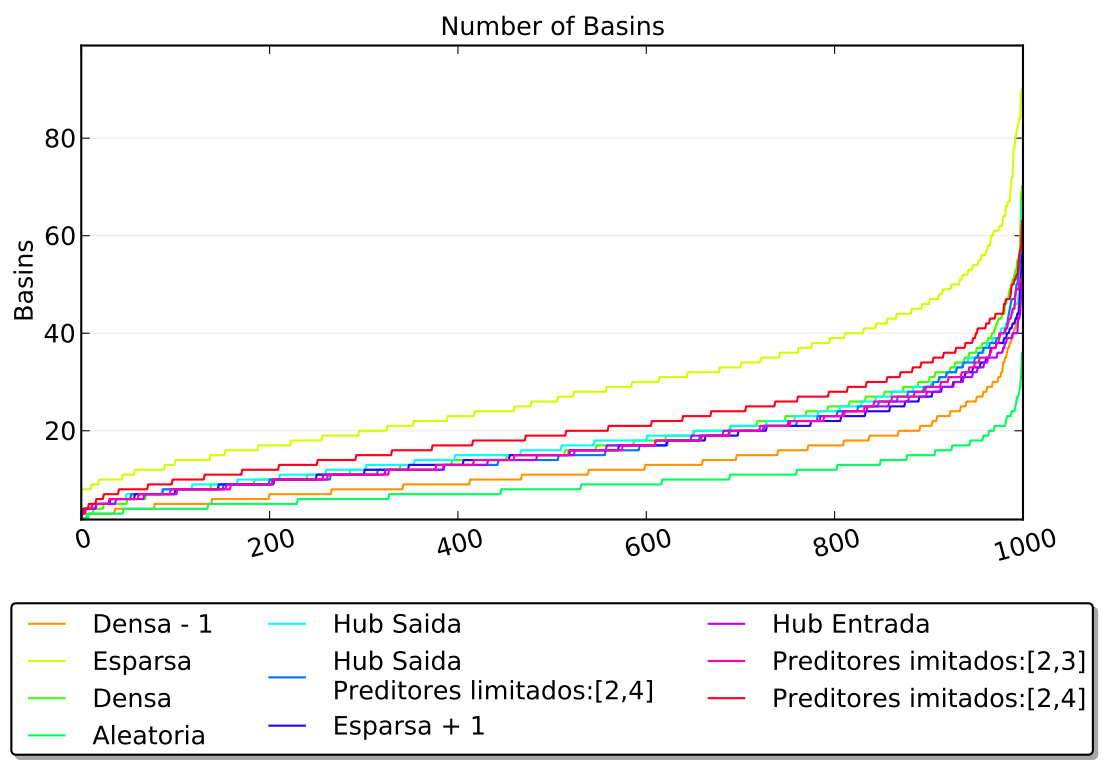

Figura 4.11: Número de bacias das redes inferias a partir da série usada como entrada para inferência de redes DER (a série é exibida na Tabela 4.4). As regiões onde o tamanho da bacia não varia (representada por degraus) representam um conjunto de redes que têm o mesmo número de bacias de atração.

Tabela 4.6: Médias dos dados de topologia para redes inferidas a partir de dados originados de uma rede artificial livre de escala geradas segundo o algoritmo descrito na Subseção 4.3.2

\begin{tabular}{ccccccccc}
\hline \\
Critério & TP & TN & FP & FN & FPR & TPR & ACC & Similaridade $(\mathbf{A}, \mathbf{B})$ \\
& & & & & & & & \\
\hline & & & & & & & & \\
Densa & 10,900 & 46,040 & 106,100 & 0,000 & 0,698 & 1,000 & 0,349 & 0,516 \\
Densa - 1 & 9,460 & 50,960 & 99,360 & 1,640 & 0,661 & 0,851 & 0,374 & 0,504 \\
Aleatória & 7,620 & 62,880 & 75,180 & 5,940 & 0,544 & 0,564 & 0,465 & 0,486 \\
4] & 3,140 & 85,100 & 34,340 & 12,540 & 0,287 & 0,202 & 0,653 & 0,473 \\
Hub de saída & & & & & & & & 0,471 \\
Hub de entrada & 3,700 & 84,120 & 34,380 & 12,420 & 0,290 & 0,231 & 0,652 & 0,464 \\
Esparsa + 1 & 4,480 & 83,000 & 35,700 & 11,940 & 0,301 & 0,273 & 0,647 & 0,458 \\
Pred. limitados: [2, 3] & 3,460 & 86,320 & 29,360 & 13,500 & 0,254 & 0,204 & 0,677 & 0,440 \\
Pred. limitados: [2, 4] & 3,360 & 88,920 & 25,460 & 13,580 & 0,222 & 0,199 & 0,703 & 0,428 \\
Esparsa & 3,700 & 88,840 & 25,100 & 13,760 & 0,220 & 0,212 & 0,704 & 0,407
\end{tabular}


Tabela 4.7: Medias dos dados da dinâmica das redes inferidas com dados da rede da Figura 4.12, a partir de uma rede com topologia livre de escala

\begin{tabular}{cccccc}
\hline & & & & & \\
Critério & Similaridade $(\mathbf{A}, \mathbf{B})$ & $\bar{H}$ & $D_{\bar{H}}(\mathbf{A}, \mathbf{B})$ & $\mu_{f u n}(\mathbf{A}, \mathbf{B})$ & $S_{c}$ \\
& & & & & \\
& & & & \\
Esparsa & 0,407 & 0,243 & 0,049 & 0,423 & 0,011 \\
Pred. lim.: [2, 4] & 0,428 & 0,219 & 0,041 & 0,403 & 0,022 \\
Densa & 0,516 & 0,077 & 0,170 & 0,550 & 0,045 \\
Pred. lim.: [2, 3] & 0,440 & 0,155 & 0,097 & 0,389 & 0,049 \\
Densa - 1 & 0,504 & 0,056 & 0,191 & 0,536 & 0,053 \\
Aleatória & 0,486 & 0,063 & 0,185 & 0,505 & 0,055 \\
Hub de entrada & 0,464 & 0,077 & 0,171 & 0,433 & 0,067 \\
Esparsa + 1 & 0,458 & 0,109 & 0,139 & 0,385 & 0,071 \\
Hub de saída & 0,471 & 0,068 & 0,179 & 0,399 & 0,084 \\
Hub de saída, pred. lim.: [2, 4] & 0,473 & 0,044 & 0,203 & 0,375 & 0,100 \\
& & & & & \\
\hline
\end{tabular}

Aqui vale lembrar que as redes artificiais para esta validação foram geradas como tendo um gene com alto grau de saída, sendo preditor de muitos genes. A rede artificial ideal pode ser vista na Figura 4.12, e a dinâmica desta rede pode ser vista na Figura 4.13. A dinâmica da rede tem entropia $H=0,742$, e $\bar{H}=0,248$. Apesar da dinâmica da rede possuir muitas bacias (20), a maior delas tem 1678 estados, enquanto 14 delas tem menos de 10 estados.

Conforme pode ser visto na Tabela 4.7, as redes inferidas com um hub (de entrada ou saída, isto é, um gene que é predito por muitos genes, ou que prediz muitos outros, respectivamente) tem os piores valores para $S_{c}$. Isso pode ser explicado: conforme explicado na Subseção 4.3.2, as redes inferidas tentam adicionar ao menos $90 \%$ dos genes conectados ao gene hub; mas como podemos ver na Figura 4.12, apenas seis genes são preditos pelo gene zero, que tem apenas dois preditores (incluindo o próprio gene zero). Podemos ainda verificar na Figura 4.14 que, exceto pelas redes densas, todas as outras estão abaixo da linha de escolha aleatória, indicando muitos FP e muitos FN. Vamos então analisar algumas redes inferidas.

Vamos começar, novamente, analisando uma rede esparsa, por possuir o menor valor para $S_{c}$. A Figura 4.15 exibe a rede, enquanto a Figura 4.16 exibe sua dinâmica.

A rede da Figura 4.15 tem $\mathrm{TP}=6, \mathrm{TN}=94, \mathrm{FP}=18, \mathrm{FN}=11, \mathrm{FPR}=0,161, \mathrm{TPR}=0,353$, $\mathrm{ACC}=0,775$. A entropia normalizada é $\bar{H}=0,253$, mas a distância da entropia da rede ideal é $D_{\bar{H}}=0,05$, bem próxima da original. Podemos ver ainda que a rede tem TPR $>$ FPR, significando que está acima da linha de escolha aleatória na curva ROC, ou seja, a identificação das regulações foi mais correta, além de mais precisa (coluna ACC da Tabela 4.6 com valor mais alto). Ou seja: apesar da média de TPR e FPR ser menor para redes esparsas do que para redes densas, a rede esparsa com menor média $S_{c}$ tem $\operatorname{Similaridade}(\mathbf{A}, \mathbf{B})$ mais alta que a média da similaridade para redes densas. Veja na Figura 4.17 o espaço ROC para as redes esparsas. Além disso, a Tabela 4.8 exibe os atratores e o tamanho das bacias.

A Figura 4.17 mostra os valores de FPR e TPR para as diversas redes filtradas. O ponto vermelho exibe a rede com menor média $S_{c}$. Apesar de parecer nesta figura que existem mais redes com similaridade alta, e portanto mais próximos da rede ideal, a Figura 4.18 mostra o histograma com as similaridades. Aqui, podemos ver que a quantidade de redes com similaridade próximas do meio do intervalo é bem maior, portanto a média é mais próxima da diagonal ascendente e, portanto, de uma escolha aleatória.

Para verificar a discrepância dos valores das redes inferidas com as desejadas (no caso, uma rede com hub de saída), podemos verificar que a série temporal gerada a partir da rede da Figura 4.12 contém apenas uma transição (exibida na Tabela 4.9), muito curta para uma inferência mais precisa. Mesmo assim, a rede esparsa inferida conseguiu identificar uma boa quantidade de regulações, 


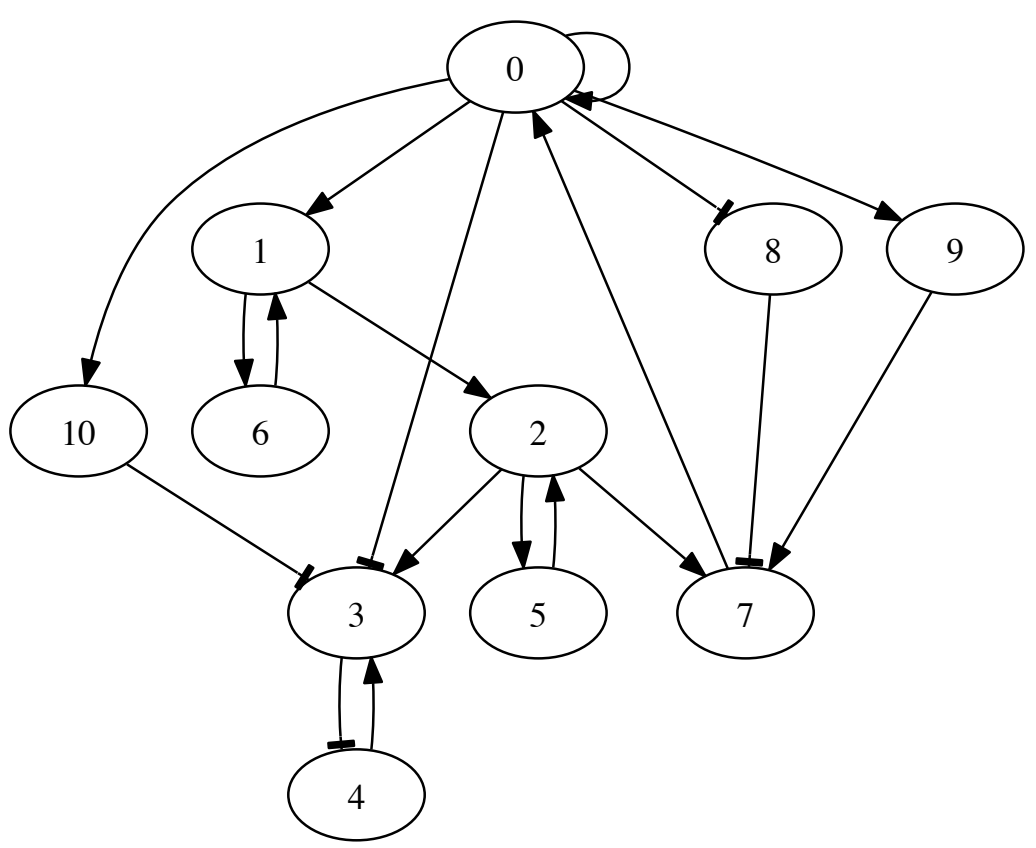

Figura 4.12: Rede artificial direcionada livre de escala, gerada pelo algoritmo da Subseção 4.3.2, usada para validação.

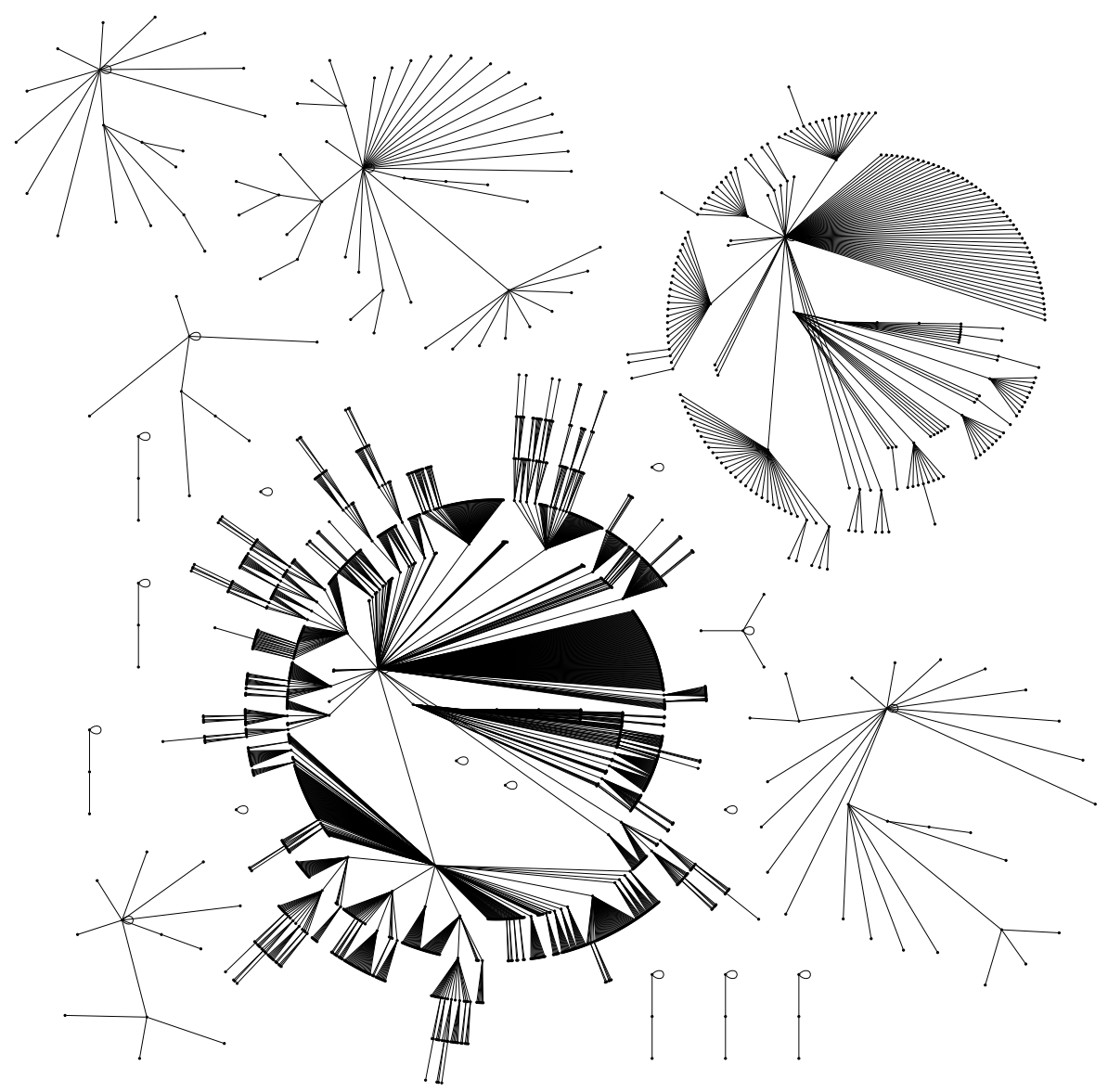

Figura 4.13: Dinâmica da rede direcionada livre de escala artificial da Figura 4.12, gerada para validação. 


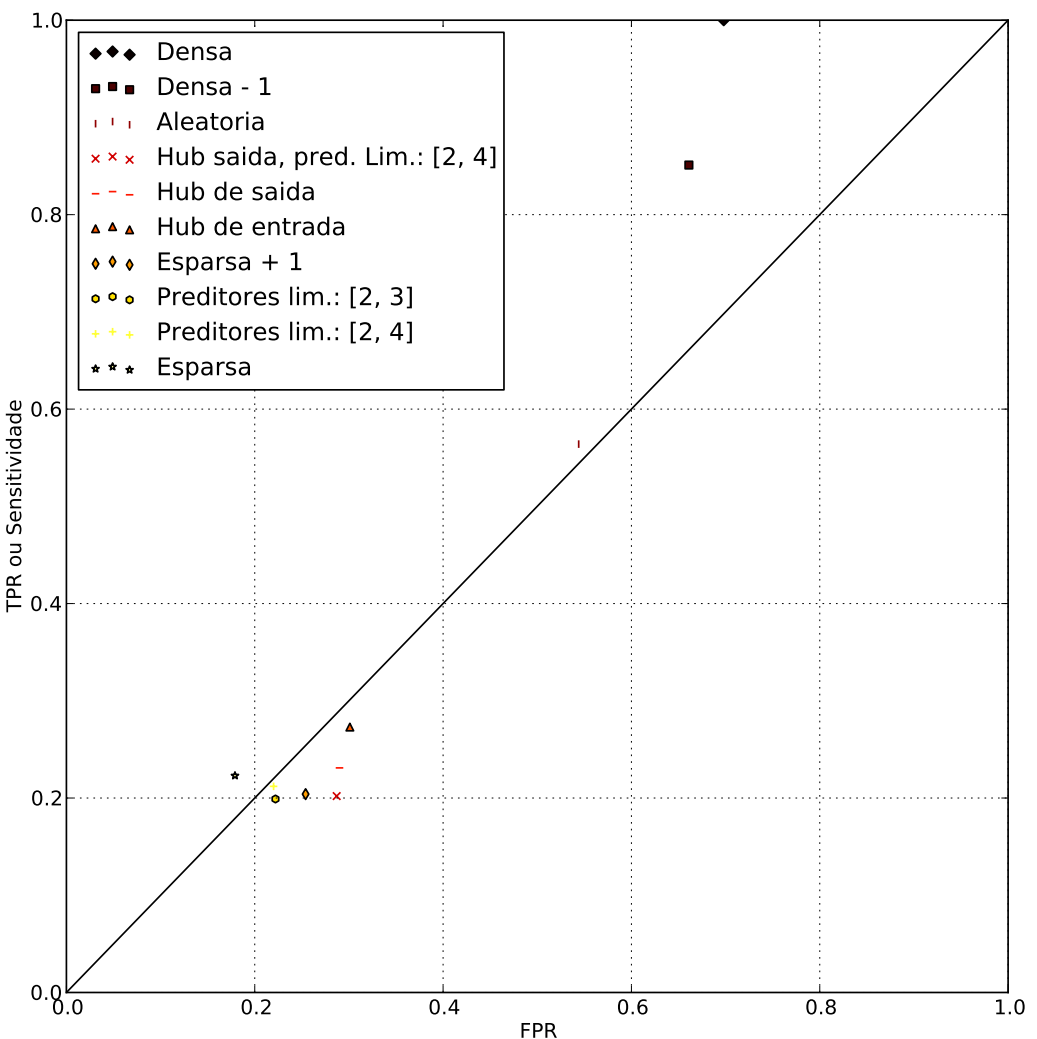

Figura 4.14: Espaço ROC para redes inferidas a partir de dados gerados da rede artificial livre de escala da Figura 4.12. A linha diagonal ascendente representa escolha puramente aleatória, enquanto pontos mais próximos do canto superior esquerdo representam redes inferidas mais próximas da rede ideal. Cada ponto representa a média sobre 50 redes, escolhidas por terem a menor entropia do tamanho das bacias de atração.

Tabela 4.8: Atratores e tamanho das bacias de atração da rede esparsa inferida exibida na Figura 4.15, a partir da rede livre de escala da Figura 4.12

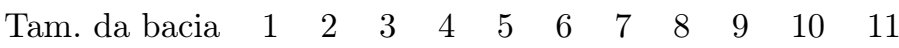

$\begin{array}{cccccccccccc}1691 & 0 & 0 & 0 & 0 & 1 & 0 & 0 & 0 & 1 & 0 & 0 \\ 275 & 0 & 1 & 0 & 0 & 1 & 0 & 0 & 0 & 1 & 0 & 0 \\ 26 & 0 & 0 & 0 & 1 & 0 & 0 & 0 & 0 & 0 & 0 & 0 \\ 18 & 0 & 1 & 0 & 1 & 0 & 0 & 0 & 0 & 0 & 0 & 0 \\ 14 & 0 & 1 & 0 & 1 & 0 & 1 & 0 & 0 & 0 & 0 & 0 \\ 10 & 0 & 0 & 0 & 1 & 0 & 1 & 0 & 0 & 0 & 0 & 0 \\ 7 & 0 & 0 & 0 & 0 & 0 & 0 & 0 & 0 & 1 & 0 & 0 \\ 3 & 0 & 1 & 0 & 0 & 0 & 0 & 0 & 0 & 1 & 0 & 0 \\ 1 & 0 & 0 & 0 & 0 & 0 & 0 & 0 & 0 & 0 & 0 & 0 \\ 1 & 0 & 0 & 0 & 0 & 1 & 0 & 0 & 0 & 0 & 0 & 0 \\ 1 & 0 & 1 & 0 & 0 & 0 & 0 & 0 & 0 & 0 & 0 & 0 \\ 1 & 0 & 1 & 0 & 0 & 1 & 0 & 0 & 0 & 0 & 0 & 0\end{array}$




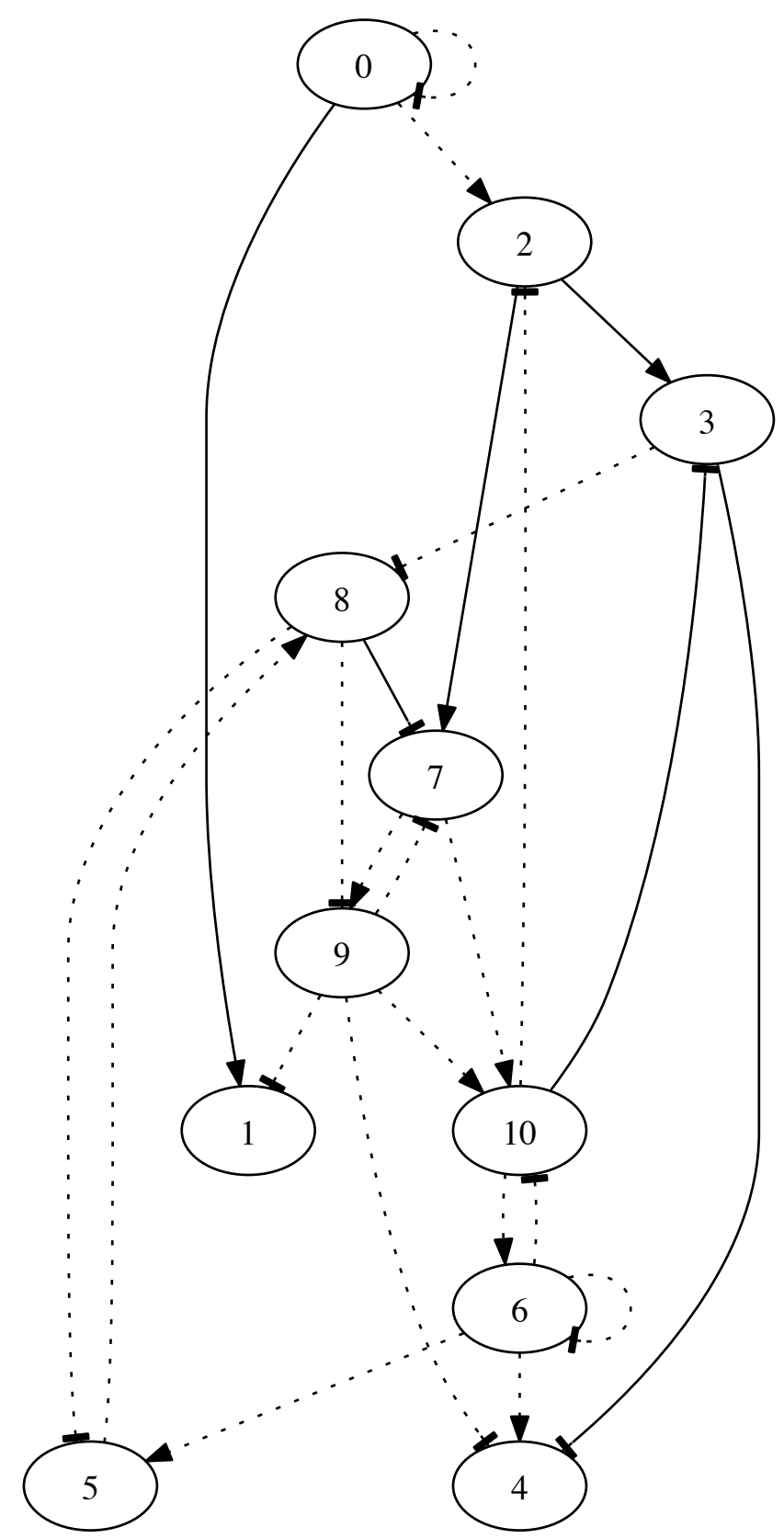

Figura 4.15: Rede esparsa inferida a partir de uma série gerada da rede livre de escala exibida na Figura 4.12. Esta rede foi escolhida para exibição por possuir a menor média $S_{c}$. As linhas cheias representam $T P$, enquanto linhas pontilhadas representam FP (regulações que foram encontradas, mas não existem na rede ideal e que foram incorretamente inferidas). 


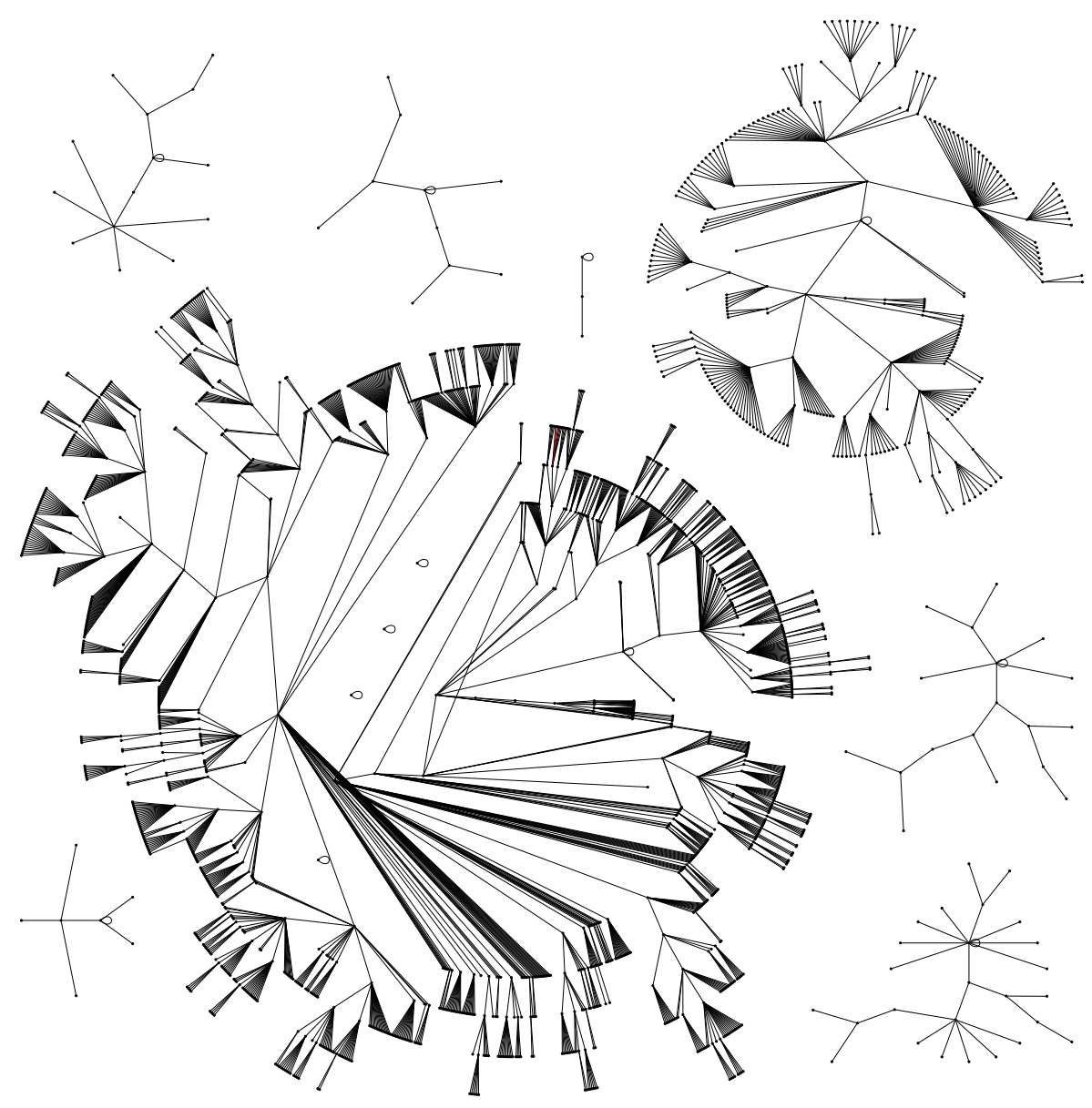

Figura 4.16: Dinâmica da rede esparsa inferida, exibida na Figura 4.15, a partir de uma rede livre de escala direcionada. 


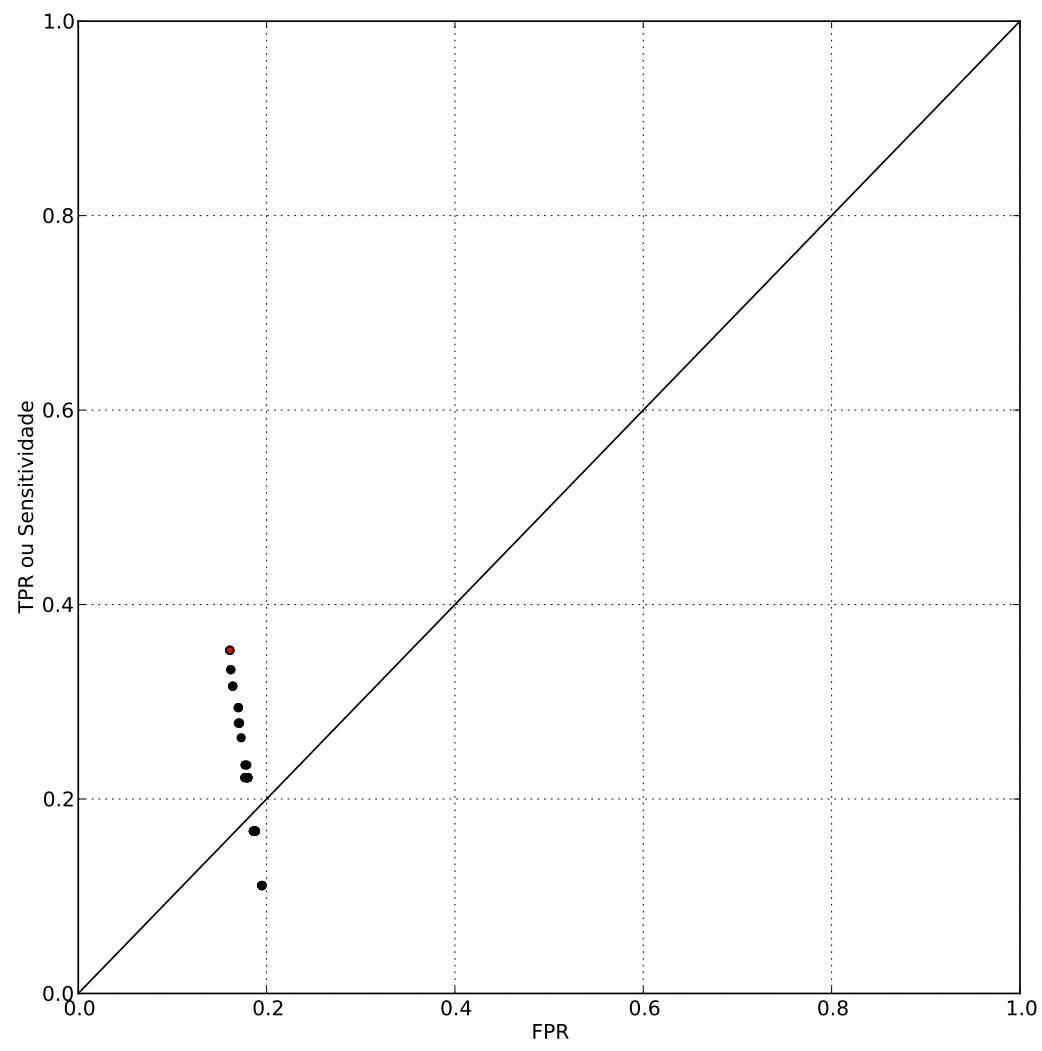

Figura 4.17: Espaço ROC com redes esparsas inferidas com dados da rede livre de escala. O ponto vermelho representa a rede com menor média $S_{c}$, exibida na Figura 4.15.

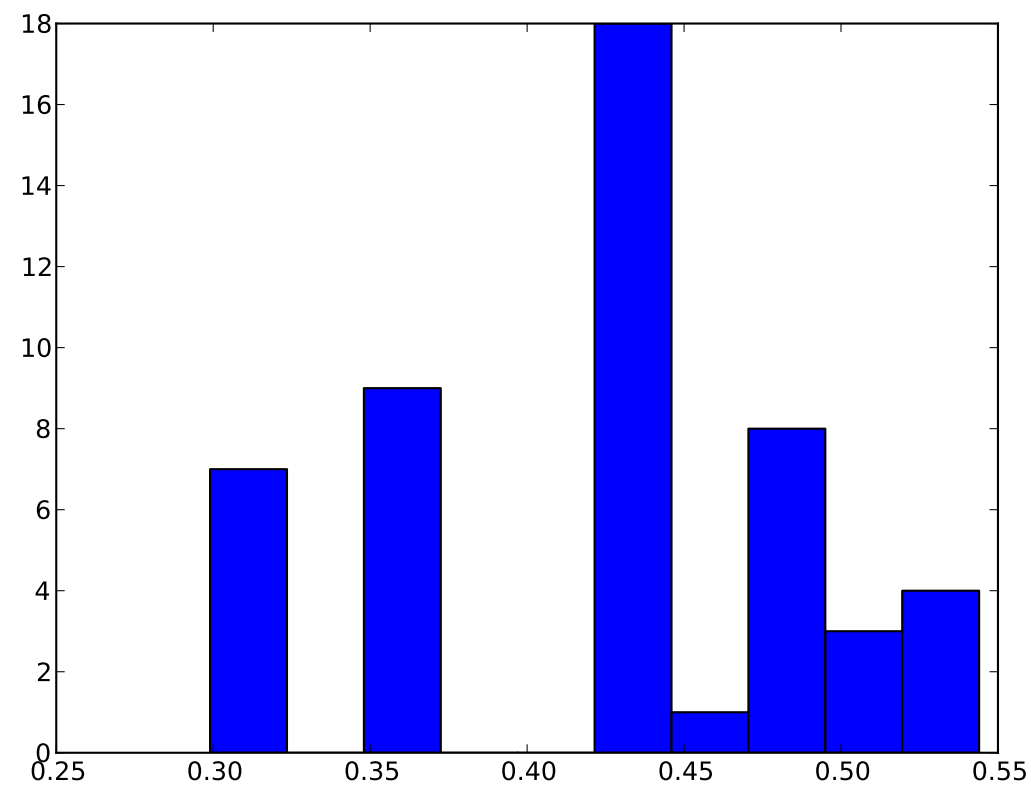

Figura 4.18: Histograma com distribuição da Similaridade $(\mathbf{A}, \mathbf{B})$ das 50 redes esparsas inferidas a partir da série temporal da rede artificial livre de escala. Apesar da Figura 4.17, aparentemente, exibir mais pontos acima da diagonal ascendente, vemos aqui que existe uma grande concentração de pontos mais próximas do meio da distribuição, o que explica o ponto mais próximo da diagonal ascendente. 
mantendo uma dinâmica bastante parecida (tanto a entropia quanto a distância baseada em regras) em relação a a rede original.

Tabela 4.9: Série temporal identificada da rede livre de escala, usada para inferência da rede da Figura 4.15

\begin{tabular}{|c|c|c|c|c|c|c|c|c|c|c|}
\hline Instante & 1 & 2 & 3 & 4 & 5 & 6 & 7 & 8 & 9 & 10 \\
\hline 1 & 1 & 1 & 1 & 0 & 0 & 1 & 1 & 1 & 0 & 1 \\
\hline 2 & 1 & 1 & 1 & 0 & 0 & 1 & 1 & 1 & 0 & 1 \\
\hline
\end{tabular}

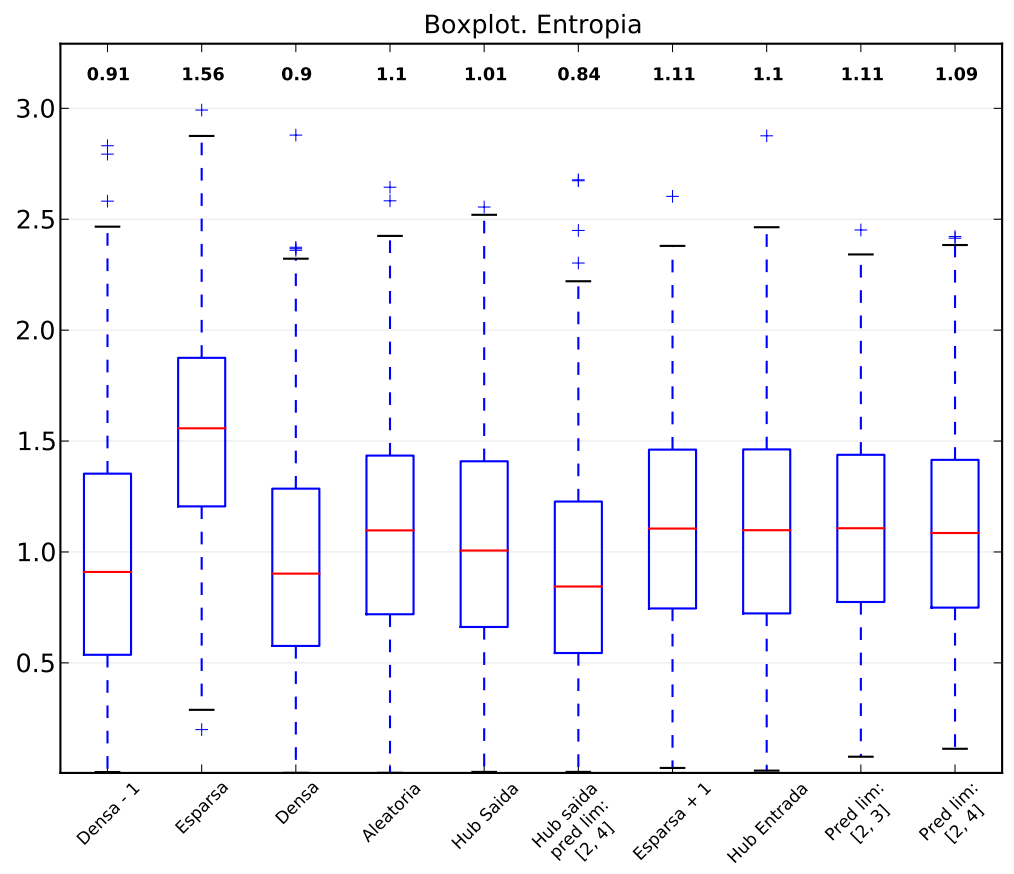

Figura 4.19: Boxplot a partir da entropia das 1000 redes inferidas, para cada critério de construção de redes, a partir de dados de uma rede com topologia livre de escala. O retângulo representa a concentração de $50 \%$ dos dados, e a linha vermelha a mediana (cujo valor está expresso no topo do gráfico). Apesar de possuir muitas redes com entropia mais alta, poucas redes esparsas tem entropia mais baixa, favorecendo encontrar redes mais interessantes. Neste caso, redes densas ou redes com hub de saída e preditores limitados entre dois e quatro têm uma grande quantidade de redes com entropia baixa, dificultando encontrar 50 mais interessantes, já que vimos que a entropia do tamanho das bacias não é a única chave para encontrar redes interessantes.

Podemos ainda estudar a variação do tamanho da maior bacia de atração Figura 4.20. Novamente, os números no topo do gráfico indica a mediana. Conforme comentamos anteriormente, dentre as 1000 simulações, a média do tamanho da maior bacia para redes esparsas é menor. Como vimos, de certo modo isso é uma vantagem já que fica mais fácil filtrar redes melhores. Podemos ver ainda que redes com hub de saída e preditores entre dois e quatro têm as maiores bacias. Conforme podemos ver na Tabela 4.7, a dinâmica dessa rede é justamente a mais distante. Considerando que gostaríamos de redes grandes, isso pode ser um indicativo que a rede artificial gerada não tenha em sua dinâmica uma rede tão grande, mesmo tendo entropia relativamente baixa $(\bar{H}=0,742)$. 


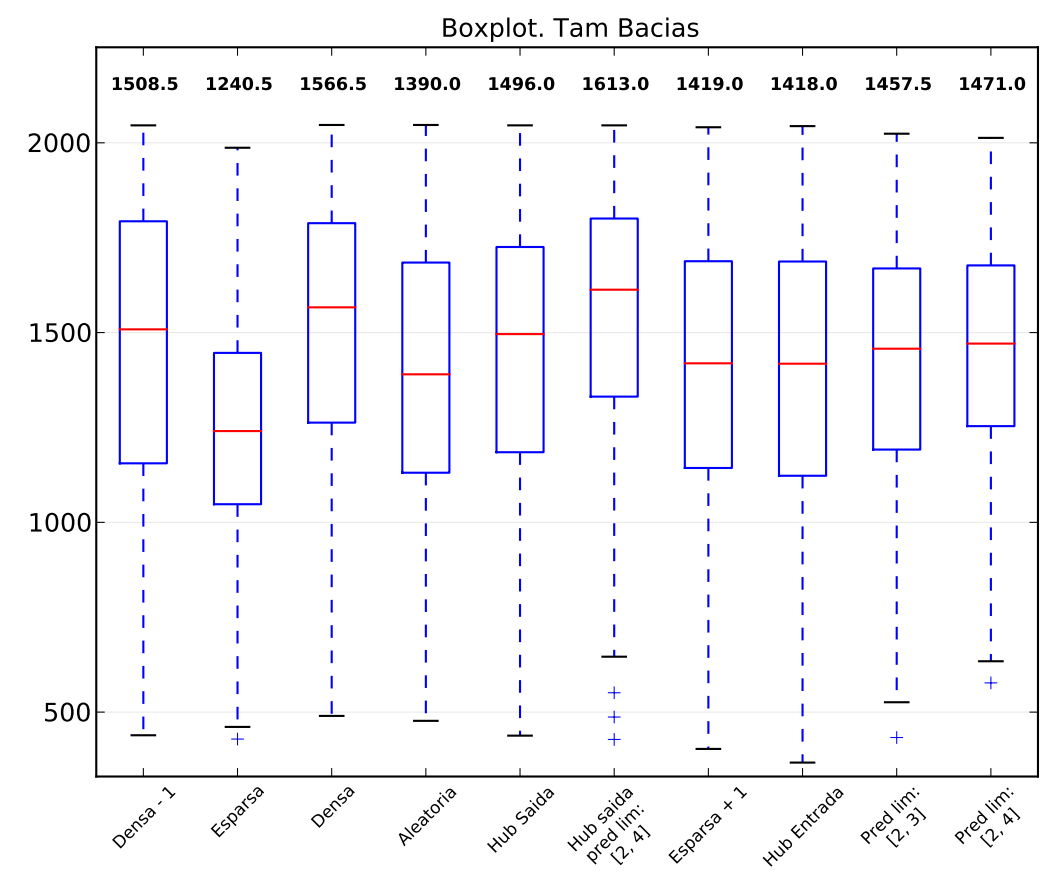

Figura 4.20: Variações do tamanho da maior bacia para 1000 redes inferidas para cada critério de construção de redes. A linha vermelha representa o tamanho mediano. Podemos ver que, em relação a Figura 4.19, os gráficos são praticamente inversos: redes com bacias maiores geram entropias menores.

\subsubsection{Resultados para rede da levedura}

Após a inferência com dados de redes artificiais geradas neste trabalho, executamos o algoritmo para a série temporal da rede artificial simulada da levedura (Saccharomyces cerevisiae). A rede ideal, usada para comparação, pode ser vista na figura Figura 4.21, conforme Li et al. (2004).

Na Tabela 4.10, extraída de Li et al. (2004), a série temporal foi dividida em quatro fases, exibidas na coluna "Fase". São elas: a fase G1, na qual a célula cresce e, sob condições apropriadas, inicia a divisão; a fase S, na qual o DNA é sintetizado e os cromossomos replicados; a fase G2, um "espaço" entre as fases S e M; e a fase M, na qual os cromossomos são separados e a célula é dividida em duas. Os dados foram extraídos de um modelo proposto por Li et al. (2004), e é baseado em uma rede de onze genes $x_{1}, \ldots, x_{11}$, a saber: $C \ln 3, M B F, S B F, C \ln 1, C d h 1, S w i 5, C d c 20, C l b 5, S i c 1, C l b 1$ e $M c m 1$, respectivamente. Além disso, foi introduzido o nó "tam. da célula" como um ponto de entrada para o processo do ciclo celular.

Considerando o modelo proposto, Li et al. (2004) estudou a dinâmica da rede. Ele encontrou sete atratores, exibidos na Tabela 4.11. Nesta tabela, cada linha representa um atrator, e na primeira coluna de cada linha é exibido o tamanho da bacia de atração. Ainda de acordo com Li et al. (2004), o atrator da maior bacia (primeira linha da tabela) é o estado biológico estacionário $G_{1}$.

De posse do tamanho dos atratores da rede da levedura, podemos calcular a entropia da dinâmica, de acordo com a Equação 3.10. De acordo com o tamanho das bacias, temos então que $H=0,543$ e $\bar{H}=0,279$.

Novamente, como primeira analise, vamos verificar os critérios topológicos das redes inferidas, em comparação com a rede ideal proposta por Li et al. (2004). A Tabela 4.12 exibe os dados de interesse.

Podemos ver na Figura 4.22 que, ao contrário de redes artificiais aleatórias, para a rede biológica artificial todos os pontos no espaço ROC estão acima da linha de escolha aleatória, indicando que para dados biológicos, a inferência é muito mais precisa. Podemos ver na Tabela 4.12 que para redes esparsas, temos $67,6 \%$ de similaridade média com $80,4 \%$ de precisão.

Olhando agora a dinâmica, podemos ver na Tabela 4.13 que a entropia das redes esparsas estão bastante próximas da entropia da rede ideal da Figura 4.21, assim como a distância baseada em 


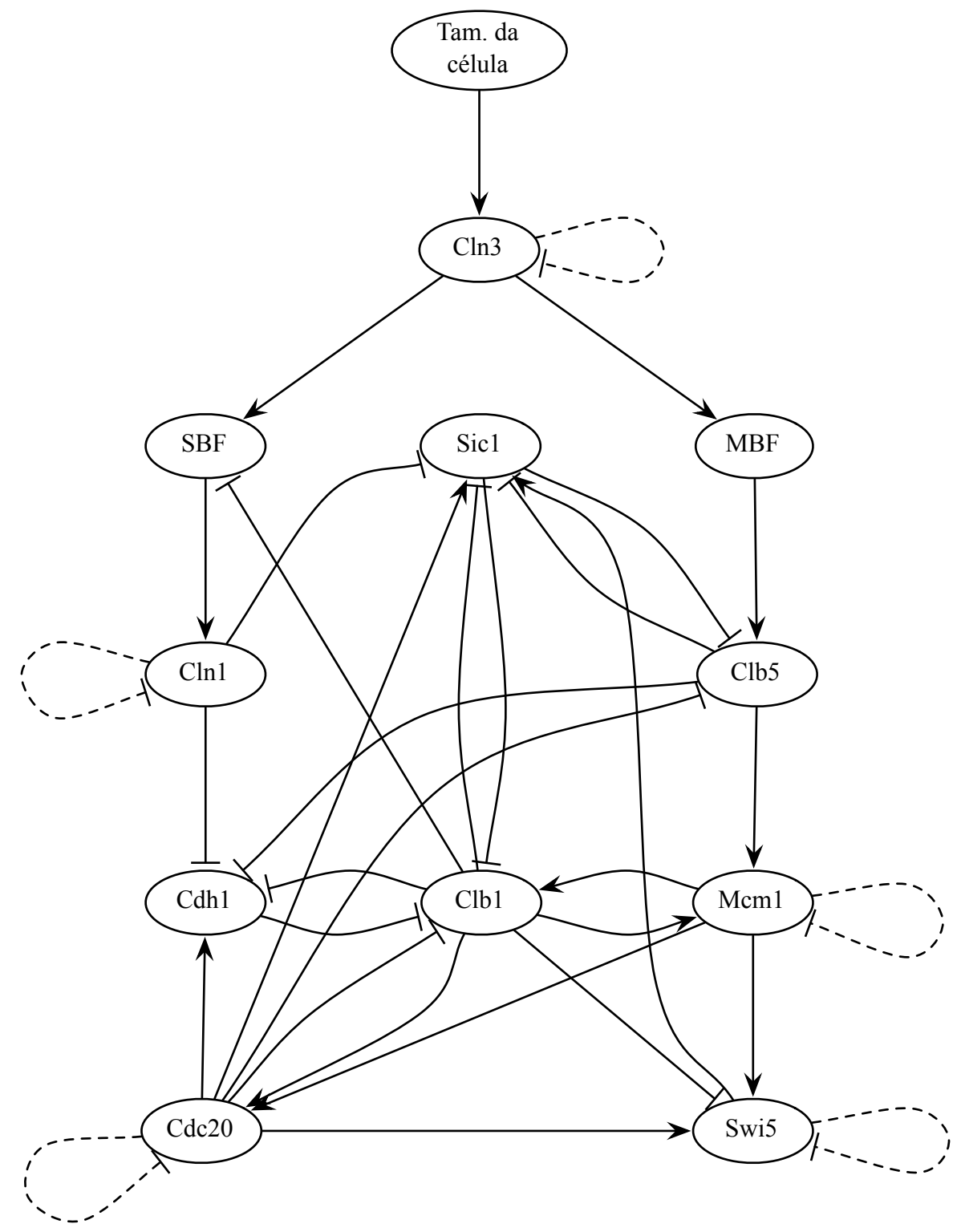

Figura 4.21: Rede para levedura. Representamos com setas $(\rightarrow)$ as ativações, e traços $(\dashv)$ as inibições. Figura adaptada de Li et al. (2004). O nó "tam. da célula" como um ponto de entrada para o processo do ciclo celular. 
Tabela 4.10: Série temporal da levedura

\begin{tabular}{|c|c|c|c|c|c|c|c|c|c|c|c|c|}
\hline $\begin{array}{l}\text { ins- } \\
\text { tante }\end{array}$ & $\mathrm{Cln} 3$ & $\mathrm{MBF}$ & $\mathrm{SBF}$ & $\mathrm{Cln} 1$ & Cdh1 & Swi5 & Cdc20 & Clb5 & Sic1 & Clb1 & Mcm1 & Fase \\
\hline 1 & 1 & 0 & 0 & 0 & 1 & 0 & 0 & 0 & 1 & 0 & 0 & Inicio \\
\hline 2 & 0 & 1 & 1 & 0 & 1 & 0 & 0 & 0 & 1 & 0 & 0 & G1 \\
\hline 3 & 0 & 1 & 1 & 1 & 1 & 0 & 0 & 0 & 1 & 0 & 0 & G1 \\
\hline 4 & 0 & 1 & 1 & 1 & 0 & 0 & 0 & 0 & 0 & 0 & 0 & G1 \\
\hline 5 & 0 & 1 & 1 & 1 & 0 & 0 & 0 & 1 & 0 & 0 & 0 & $\mathrm{~S}$ \\
\hline 6 & 0 & 1 & 1 & 1 & 0 & 0 & 0 & 1 & 0 & 1 & 1 & G2 \\
\hline 7 & 0 & 0 & 0 & 1 & 0 & 0 & 1 & 1 & 0 & 1 & 1 & $\mathrm{M}$ \\
\hline 8 & 0 & 0 & 0 & 0 & 0 & 1 & 1 & 0 & 0 & 1 & 1 & M \\
\hline 9 & 0 & 0 & 0 & 0 & 0 & 1 & 1 & 0 & 1 & 1 & 1 & M \\
\hline 10 & 0 & 0 & 0 & 0 & 0 & 1 & 1 & 0 & 1 & 0 & 1 & M \\
\hline 11 & 0 & 0 & 0 & 0 & 1 & 1 & 1 & 0 & 1 & 0 & 0 & $\mathrm{M}$ \\
\hline 12 & 0 & 0 & 0 & 0 & 1 & 1 & 0 & 0 & 1 & 0 & 0 & G1 \\
\hline 13 & 0 & 0 & 0 & 0 & 1 & 0 & 0 & 0 & 1 & 0 & 0 & $\begin{array}{c}\text { Estacionário } \\
\text { G1 }\end{array}$ \\
\hline
\end{tabular}

Tabela 4.11: Bacias para a rede artificial da levedura

$\begin{array}{llllllllllll}\text { Tam. Da bacia } & \text { Cln } 3 & \text { MBF } & \text { SBF } & \text { Cln } 1 & \text { Cdh1 } & \text { Swi5 } & \text { Cdc20 } & \text { Clb5 } & \text { Sic1 } & \text { Clb1 } & \text { Mcm } 1\end{array}$

\begin{tabular}{ccccccccccccc}
\hline 1.764 & 0 & 0 & 0 & 0 & 1 & 0 & 0 & 0 & 1 & 0 & 0 \\
151 & 0 & 0 & 1 & 1 & 0 & 0 & 0 & 0 & 0 & 0 & 0 \\
109 & 0 & 1 & 0 & 0 & 1 & 0 & 0 & 0 & 1 & 0 & 0 \\
9 & 0 & 0 & 0 & 0 & 0 & 0 & 0 & 0 & 1 & 0 & 0 \\
7 & 0 & 1 & 0 & 0 & 0 & 0 & 0 & 0 & 1 & 0 & 0 \\
7 & 0 & 0 & 0 & 0 & 0 & 0 & 0 & 0 & 0 & 0 & 0 \\
1 & 0 & 0 & 0 & 0 & 1 & 0 & 0 & 0 & 0 & 0 & 0 \\
\hline
\end{tabular}

Tabela 4.12: Dados da topologia para rede inferida com dados da levedura

\begin{tabular}{ccccccccc}
\hline & & & & & & & & \\
Critério & TP & TN & FP & FN & FPR & TPR & Similaridade $(\mathbf{A}, \mathbf{B})$ & ACC \\
& & & & & & & & \\
& & & & & & & & \\
Esparsa & 16,860 & 81,840 & 7,140 & 17,000 & 0,080 & 0,498 & 0,676 & 0,804 \\
Preditores lim.: [2, 3] & 16,240 & 78,860 & 11,800 & 17,500 & 0,130 & 0,481 & 0,646 & 0,765 \\
Preditores lim.: [2, 4] & 16,620 & 78,300 & 12,760 & 17,080 & 0,140 & 0,493 & 0,650 & 0,761 \\
Hub de entrada & 17,900 & 72,500 & 22,440 & 14,240 & 0,236 & 0,557 & 0,651 & 0,712 \\
Hub saída, pred. lim.: [2, & 17,860 & 75,140 & 18,760 & 15,860 & 0,200 & 0,530 & 0,650 & 0,729 \\
4] & & & & & & & & \\
Esparsa + 1 & 16,600 & 75,340 & 16,940 & 16,540 & 0,183 & 0,501 & 0,639 & 0,733 \\
Hub de saída & 17,800 & 73,100 & 22,340 & 14,880 & 0,234 & 0,544 & 0,645 & 0,710 \\
Aleatoria & 22,800 & 53,560 & 60,520 & 6,700 & 0,530 & 0,774 & 0,603 & 0,532 \\
Densa & 28,080 & 36,300 & 88,920 & 0,640 & 0,710 & 0,978 & 0,532 & 0,418 \\
Densa - 1 & 26,580 & 40,540 & 82,100 & 2,380 & 0,669 & 0,918 & 0,551 & 0,443
\end{tabular}




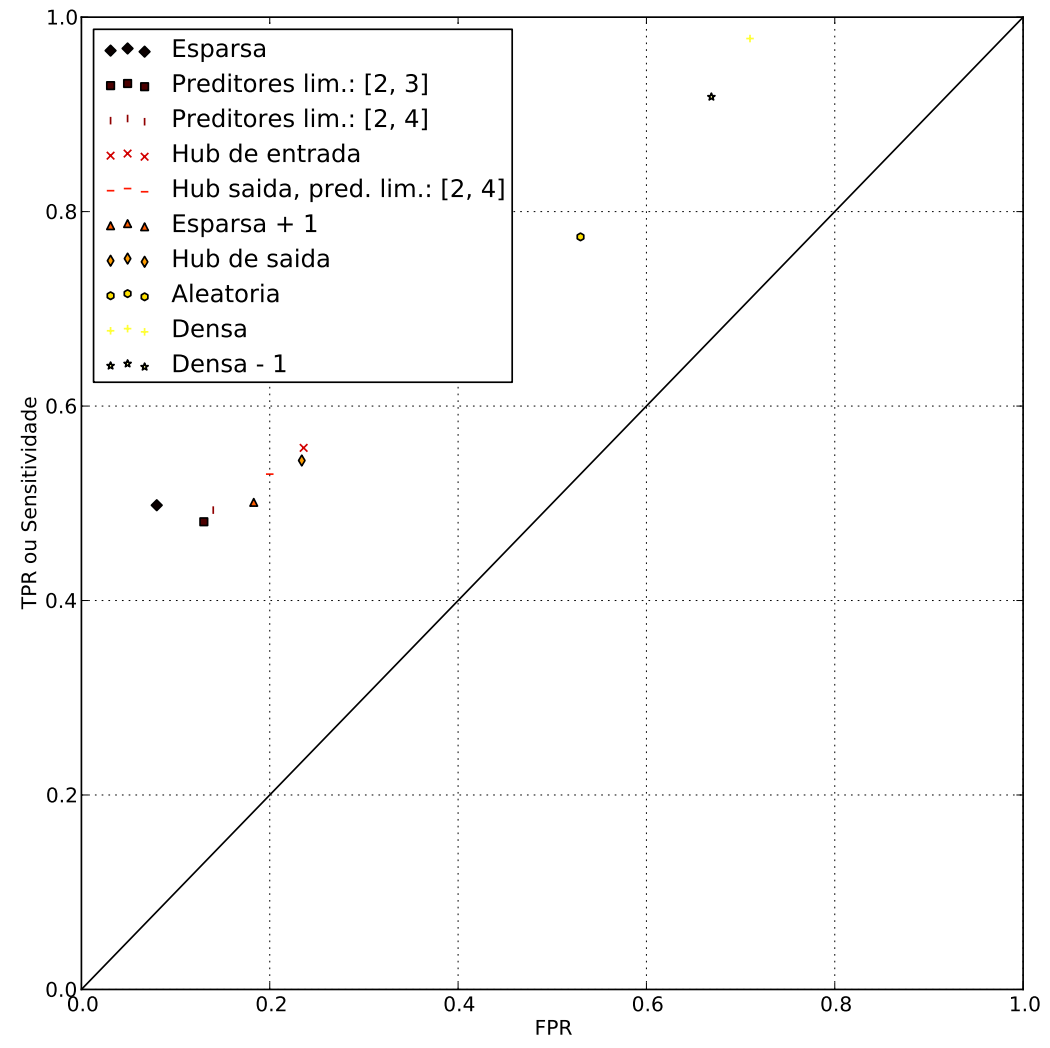

Figura 4.22: Espaço ROC para médias encontradas para cada critério de seleção de 50 redes inferidas com dados da Série temporal da levedura (Tabela 4.10). 
regras

Tabela 4.13: Dados da dinâmica das redes inferidas da levedura

\begin{tabular}{cccccc}
\hline Critério & $\bar{H}$ & $D_{\bar{H}}(\mathbf{A}, \mathbf{B})$ & Similaridade $(\mathbf{A}, \mathbf{B})$ & $\mu_{\text {fun }}(\mathbf{A}, \mathbf{B})$ & $S_{c}$ \\
& & & & & \\
Esparsa & 0,249 & 0,052 & 0,676 & 0,220 & $-0,135$ \\
Preditores lim.: [2, 3] & 0,124 & 0,155 & 0,646 & 0,252 & $-0,080$ \\
Preditores lim.: [2, 4] & 0,096 & 0,184 & 0,650 & 0,242 & $-0,075$ \\
Hub de entrada & 0,132 & 0,147 & 0,651 & 0,291 & $-0,071$ \\
Hub saída, pred. lim.: [2, 4] & 0,101 & 0,179 & 0,650 & 0,278 & $-0,065$ \\
Esparsa + 1 & 0,098 & 0,181 & 0,639 & 0,295 & $-0,054$ \\
Hub de saída & 0,051 & 0,228 & 0,645 & 0,288 & $-0,043$ \\
Aleatoria & 0,058 & 0,221 & 0,603 & 0,335 & $-0,016$ \\
Densa & 0,083 & 0,197 & 0,532 & 0,338 & 0,001 \\
Densa - 1 & 0,049 & 0,230 & 0,551 & 0,335 & 0,005 \\
& & & & & \\
\hline
\end{tabular}

Sabendo que as redes esparsas tem maior similaridade, menor distância baseada em regras e menor distância da entropia real, vamos então analisar uma rede esparsa inferida. Veja a Figura 4.23. A rede foi escolhida, novamente, por possuir a menor distância $S_{c}$.

Para esta rede inferida, temos uma dinâmica com nove bacias, a maior delas com 1868 estados. Assim como na rede de Li et al. (2004), a maior destas bacias é o estado G1 estacionário. Um ponto curioso de notar aqui, é que apesar das redes artificiais da Subseção 4.4.1 e da Subseção 4.4.2 terem sido geradas de forma independente, seguindo os algoritmos descritos na Subseção 4.3.1 e na Subseção 4.3.2, os atratores das maiores bacias das três redes são idênticos, se considerarmos equivalência entre os genes e as redes selecionadas. Assim, o atrator das bacias das redes inferidas nas sessões anteriores podem ser considerados como equivalente ao G1 estacionário.

Tabela 4.14: Bacias para rede da levedura Inferida: Esparsa

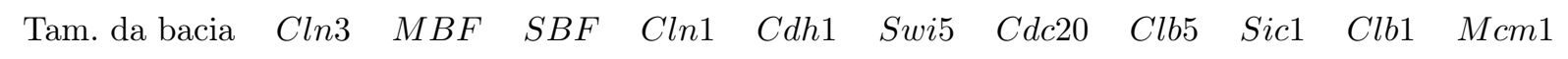

\begin{tabular}{cccccccccccc}
\hline & & & & & & & & & & & \\
1827 & 0 & 0 & 0 & 0 & 1 & 0 & 0 & 0 & 1 & 0 & 0 \\
75 & 0 & 1 & 0 & 0 & 1 & 0 & 0 & 0 & 1 & 0 & 0 \\
72 & 0 & 0 & 0 & 1 & 0 & 1 & 0 & 0 & 0 & 0 & 0 \\
32 & 0 & 1 & 0 & 1 & 0 & 1 & 0 & 0 & 0 & 0 & 0 \\
16 & 0 & 0 & 0 & 1 & 0 & 0 & 0 & 0 & 0 & 0 & 0 \\
16 & 0 & 1 & 0 & 1 & 0 & 0 & 0 & 0 & 0 & 0 & 0 \\
3 & 0 & 0 & 0 & 0 & 1 & 0 & 0 & 0 & 0 & 0 & 0 \\
3 & 0 & 1 & 0 & 0 & 1 & 0 & 0 & 0 & 0 & 0 & 0 \\
1 & 0 & 0 & 0 & 0 & 0 & 0 & 0 & 0 & 0 & 0 & 0 \\
1 & 0 & 0 & 0 & 0 & 0 & 0 & 0 & 0 & 1 & 0 & 0 \\
1 & 0 & 1 & 0 & 0 & 0 & 0 & 0 & 0 & 0 & 0 & 0 \\
1 & 0 & 1 & 0 & 0 & 0 & 0 & 0 & 0 & 1 & 0 & 0 \\
\hline
\end{tabular}

Podemos ainda ter o gráfico de espaço ROC das redes esparsas, exibido na Figura 4.25. O ponto vermelho novamente indica a rede inferida exibida neste trabalho, exibida na Figura 4.23. Podemos ver que ela não é, ao contrário das redes exibidas na Subseção 4.4.1 e na Subseção 4.4.2, a que tem a melhor similaridade topológica, então ela deve estar mais próxima da dinâmica da rede ideal. 


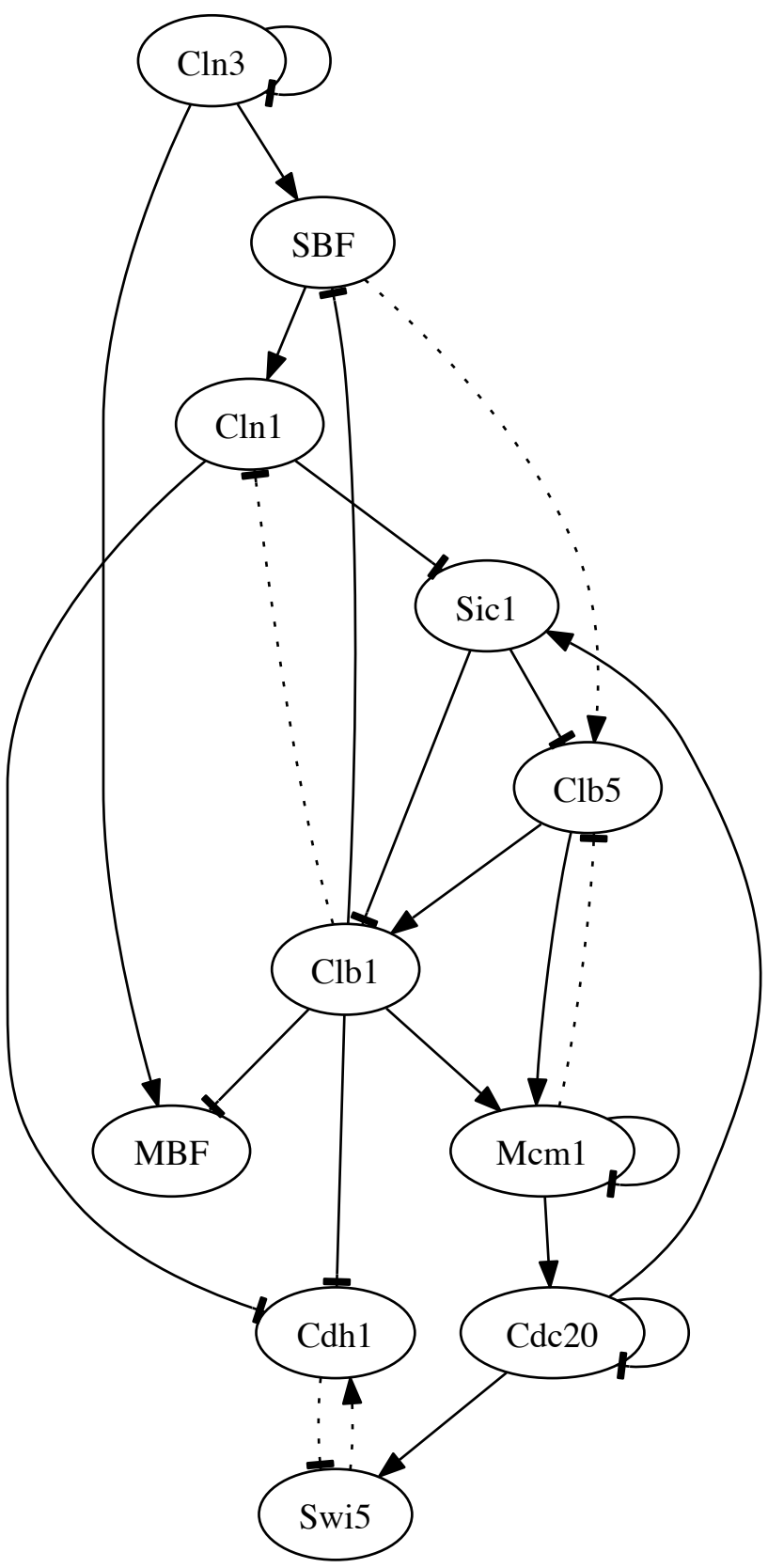

Figura 4.23: Rede inferida a partir da Série temporal da levedura com menor média $S_{c}$ (a série usada para inferência é exibida na Tabela 4.10). Linhas cheias representam TP, linhas pontilhadas representam FP. Setas $(\rightarrow)$ representam ativação, enquanto traços $(-1)$ representam inibições. 


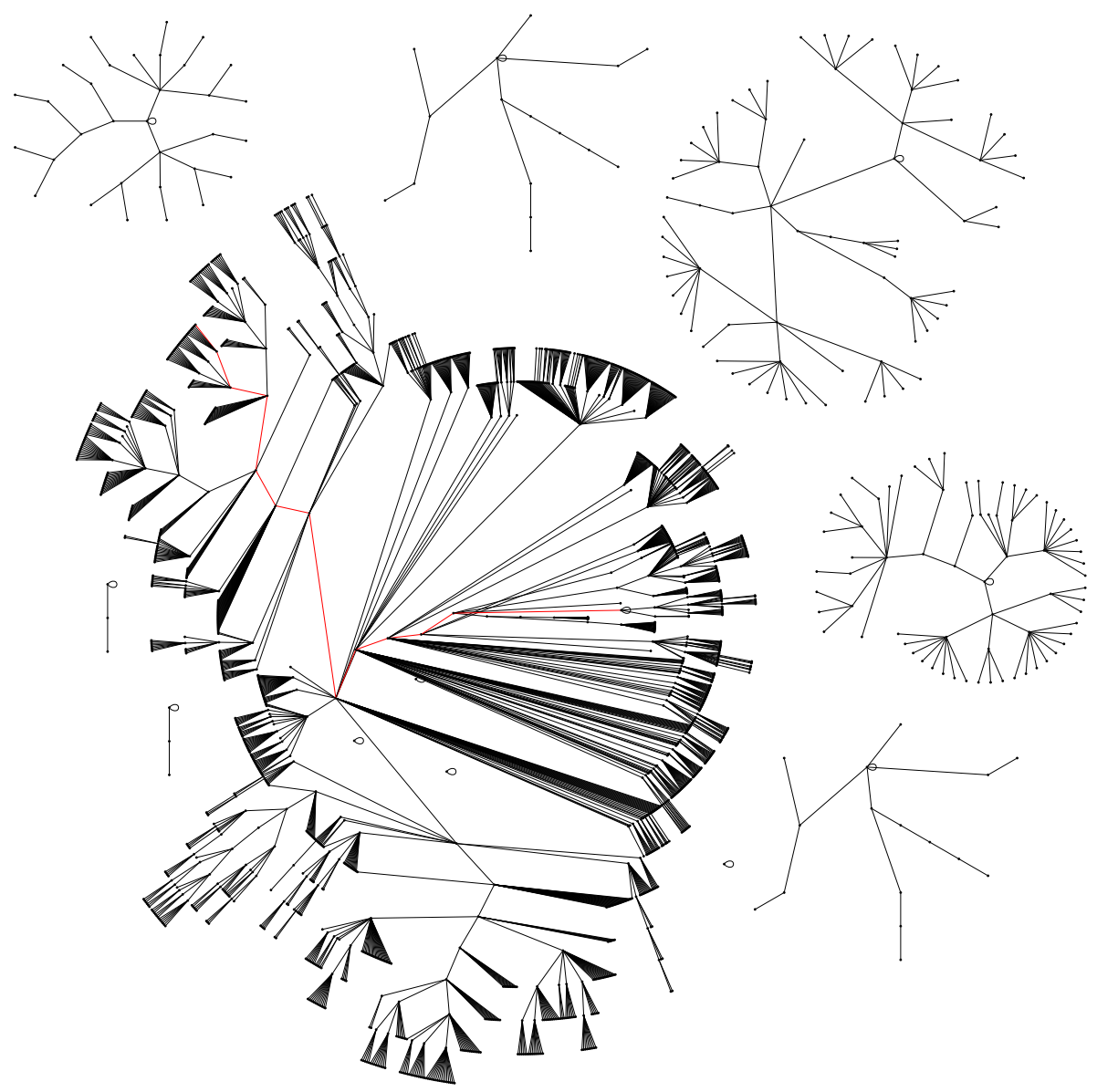

Figura 4.24: Dinâmica da rede esparsa com menor média $S_{c}$, exibida na Figura 4.23, inferida a partir da Série temporal da levedura (a série usada como entrada do algoritmo é exibida na Tabela 4.10). A série é representada na figura por linhas vermelhas. 


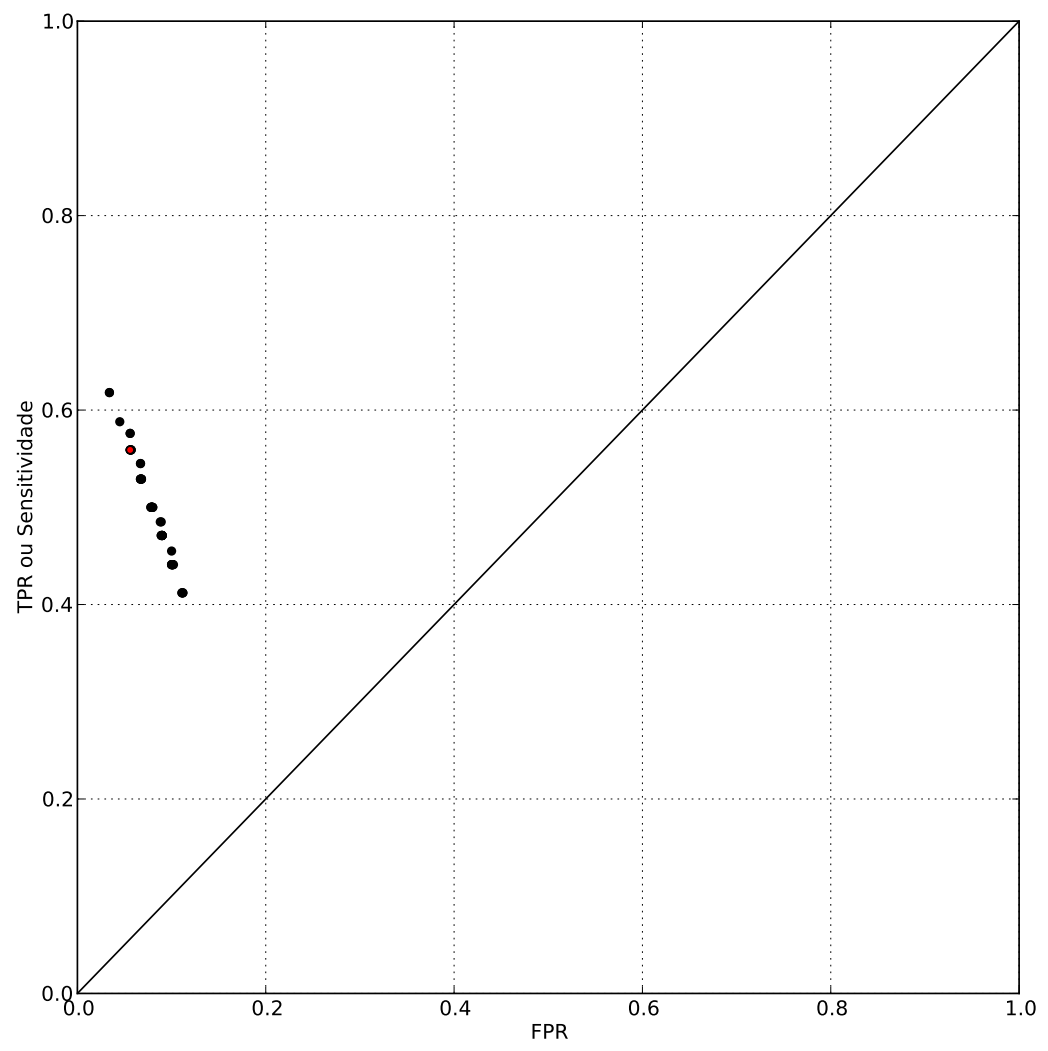

Figura 4.25: Espaço ROC das 50 redes inferidas usando critério de redes esparsas, para dados da rede artificial da levedura. O ponto vermelho representa a rede com menor média $S_{c}$, exibida na Figura 4.23. 


\section{Capítulo 5}

\section{Considerações finais}

Experimentos práticos em laboratório podem gerar grandes quantidades de dados a serem explorados computacionalmente. E uma das possibilidades de exploração computacional desses dados é o processo de inferência de redes gênicas, isto é, determinar como os genes se relacionam, a fim de tentar entender melhor através destes relacionamentos como ocorrem as atividades celulares, como divisão e diferenciação celular. Dentre os dados gerados experimentalmente, estivemos, neste trabalho, interessados na série temporal de um grupo de genes, a fim de usá-los para o processo de inferência. Os dados biológicos usados foram obtidos através de técnicas de microarray.

Por ser um problema mal posto, ainda não sabemos exatamente qual a pergunta exata a fazer a fim de encontrar uma "função", na qual se apliquem os dados experimentais (no nosso caso, a série temporal) a fim de obtermos uma resposta precisa de como os genes se comunicam dentro da célula. Assim, o que existem são modelos aproximados, levando em consideração comportamentos celulares e crenças biológicas. É necessário então o uso de técnicas e ferramentas de diversas áreas, como Biologia, Física e Ciências da Computação.

Usamos neste trabalho o modelo de Redes Booleanas, mais especificamente usando Redes Booleanas Limiarizadas. O modelo foi proposto por Li et al. (2004), extendido por Zhang et al. (2006), a fim de incluir estocasticidade e mais recentemente por Higa et al. (2012), que propôs uma extensão baseada em Redes Booleanas Probabilísticas sensíveis ao contexto e uma baseada em Cadeias de Markov Não Homogeneas. Usamos ainda o Problema de Satisfação de Restrições, ou CSP, para impor restrições sobre o comportamento observado do conjunto de genes, a fim de encontrar conjuntos de redes consistentes com os dados de entrada. Construímos assim, partir do CSP e usando Programação de Restrições, um solver, que foi usado para encontrar redes consistentes com a série temporal usada como entrada. Este solver foi usado para inferir redes consistentes com séries temporais de entrada, e com isso publicamos o trabalho Higa et al. (2011). O solver criado durante esse trabalho foi usado como base para outras ferramentas propostas por Higa et al. (2012).

Estudamos ainda o comportamento dinâmico das redes a partir de diversos modelos da topologia das redes, usando de suposições de relacionamento entre as redes. Estudamos assim o comportamento dinâmico considerando diversos tipos de topologia, dentre elas modelos clássicos de redes aleatórias, e redes baseadas em modelos de redes complexas, analisando as redes consistentes encontradas pelo solver de acordo com topologias de nosso interesse. As experiências foram feitas usando dados de uma rede artificial biológica conhecida, modelada a partir do ciclo celular da levedura (Sacchacomyces cerevisiae) e de duas redes artificiais geradas para nossos experimentos usando topologias conhecidas de redes.

Como o problema de inferência é mal posto, nosso algoritmo não se propõe a identificar apenas uma rede, mas um conjunto de redes consistentes com dados de entrada. O conjunto de redes é identificado por um parâmetro relacionado puramente com o comportamento dinâmico da rede: a entropia do tamanho das bacias de atração da rede, simulada após a identificação.

Em conversas particulares com Higa, percebemos que a melhoria de performance é bastante significativa em relação ao trabalho de Higa et al. (2010): para simular 1000 redes para todos os critérios, nossa ferramenta demorava em média três minutos, sendo feito posterior a isso e a parte 
mais demorada o processamento dos dados gerados para geração dos gráficos e analises, pois milhares de arquivos são gerados após o processamento.

Apesar de usar um parâmetro puramente dinâmico, verificamos após a inferência que boa parte da topologia da rede original é identificada. Partindo de dados biológicos, a inferência é ainda mais precisa, chegando a identificar a topologia em média com 67,6\% de similaridade com a rede original, garantindo 80,4\% de precisão, mesmo que o algoritmo de inferência não trate a topologia. Pudemos ver também que com dados biológicos, as redes são esparsas, isto é, existem poucos genes reguladores para cada gene. Além disso, vimos que mesmo com dados puramente artificiais, mesmo com a série temporal usada como entrada tendo apenas uma transição, nosso algoritmo identificou redes com dinâmica bastante próxima da rede original e aproximadamente $50 \%$ de acerto na identificação das regulações.

Para redes artificiais geradas para nossos experimentos, as melhores redes inferidas em relação à topologia eram densas, mesmo que tenhamos tentado gerar redes menos densas. Isso talvez tenha a ver com o fato de que não é possível garantir um comportamento biológico a partir de uma rede puramente artificial (ainda que tentando garantir alguma semelhança topológica através dos algoritmos de geração das redes). Assim, é claro que redes densas, por incluírem muito mais regulações, acabam acertando mais a quantidade de TP e TN, mas erram muito em adicionar as redes inferidas muitos FP e com isso, poucos FN. Além disso, como vimos nesse trabalho, redes densas tem mais facilidade de gerar bacias grandes, diminuindo a entropia, aproximando-se mais das redes artificiais (que garantiam bacias relativamente grandes, mas não necessariamente com a enorme maioria dos estados). O problema é que filtrar redes mais significativas nesse caso se torna mais difícil. Apesar de não garantir uma similaridade topológica muito satisfatória, se desconsiderarmos a topologia (que, vale lembrar, não foi usado para inferência), as redes com menos regulações se tornam então mais interessantes, com uma dinâmica mais próxima da dinâmica da rede ideal. Vale lembrar que mesmo não considerando a topologia como parte da inferência, aproximadamente entre $45 \%$ e $50 \%$ das regulações foram recuperadas corretamente em todos os casos.

\subsection{Trabalhos futuros}

Nossos estudos mostraram que encontramos, em média, por volta de $50 \%$ das regulações em uma rede inferida, mesmo considerando para inferência apenas um parâmetro do comportamento dinâmico. Usamos ainda uma implementação do simulador de redes booleanas usando CUDA, que demonstra ter excelente performance. Como o solver foi implementado em $\mathrm{C}++$, poderíamos integra-lo com o simulador, ou usando alguma outra técnica para uso de GPGPU, sendo então possível filtrar mais rapidamente um número maior de redes, talvez encontrando redes melhores (por termos explorado uma parte pequena do espaço de buscas).

Um outro fator importante passível de extensão é aumentar o número de genes simulados. Isso pode ser feito otimizando a paralelização do processamento da dinâmica das redes, ou transformando em um sistema distribuído de simulação.

Vimos que, ao localizar uma trajetória dentro da dinâmica para geração da série temporal, durante os processos de validação, usando distancia Hamming igual a um entre o estado inicial da trajetória e o estado final (pertencente ao atrator), pode facilmente gerar séries muito curtas, prejudicando a inferência. Um ponto seria então tentar gerar séries maiores, possivelmente com distância Hamming igual a dois, ou sorteando aleatoriamente algum estado da maior bacia.

Outro ponto que pode gerar mais algumas analises e resultados possivelmente melhores é na adição de pesos para os valores de $\mu_{\text {fun }}(\mathbf{A}, \mathbf{B})$, Similaridade $(\mathbf{A}, \mathbf{B})$ e $D_{\bar{H}}(\mathbf{A}, \mathbf{B})$. Vimos neste trabalho que individualmente eles podem interferir nos resultados, melhorando ou prejudicando os mesmos. Por exemplo, poderíamos dar um peso maior a similaridade topológica, talvez encontrando nas redes inferidas uma rede possivelmente melhor.

Vimos também que a inferência da topologia das redes artificiais geradas não foi tão boa quando da rede biológica. Isso pode ser devido a alguma restrição desconhecida da dinâmica biológica. Por exemplo, estaria a entropia do tamanho das bacias dentro de uma certa faixa de valores? Ou estaria 
ela apenas abaixo de um valor mínimo? O mesmo ocorre na construção da rede inferida para o critério de redes com hub de saída, que tentam colocar o gene hub regulando $90 \%$ dos outros genes. Esse valor foi parametrizado, mas talvez tenha sido um valor muito alto, e para um valor mais baixo, digamos 75\%, talvez ela tivesse inferido com mais precisão a rede livre de escala na Subseção 4.4.2.

Nesse trabalho estudamos redes limiarizadas, mas tratamos de um valor especifico, $\tau=0$. Não é lógico forçar tal valor, afinal as redes reais não são determinísticas, apesar dessa simplificação ter sido útil para o estudo. Assim, outra possibilidade de analise seria com a Equação 2.1 limitada, quem sabe, limitado $0 \leq \tau \leq 1$.

Outro ponto importante para um trabalho futuro é a comparação de nossos resultados com trabalhos e técnicas anteriores. Além da excelente performance na simulação da dinâmica devida à tecnologia CUDA, temos também a excelente performance da biblioteca Gecode. Mas além disso, é importante comparar os resultados da qualidade da inferência em relação à similaridade em relação à rede ideal.

Por último, apresentamos neste trabalho dados de precisão de inferência, mas estes dados não foram comparados com outras técnicas. Um trabalho importante, portanto, seria a comparação e verificação se nosso algoritmo é mais ou menos preciso em relação a outros algoritmos. 


\section{Capítulo 6}

\section{Trabalhos publicados}

Usando partes deste trabalho, Higa (2012) estendeu e aplicou na técnica de crescimento de sementes, a fim de restringir o conjunto de genes em subconjuntos mais significativos, através do uso de CSP. O algoritmo foi usado também para inferir redes consistentes com dados de entrada por Higa et al. (2011), considerando apenas redes com número de preditores limitado entre dois e três, e para redes com um hub de saída e número de preditores limitados entre dois e três.

- "Constraint-based analysis of gene interactions using restricted Boolean networks and time-series data" Carlos H. A. Higa, Vitor H. P. Louzada, Tales P. Andrade e Ronaldo F. Hashimoto. BMC Proceedings 5(Suppl 2):S5, 2011.

- "Growing seed genes from time series data and thresholded Boolean networks with perturbation" Carlos H. A. Higa, Tales P. Andrade e Ronaldo F. Hashimoto. (submetido). 
TRABALHOS PUBLICADOS 


\section{Referências Bibliográficas}

Albert e Barabási(2000) R Albert e A Barabási. Dynamics of complex systems: Scaling laws for the period of boolean networks. Physical review letters. URL http://link.aps.org/doi/10.1103/ PhysRevLett.84.5660. Citado na pág. 27

Alberts et al.(2007) B. Alberts, A. Johnson, J. Lewis, M. Raff, K. Roberts e P. Walter. Molecular biology of the cell. Garland Science,. Citado na pág. 6

Barabasi e Albert(1999) AL Barabasi e R Albert. Emergence of scaling in random networks. Science, 286(5439):509. Citado na pág. 27

Bollobás et al.(2003) B Bollobás, C Borgs, J Chayes e O Riordan. Directed scale-free graphs. Em Proceedings of the fourteenth annual ACM-SIAM symposium on Discrete algorithms. Citado na pág. 34

Boltzmann(1877) L. Boltzmann. Über die natur der gasmoleküle. Annalen der Physik, 236(1): 175-176. Citado na pág. 28

Boltzmann(1974) L. Boltzmann. Theoretical physics and philosophical problems: selected writings, volume 5. Springer. Citado na pág. 28

Chen et al.(2002) Y. Chen, V. Kamat, E.R. Dougherty, M.L. Bittner, P.S. Meltzer e J.M. Trent. Ratio statistics of gene expression levels and applications to microarray data analysis. Bioinformatics, 18(9):1207-1215. Citado na pág. 6

Clausius(1850) R. Clausius. Ueber die bewegende kraft der wärme und die gesetze, welche sich daraus für die wärmelehre selbst ableiten lassen. Annalen der Physik, 155(3):368-397. Citado na pág. 28

Clausius(1867) R. Clausius. The mechanical theory of heat: with its applications to the steamengine and to the physical properties of bodies. J. van Voorst. Citado na pág. 28

Datta e Dougherty(2007) A. Datta e E.R. Dougherty. Introduction to genomic signal processing with control. CRC. Citado na pág. 6

D'haeseleer et al.(1999) P. D'haeseleer, S. Liang e R. Somogyi. Gene expression data analysis and modeling. Em Pacific Symposium on Biocomputing, volume 99. Citado na pág. 2

Dougherty(2007) E.R. Dougherty. Validation of inference procedures for gene regulatory networks. Current Genomics, 8(6):351. Citado na pág. 36, 38

Duggan et al.(1999) DJ Duggan, M Bittner, Y Chen, P Meltzer e JM Trent. Expression profiling using cDNA microarrays. Nature Genetics, 21(1 Suppl):10-14. Citado na pág. 1

Erdôs e Rényi(1959) P Erdôs e A Rényi. On random graphs I. Publ. Math. Debrecen, 6:290-297. Citado na pág. 33 
Ferreira(2010 - Trabalho em andamento) William Lira Ferreira. Análise da dinâmica de redes de regulação gênica utilizando gpus: Uma ferramenta para auxílio no problema de inferência de redes booleanas. Dissertação de Mestrado, Instituto de Matemática e Estatística - Universidade de São Paulo. Citado na pág. 32

Flach(2003) P.A. Flach. The geometry of ROC space: understanding machine learning metrics through ROC isometrics. MACHINE LEARNING-INTERNATIONAL WORKSHOP THEN CONFERENCE-, 20(1):194. Citado na pág. 36, 37

Friedman et al.(2000) N Friedman, M Linial, I Nachman e D Pe'er. Using bayesian networks to analyze expression data. Journal of computational biology, 7(3-4):601-620. Citado na pág. 2

Goodwin(1963) BC Goodwin. Temporal organization in cells: a dynamic theory of cellular control processes. Citado na pág. 2

Hagberg et al.() Aric Hagberg, Dan Schult, Pieter Swart, Drew Conway, Loïc SéguinCharbonneau, Christopher Ellison, Ben Edwards e Jordi Torrents. Networkx: High productivity software for complex networks. URL http://networkx.lanl.gov/index.html. Citado na pág. 33

Hawick e Leist(2010) KA Hawick e A Leist. Parallel graph component labelling with GPUs and CUDA. Parallel Computing. Citado na pág. 32

Higa(2012) C Higa. Inferência de redes de regulação gênica utilizando o paradigma de crescimento de sementes. Tese de Doutorado, Instituto de Matemática e Estatística - Universidade de São Paulo. Citado na pág. 1, 8, 69

Higa et al.(2010) C Higa, V Louzada e R Hashimoto. Analysis of gene interactions using restricted boolean networks and time-series data. Bioinformatics Research and Applications. URL http: //www.ime.usp.br/ higa/files/papISBRA2010_higa.pdf. Citado na pág. 3, 9, 21, 65

Higa et al.(2011) Carlos Henrique Aguena Higa, Vitor H P Louzada, Tales P Andrade e Ronaldo F Hashimoto. Constraint-based analysis of gene interactions using restricted boolean networks and time-series data. BMC proceedings, 5(Suppl 2):S5. Citado na pág. 3, 21, 65, 69

Higa et al.(2012) Carlos Henrique Aguena Higa, Tales P Andrade e Ronaldo F Hashimoto. Growing seed genes from time series data and thresholded boolean networks with perturbation. Submitted. Citado na pág. 3, 65

Hogeweg(2011) P. Hogeweg. The roots of bioinformatics in theoretical biology. PLoS computational biology, 7(3):e1002021. Citado na pág. 1

Huang(1999) S. Huang. Gene expression profiling, genetic networks, and cellular states: an integrating concept for tumorigenesis and drug discovery. Journal of Molecular Medicine, 77(6): 469-480. ISSN 0946-2716. Citado na pág. 1, 2, 9, 27

Jeong et al.(2000) H. Jeong, B. Tombor, R. Albert, Z.N. Oltvai e A.L. Barabási. The large-scale organization of metabolic networks. Nature, 407(6804):651-654. Citado na pág. 27, 33

Jong(2002) H De Jong. Modeling and simulation of genetic regulatory systems: a literature review. Journal of computational biology, 9(1):67-103. Citado na pág. 2

Karlebach e Shamir(2008) G Karlebach e R Shamir. Modelling and analysis of gene regulatory networks. Nature Reviews Molecular Cell Biology, 9(10):770-780. Citado na pág. 2

Kauffman(1969) SA Kauffman. Metabolic stability and epigenesis in randomly constructed genetic nets. Journal of Theoretical Biology, 22(3):437-467. Citado na pág. 1, 2, 9, 26

Kauffman(1993) S.A. Kauffman. The origins of order: Self organization and selection in evolution. Oxford University Press, USA. ISBN 0195079515. Citado na pág. 9, 28 
Kerr et al.(2000) M.K. Kerr, M. Martin e G.A. Churchill. Analysis of variance for gene expression microarray data. Journal of Computational Biology, 7(6):819-837. Citado na pág. 6

Kitano(2002) H. Kitano. Systems biology: a brief overview. Science, 295(5560):1662. Citado na pág. 1

Kohavi e Provost(1998) R. Kohavi e F. Provost. Glossary of terms. Machine Learning, 30(June): 271-274. Citado na pág. 36

Lashkari et al.(1997) D.A. Lashkari, J.L. DeRisi, J.H. McCusker, A.F. Namath, C. Gentile, S.Y. Hwang, P.O. Brown e R.W. Davis. Yeast microarrays for genome wide parallel genetic and gene expression analysis. Proceedings of the National Academy of Sciences, 94(24):13057. Citado na pág. 6

Lau et al.(2007) KY Lau, S Ganguli e C Tang. Function constrains network architecture and dynamics: A case study on the yeast cell cycle boolean network. Physical Review E, 75(5):51907. Citado na pág. 10

Lee et al.(2000) M.L.T. Lee, F.C. Kuo, GA Whitmore e J. Sklar. Importance of replication in microarray gene expression studies: statistical methods and evidence from repetitive cdna hybridizations. Proceedings of the National Academy of Sciences, 97(18):9834. Citado na pág. 6

Li et al.(2004) F Li, T Long, Y Lu, Q Ouyang e C Tang. The yeast cell-cycle network is robustly designed. Proceedings of the National Academy of Sciences of the United States of America, 101 (14):4781. Citado na pág. xiii, 9, 10, 28, 36, 39, 57, 58, 59, 65

Liang e Pardee(1992) P. Liang e A.B. Pardee. Differential display of eukaryotic messenger rna by means of the polymerase chain reaction. Science, 257(5072):967. Citado na pág. 1

Lipshutz et al.(1999) RJ Lipshutz, SPA Fodor, TR Gingeras e DJ Lockhart. High density synthetic oligonucleotide arrays. Nature Genetics, 21(Suppl 1):20-24. Citado na pág. 1

Lönnstedt e Speed(2002) I Lönnstedt e TP Speed. Replicated microarray data. Statistica Sinica, 12(1):31-46. Citado na pág. 8

Lopes(2011) Fabrício Martins Lopes. Redes complexas de expressão gênica: sintese, identificação, análise e aplicações. Tese de Doutorado. Citado na pág. 28, 33, 36

Mackworth(1977) AK Mackworth. Consistency in networks of relations. Artificial intelligence, 8(1):99-118. Citado na pág. 18

Marioni et al.(2008) J.C. Marioni, C.E. Mason, S.M. Mane, M. Stephens e Y. Gilad. RNA-seq: an assessment of technical reproducibility and comparison with gene expression arrays. Genome research, 18(9):1509. ISSN 1088-9051. Citado na pág. 2

Morin et al.(2008) R.D. Morin, M. Bainbridge, A. Fejes, M. Hirst, M. Krzywinski, T.J. Pugh, H. McDonald, R. Varhol, S.J.M. Jones e M.A. Marra. Profiling the HeLa S3 transcriptome using randomly primed cDNA and massively parallel short-read sequencing. Biotechniques, 45 (1):81-94. ISSN 0736-6205. Citado na pág. 2

Pal et al.(2005) R Pal, A Datta, ML Bittner e ER Dougherty. Intervention in context-sensitive probabilistic boolean networks. Bioinformatics, 21(7):1211. Citado na pág. 3

Patterson et al.(2006) T.A. Patterson, E.K. Lobenhofer, S.B. Fulmer-Smentek, P.J. Collins, T.M. Chu, W. Bao, H. Fang, E.S. Kawasaki, J. Hager, I.R. Tikhonova et al. Performance comparison of one-color and two-color platforms within the MicroArray Quality Control (MAQC) project. Nature biotechnology, 24(9):1140-1150. ISSN 1087-0156. Citado na pág. 8 
Quackenbush et al.(2002) J. Quackenbush et al. Microarray data normalization and transformation. nature genetics, 32(supp):496-501. Citado na pág. 8

Rodrigues e Travieso(2007) FA Rodrigues e G Travieso. Characterization of complex networks: A survey of measurements. Advances in Physics. Citado na pág. 33

Russell e Norvig(2002) S J Russell e P Norvig. Artificial intelligence: A modern approach, 2nd ed. Prentice Hall, páginas 1-24. Citado na pág. 3, 11, 13, 14, 15, 16, 17, 19

Schena et al.(1995) M. Schena, D. Shalon, R.W. Davis e P.O. Brown. Quantitative monitoring of gene expression patterns with a complementary dna microarray. Science, 270(5235):467. Citado na pág. 1,6

Schulte et al.(2010) Christian Schulte, Guido Tack e Mikael Z. Lagerkvist. Modeling. Em Modeling and Programming with Gecode. Corresponds to Gecode 3.4.0. Citado na pág. 15

Shalon et al.(1996) D. Shalon, S.J. Smith e P.O. Brown. A dna microarray system for analyzing complex dna samples using two-color fluorescent probe hybridization. Genome research, 6(7): 639-645. Citado na pág. 1

Shannon(2001) C.E. Shannon. A mathematical theory of communication. ACM SIGMOBILE Mobile Computing and Communications Review, 5(1):3-55. Citado na pág. 28

Shendure et al.(2008) J. Shendure et al. The beginning of the end for microarrays? Nature methods, 5(7):585-586. ISSN 1548-7091. Citado na pág. 2

Shmulevich et al.(2002) I Shmulevich, ER Dougherty, S Kim e W Zhang. Probabilistic boolean networks: a rule-based uncertainty model for gene regulatory networks. Bioinformatics, 18(2): 261. Citado na pág. 2, 9

Smyth(2004) GK Smyth. Linear models and empirical bayes methods for assessing differential expression in microarray experiments. Statistical applications in genetics and molecular biology, 3(1):1027. Citado na pág. 8

Smyth e Speed(2003) G.K. Smyth e T. Speed. Normalization of cdna microarray data. Methods, 31(4):265-273. Citado na pág. 8

Southern et al.(1999) E Southern, K Mir e M Shchepinov. Molecular interactions on microarrays. Nature Genetics, 21(1):5-9. Citado na pág. 1

Tack(2009) Guido Tack. Constraint Propagation. Tese de Doutorado, Universität des Saarlandes. Citado na pág. xi, 15, 17, 19, 31

Tsallis(2009) C. Tsallis. Nonadditive entropy: the concept and its use. The European Physical Journal A-Hadrons and Nuclei, 40(3):257-266. Citado na pág. 28

Tsang(1993) Edward Tsang. Chapter 01 - introduction. Foundations of Constraint Satisfaction, páginas 1-30. Citado na pág. 3, 11, 12, 13

Velculescu et al.(1995) V.E. Velculescu, L. Zhang, B. Vogelstein e K.W. Kinzler. Serial analysis of gene expression. Science, 270(5235):484. Citado na pág. 1

Waddington et al.(1972) C.H. Waddington, International Union of Biological Sciences e Union Internationale des Sciences Biologiques. Towards a theoretical biology. Citado na pág. 1

Wahde e Hertz(2000) M Wahde e J Hertz. Coarse-grained reverse engineering of genetic regulatory networks. Biosystems, 55(1-3):129-136. Citado na pág. 2 
Wang et al.(2009) Z. Wang, M. Gerstein e M. Snyder. Rna-seq: a revolutionary tool for transcriptomics. Nature Reviews Genetics, 10(1):57-63. Citado na pág. 2

Webb(2002) A.R. Webb. Statistical pattern recognition. John Wiley \& Sons Inc. Citado na pág. 36

Wikipedia(2012a) Wikipedia. Dna microarray — wikipedia, the free encyclopedia, 2012a. URL http://en.wikipedia.org/w/index.php?title=DNA_microarray\&oldid=474567479. [Online; accessed 16-February-2012]. Citado na pág. xi, 7

Wikipedia(2012b) Wikipedia. Box plot — wikipedia, the free encyclopedia, 2012b. URL http://en.wikipedia.org/w/index.php?title=Box_plot\&oldid=476503062. [Online; accessed 21February-2012]. Citado na pág. 46

Woo et al.(2004) Y. Woo, J. Affourtit, S. Daigle, A. Viale, K. Johnson, J. Naggert e G. Churchill. A comparison of cDNA, oligonucleotide, and Affymetrix GeneChip gene expression microarray platforms. Journal of biomolecular techniques: JBT, 15(4):276. Citado na pág. 8

Wuensche(1998) A Wuensche. Genomic regulation modeled as a network with basins of attraction. Pac. Symp. Biocomput, páginas 89-102. Citado na pág. 9

Yang e Speed(2002) YH Yang e T Speed. Design issues for cdna microarray experiments. Nat Rev Genet, 3(8):579-588. Citado na pág. 8

Yang et al.(2002) Y.H. Yang, S. Dudoit, P. Luu, D.M. Lin, V. Peng, J. Ngai e T.P. Speed. Normalization for cdna microarray data: a robust composite method addressing single and multiple slide systematic variation. Nucleic acids research, 30(4):e15-e15. Citado na pág. 8

Zhang et al.(2006) Y Zhang, M Qian, Q Ouyang, M Deng, F Li e C Tang. Stochastic model of yeast cell-cycle network. Physica D: Nonlinear Phenomena, 219(1):35-39. Citado na pág. 65 